\title{
On the structure-function relationship of heparins
}

Citation for published version (APA):

al Dieri, R. (2000). On the structure-function relationship of heparins. [Doctoral Thesis, Maastricht University]. Universiteit Maastricht. https://doi.org/10.26481/dis.20000225ra

Document status and date:

Published: 01/01/2000

DOI:

10.26481/dis.20000225ra

Document Version:

Publisher's PDF, also known as Version of record

\section{Please check the document version of this publication:}

- A submitted manuscript is the version of the article upon submission and before peer-review. There can be important differences between the submitted version and the official published version of record.

People interested in the research are advised to contact the author for the final version of the publication, or visit the DOI to the publisher's website.

- The final author version and the galley proof are versions of the publication after peer review.

- The final published version features the final layout of the paper including the volume, issue and page numbers.

Link to publication

\footnotetext{
General rights rights.

- You may freely distribute the URL identifying the publication in the public portal. please follow below link for the End User Agreement:

www.umlib.nl/taverne-license

Take down policy

If you believe that this document breaches copyright please contact us at:

repository@maastrichtuniversity.nl

providing details and we will investigate your claim.
}

Copyright and moral rights for the publications made accessible in the public portal are retained by the authors and/or other copyright owners and it is a condition of accessing publications that users recognise and abide by the legal requirements associated with these

- Users may download and print one copy of any publication from the public portal for the purpose of private study or research.

- You may not further distribute the material or use it for any profit-making activity or commercial gain

If the publication is distributed under the terms of Article $25 \mathrm{fa}$ of the Dutch Copyright Act, indicated by the "Taverne" license above, 
On The Structure-Function Relationship of Heparins 



\title{
On The Structure-Function Relationship of Heparins
}

\author{
Proefschrift
}

ter verkrijging van de graad van doctor aan de Universiteit Maastricht, op gezag van de Rector Magnificus, Prof. Dr. A.C. Nieuwenhuijzen Kruseman volgens het besluit van het College van Decanen, in het openbaar te verdedigen op vrijdag 25 februari 2000 om 12.00 uur

door

Raed Al Dieri 
Promotor: $\quad$ Prof. Dr. H.C. Hemker

\section{Co-promotores:}

Dr. S. Béguin

Dr. R.J. Wagenvoord

Beoordelingscommissie:

Prof. Dr. F. Bär, (voorzitter)

Prof. Dr. G. van Dedem, Technische Universiteit Delft

Dr. M. Petitou, Sanofi Recherche, Toulouse

Dr. M.J. Lindhout

Prof. Dr. R.W. Stockbrügger

ISBN 90-5681-068-5 
"Reading involves a fair measure of push and shave. You make your mark on a book and it makes its mark on you. Reading is not simply a matter of hanging back and waiting for a piece, or its author, to tell you what the writing has to say"

(David Bartholomae and Anthony Petrosky, Authors of Ways of Readings)

اللهم علمنا ما ينفعنا، و/نفعنا بما علمتنا، إنك أنت العليم الحكيم.

To:

My parents and my sister, who encouraged me, and My teachers, who enabled me. 

Contents

Chapter 1 General introduction

Chapter 2 A critical appraisal of the control of the anti-thrombotic 43 therapy: Particularly of heparin therapy.

Chapter 3 Materials \& Methods

Chapter 4 An end-point assay to determine the decay constant of enzyme inactivation by an inhibitor, its application in measuring the catalytic activity of heparin.

Chapter 5 The mechanism of interaction of the antithrombin83 heparin complex with thrombin and activated factor X.

Chapter 6 On the relation between the molecular weight of 99 heparins and their specific anticoagulant activity, an in vitro study in plasma.

Chapter $7 \quad$ Summary and conclusions.

Samenvatting en conclusies

Curriculum Vitae

Acknowledgments 
ACLM Above critical length material

A-domain Specific pentasaccharide sequence

alla

Anti-thrombin activity

AMI

Acute myocardial infarction

APC

Activated protein $\mathrm{C}$

aPTT

Activated partial thromboplastin time

AT

Antithrombin

$\mathrm{aXa}$

Anti-Factor Xa activity

BCLM

Below critical length material

$\mathrm{E}$

Enzyme

ETP

Endogenous thrombin potential

FDA

Food and drug administration

GAG

Glycosaminoglycans

HAM

Antithrombin-high affinity material

$\mathrm{HCII}$

Heparin cofactor II

HDL

High-density lipoprotein

HIT

Heparin-induced thrombocytopenia

HL

Hepatic triglyceridelipase

HPSEC

High pressure size exclusion chromatography

INR

International normalized ratio

ISH

International standard heparin

ISI

International sensitivity index

IU

International unit

$\mathrm{K}_{\mathrm{cat}}$

Catalytic constant

$\mathrm{Kd}$

Dissociation constant

$\mathrm{k}_{\mathrm{dec}}$

Decay constant

$\mathrm{K}_{\mathrm{m}}$

Michaelis-Menten constant 
LAM Antithrombin-low affinity material

LDL Low-density lipoprotein

LMWH Low molecular weight heparin

LPL Lipoproteinlipase

m Molecular mass

$\mathrm{Mr} \quad$ Relative molecular mass (molecular weight)

MSM Medium size material

MW Molecular weight

OAC Oral anticoagulant

PF-4 Platelet factor 4

PPP Platelet-poor plasma

PRP Platelet-rich plasma

PS/PE Phosphatidylserine/ phosphatidylethanolamine

PT Prothrombin time or thromboplastin time

S Substrate

SIU Standard-independent unit

TCT Thrombin clotting time

TFPI Tissue factor pathway inhibitor

TM Thrombomodulin

UFH Unfractionated heparin

VLDL Very low-density lipoprotein

vWF Von Willebrand factor

WHO World health organization

XLM Extra large material

a2-M Alpha2-Macroglobulin 


\section{CHAPTER I}

General Introduction 



\section{Prologue}

Substances that inhibit the coagulation system and platelet activity are essential agents for the prevention and the treatment of varied thrombotic disorders. Heparin and oral anticoagulant agents are the most universally prescribed. Heparin has been considered a drug of choice for many thrombotic cases. Since the inception of heparin therapy, frequent attempts have been made to better understand its interference with coagulation and thrombosis. Before we address the structure- function relationship of heparins, we would discuss the coagulation system and thrombosis.

\section{Introduction to Coagulation and Thrombosis}

The group of diseases at the basis of which thrombosis is the pathogenic mechanism comprises such common members as coronary infarction, stroke and pulmonary embolism. This makes thrombotic diseases the most frequent cause of death and disability in the western world. Worldwide it is number four now, but expected to be number one within 25 years. Thrombotic disease strongly increases with age, it hardly occurs in-or before the gestational age. Life expectancy under primitive conditions must have been such that thrombotic disease hardly occurred. This automatically means that there has been hardly any evolutionary pressure to avoid thrombotic disease as we know it.

The haemostatic system, as it developed from the early vertebrates on, is a complicated mechanism that ensures that haemostasis occurs promptly at the site of a wound but does not spread unduely outside the wound area and stops as soon as haemostasis is achieved; i.e. it is limited in time and space.

Nevertheless, it has developed primarily in the sense of favoring adequate haemostasis rather than preventing the possibility of thrombosis. This is comprehensible, because bloodshed is an important element of the struggle for life. A species without adequate haemostasis stands no chance to survive in "nature red in tooth and claw". Also, in the mammalians, normal reproduction asks for an extremely competent haemostatic mechanism.

The very mechanism that is required for survival into and during gestation becomes a risk to survival after the gestational age. Factor $\mathrm{V}$ Leiden is a good illustration. The breakdown of activated factor $\mathrm{V}$ by activated protein $C$ (APC) is one of the elements that limits the haemostatic process. A mutation that occurred in the past in one of the progenitors of the 
Europeans, makes a factor Va variant that is less susceptible to APC action. This mutation maintained itself in the population at a $5 \%$ level. Nowadays it is known as a risk factor for thrombosis, but it probably persisted because it causes a slightly more efficient haemostasis.

\section{Arterial and Venous Thrombosis; Primary and Secondary Haemostasis}

The clinical division between arterial and venous thrombosis is closely linked to the concept of primary - and secondary haemostasis.

Primary haemostasis is the arrest of bleeding in the seconds after a wound occurred. It is described as being caused by contraction of the vessels and the formation of a platelet plug. Indeed the bleeding time is increased in platelet disease (thrombopenia and the thrombopathies) and normal in hemophiliacs, a clotting disease. From there it has been inferred that the adhesion of platelets to the sub-endothelial matrix and their aggregation is the responsible mechanism. Arterial thrombosis is assimilated to the primary haemostatic plug because the thrombus consists mainly of platelets. Secondary haemostasis is the phenomena that a wound does not restart bleeding after the primary haemostatic phase has passed. In haemophilia, blood clotting is retarded, primary haemostasis is normal but secondary haemostasis is not. Wounds will start re-bleeding after minutes and continue to do so for hours.

If one disregards the platelet rich "head" (i.e. the origin) of a venous thrombosis, it indeed looks like a clot. Hence the idea that blood clotting is responsible for venous thrombosis. A venous thrombosis resembles a blood clot in that it contains many red cells entrapped in a fibrin network over most of its length.

From these observations it appears clear that drugs that interfere with coagulation, such as heparin and oral anticoagulation, are the drugs of choice against venous thrombosis, whereas arterial thrombosis would logically be subject to treatment with anti-platelet drugs. There are some observations, however, that disturb this classical picture.

In the first place, there is now plenty of evidence that the dissolution of a clot is beneficial in acute myocardial infarction (AMI). This means that there has been a clot in the first place, so thrombin must have been there. Indeed diminishing the amount of thrombin decreases the rate of reinfarction. This can be done with oral anticoagulants $\left(60^{+}\right.$study, 1980) or with heparin (Neri Serneri, 1987). In experimental thrombosis a direct thrombin inhibitor (such as hirudin, Fuster 1986) has been shown to be effective. 
In the light of such observations the sharp distinction between arterial and venous thrombi reduces to quantitative differences. A more modern viewpoint is that all thrombi arise from an interaction between platelets, the vessel wall and the coagulation system of plasma.

At the site of a lesion of a vessel, platelets adhere to the subendothelial matrix and aggregate and plasma becomes exposed to tissue factor. Thrombin activates the platelets and makes them procoagulant (see later). In the interstitial space between the adhering platelets the circumstances are particularly favorable for thrombin formation. The thrombin that diffuses out of the aggregate will be washed away if the flow is strong (in arteria) or remains long enough to make the blood clot (in veins). The fibrin thus formed is itself a platelet activator, which accounts for the growth of the arterial thrombus and the haemostatic plug, for as long as new platelets are brought by flowing blood (see below).

The fact that primary haemostasis is normal in blood coagulation disturbances such as haemophilias, does not necessarily mean that thrombin does not play a role there. It may also mean that the process is so sensitive to thrombin that small amounts of thrombin are sufficient already. Indeed $\underline{i n}$ vitro $5 \mathrm{nM}$ of thrombin, i.e. $0.5 \%$ of the prothrombin in the blood converted, suffices for full platelet activation.

The main axis of the coagulation system is the activation cascade: tissue factor at the surface of perivascular cells complexes with factor VIIa, that probably always circulates in minute amounts. This complex activates factor X. Factor Xa, complexes with factor Va at the surface of an amino phospholipid (PS/PE) containing membrane. This complex activates prothrombin. The formed thrombin is inactivated mainly by antithrombin (AT) and minor other inhibitors (fig.1).

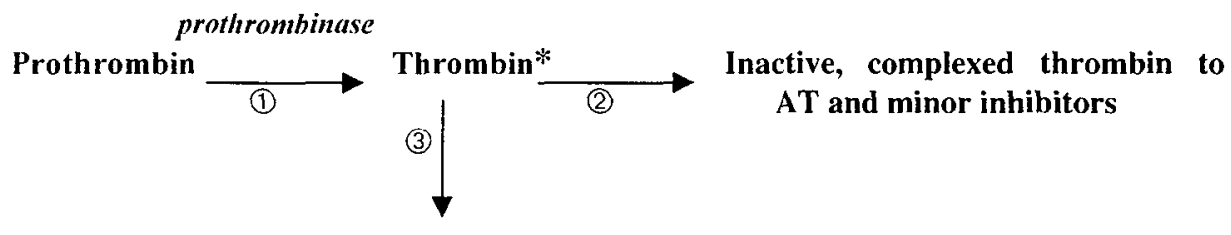

Thrombin- $\alpha_{2}$ M Complex*

Fig. 1 The processes that govern appearance and disappearance of thrombin in plasma. $\mathrm{AT}=$ antithrombin, $\alpha_{2} \mathrm{M}=\alpha_{2}$ macroglobulin. * Indicates amidolytically active species.

In the beginning of the process thrombin formation velocity exceeds the breakdown velocity, so thrombin concentration increases. Breakdown 
velocity is proportional to thrombin concentration however, and prothrombin conversion velocity slows down in time (see below). Therefore, after reaching a peak, the concentration of thrombin declines (fig. 2). The thrombin generation curve in fact yields much useful information about the clotting and thrombotic capacity of the blood. The course of thrombin in time we call the thrombogram (fig.2).

\section{The Thrombogram}

The thrombogram, as depicted in fig.2, contains all the relevant information about the function of the clotting system. The most important parameters that can be derived from it are:

\section{a) Lag-Time}

Because of the strong positive feedback that thrombin exerts on its own formation there may be a certain period during which thrombin generation does not exceed a few $\mathrm{nM}$ and hence is hardly seen (see later). We arbitrarily defined the lag time as the time required to reach roughly the 5 $\mathrm{nM}$ level. Plasma clots as soon as $5-10 \mathrm{nM}$ of thrombin is formed, i.e. at the end of the lag phase. Thus the lag time is for all practical purposes equal to the clotting time.

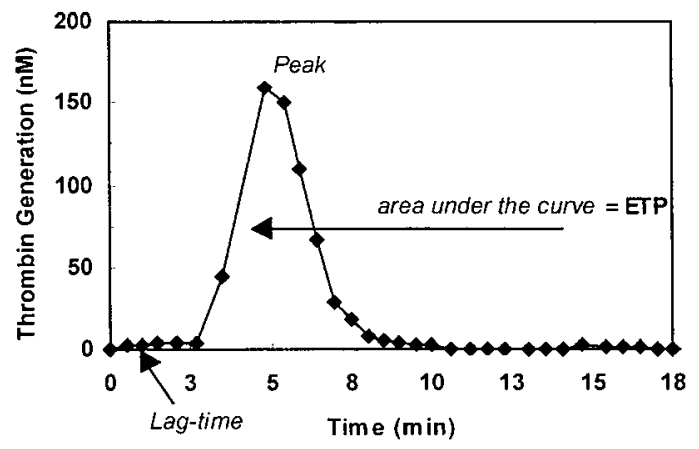

Fig. 2 A thrombin generation curve (the thrombogram) 


\section{b) Peak}

We have observed that small changes (positive or negative) in thrombin generation will be seen more readily as a change in the time and the height of the peak than as a change in the ETP. The explanation of this phenomenon is beyond the scope of this introduction.

\section{c) The Endogenous Thrombin Potential (ETP)}

Thrombin is an enzyme. The amount of substrate that it can be potentially converted is proportional to its concentration. If there were two times as much thrombin at any moment, two times as much substrate could in principle be converted, provided of course that it would be not exhausted. Fibrinogen is a good example of a product that is exhausted quickly. It is completely converted, i.e. clotted, a few seconds after the lag time. Most of thrombin forms after clotting has taken place. The amount of product formed is also proportional to the time that thrombin is present in an active form. This double proportionality, with concentration and with time, makes that the amount of substrate that can be potentially converted by thrombin during its lifetime is proportional to the area under the thrombogram. This area we call the endogenous thrombin potential, or ETP (figs 2, 3).

In clotting plasma (in vitro) most thrombin will be inactivated without having acted on a natural substrate. In vivo, however, this thrombin is transported via flow and diffusion. This creates a thrombin gradient in the space around a unit of plasma that clots. The area within this gradient where the thrombin concentration is high enough (roughly $>5 \mathrm{nM}$ ) will be the area in which platelets, other blood cells and vessel cells are activated and where plasma clots. The more thrombin is generated the larger will be the space over which this activation spreads. This explains the direct relation between ETP and the extent of thrombosis that we have observed (see below).

\section{d) Prothrombinase Activity}

The observed change in thrombin concentration is the result of prothrombin conversion velocity minus thrombin breakdown velocity. Because the latter can be calculated, it is possible to reconstruct prothrombin-conversion velocity over the whole span of the thrombogram (fig. 3). 
For the understanding of heparin's mode of action, it is of particular interest that, from the thrombogram the velocity of prothrombin conversion can be calculated. The velocity of thrombin inactivation is proportional to the concentration of thrombin and antithrombin. This makes that anywhere along the curve we can calculate the velocity of thrombin formation, provided we know the reaction constants and the initial antithrombin concentration. In this way it can be determined whether a heparin acts by increasing thrombin breakdown or by inhibiting prothrombinase activity.

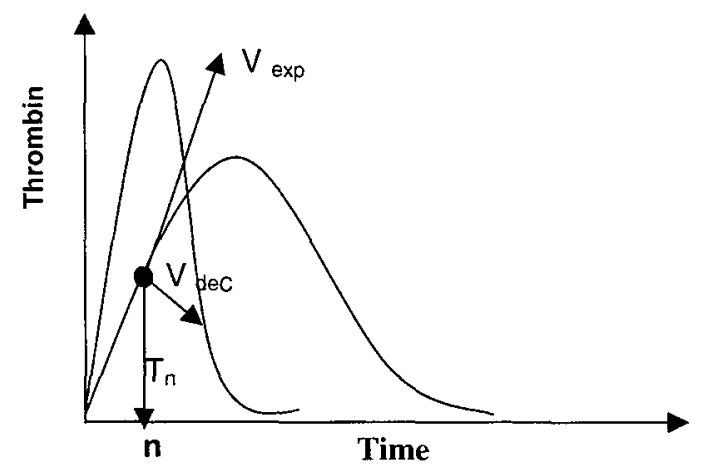

Fig. 3 Calculation of the prothrombin conversion velocity from the course of thrombin. At any moment (n) the course of prothrombin conversion velocity can be calculated as the sum of the experimentally observed rate of thrombin concentration ( $\mathrm{V}$ exp) plus the calculated decay velocity $\left(\mathrm{V} ._{\text {dec }}=\mathrm{k}_{\text {dec. }} \mathrm{T}_{\mathrm{n}}\right)$. (see refs. ${ }^{2.57}$ for more details).

\section{The First Law of Haemostasis and Thrombosis}

Congenital conditions that cause less than the normal amount of thrombin to be formed, will cause bleeding, no matter whether this due to a deficiency of a clotting factor (e.g. the hemophiliacs) or to a hyperactive antithrombin (antitrypsin Baltimore). Congenital conditions that increase thrombin, such as high prothrombin concentrations (prothrombin A20210G), hyperactive prothrombinase (deficiency of proteins C and S, factor V Leiden) or a lack of antithrombin (antithrombin deficiency) will cause a thrombotic tendency.

Drugs that diminish the amount of thrombin formed have antithrombotic properties, independent of their mode of action. Oral anticoagulation diminishes prothrombin and prothrombinase. Heparins increase thrombin 
breakdown, Hirudin attacks thrombin directly and Pentasaccharide diminishes prothrombin conversion.

These observations made Hemker (personal communication) propose the first law of haemostasis and thrombosis:

"If less than a normal amount of thrombin is formed, haemostatic potency and thrombotic tendency decrease. If more than a normal amount of thrombin is formed, thrombotic tendency increases".

Because the function of the haemostatic mechanism is near to optimal when it is normal- due to the evolutionary pressure in that direction, as discussed above- a "higher than normal haemostatic potency" is not easily observed in practice.

One may ask why this simple law has not been explicitly formulated earlier. One of the most important reasons is that the overall function of the clotting system was until quite recently primarily probed with the aid of clotting times. We saw above that the clotting time equals the lag time of thrombin formation, but that haemorrhagic and thrombotic tendencies are primarily determined by the amount of thrombin formed. There exists no fixed relation between the lag time and the ETP. Observations on clotting times therefore do not automatically lead to the recognition of the relation between thrombin-quantities and haemorrhagic or thrombotic tendencies

\section{How to Measure the Thrombogram}

The important advantage of a clotting time over any other function test of the clotting mechanism is that it is quick, easy and cheap. Measuring the thrombogram by the sub-sampling method, on the contrary, is cumbersome and expensive in time and money. Therefore methods to obtain the thrombogram become a must, if this approach is to be used in practice.

In the last 15 years, Hemker and Béguin developed a technique in which a substrate is added to clotting plasma and the course of product formation is monitored (fig. 4). The kinetic properties of the substrate must be chosen such that the velocity of product formation is always proportional to the amount of free thrombin present.

This means that the substrate concentration should not change substantially during the experiment, which requires high substrate concentration and low catalytic activity (low $\mathrm{k}_{\text {cat }}$ ). At these high concentration not much enzyme should be bound to substrate, otherwise the reactions with the antithrombins would be seriously inhibited (high $\mathrm{K}_{\mathrm{m}}$ ). High $\mathrm{K}_{\mathrm{m}}$, low $\mathrm{k}_{\text {cal }}$ substrates have 
been developed. They release para-nitroaniline (pNA) that can be monitored continuously in a photometer.

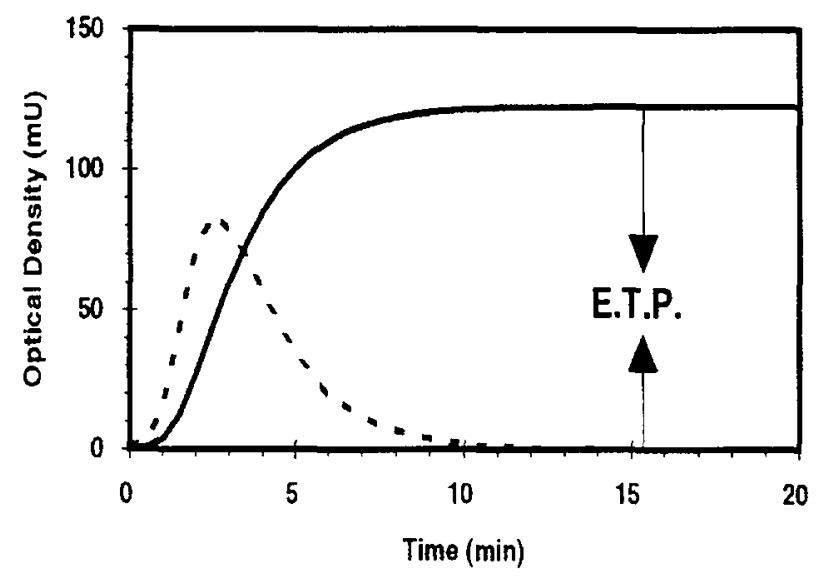

Fig. 4 Conversion of a signal substrate by thrombin generated in clotting plasma. A chromogenic substrate is added to clotting plasma in high enough concentration for the reaction velocity to be proportional to the thrombin concentration. Product formation is monitored via the optical density (solid line). The first derivative (dotted line) of this curve then is proportional to the thrombin generation curve. The end level of product is proportional to the endogenous thrombin potential. From Ref ${ }^{2}$

Photometric detection requires an optically clear medium. Clotting plasma becomes turbid at the moment of clotting, so, in such experiments the fibrinogen has to be removed before the experiment starts. This is possible with the aid of fibrinogen clotting enzymes from snake venoms. This has three drawbacks however. a) it introduces an extra experimental step, b) it removes a reaction that has been shown to play a role in the thrombin generating process per se and $c$ ) it renders impossible to carry out the experiments in platelet rich plasma because the platelets are removed together with the fibrin(ogen).

It therefore was a real step forward when it was found that also fluorescent substrates with the required kinetic properties could be used to monitor thrombin generation (Hemker et al, publication planned for march 2000). Nevertheless, with the spectrophotometric methods, enough results were obtained to show the potential usefulness of the thrombogram and of the ETP parameter. 
In congenital hypercoagulable states, the thrombogram is increased. This shows as an increase of the ETP in AT deficiency and in prothrombin A20210G and primarily as an increase of the peak in protein $C$ and protein $\mathrm{S}$ deficiency and in the factor $\mathrm{V}$ Leiden mutation. In the disorders of the protein $C$ system, the pathological changes can be brought about very clearly by addition of APC or TM.

In congenital deficiencies of clotting factors, the thrombogram is diminished. Of special importance is, that anticoagulant therapy diminishes the ETP and that the therapeutic range, as defined by INR (oral anticoagulation) or aPTT (heparin) coincides with an inhibition of the ETP of between 20 and $50 \%$ independent of the mode of anticoagulation. Also the effect of mixed OAC and heparin therapies is rendered faithfully by the ETP. It thus seems that completely different ways of anticoagulation (OAC, Heparin) that normally must be monitored by completely different tests (PT, aPTT) influence the ETP in the same way. This strongly suggests that the ETP is the essential variable in anticoagulation. An increase of the ETP is seen in thrombotic disease, both arterial (myocardial infarction 2-6 months after the event) and venous (acute venous thrombosis at admission).

The use of oral contraceptives leads to a $10 \%$ increase of the ETP. ${ }^{6}$ This effect is much more prominent in the presence of APC and must be attributed to an acquired APC resistance of factor $\mathrm{V}^{7}$

One of the major conclusions of the work to be presented is that heparins act via inhibition of thrombin. Thrombin, among other things, is an important inducer of its own formation, in the following we will explain this role in more detail. We will explore the reaction mechanism of blood coagulation, only to the limited extend required for the comprehension of the action of heparins, however.

\section{The Mechanism of Coagulation}

As shown above, thrombin arises from the action of prothrombinase on prothrombin. Prothrombinase is a four component complex of factor $\mathrm{Xa}$, factor $\mathrm{Va}$, procoagulant phospholipids and $\mathrm{Ca}^{2+}$. None of the first three components is available in blood as such. Each of the three components defines one of the "axes" of the simplified coagulation scheme in figure 5.

Procoagulant phospholipids (PS/PC) occur in cell membranes. Due to the natural physiological asymmetry of the cell membrane in the intact cell they are localized in the inside, i.e. away from the contact with extracellular 
fluids, such as blood, that contains clotting factors. Cell damage brings them to the exterior.

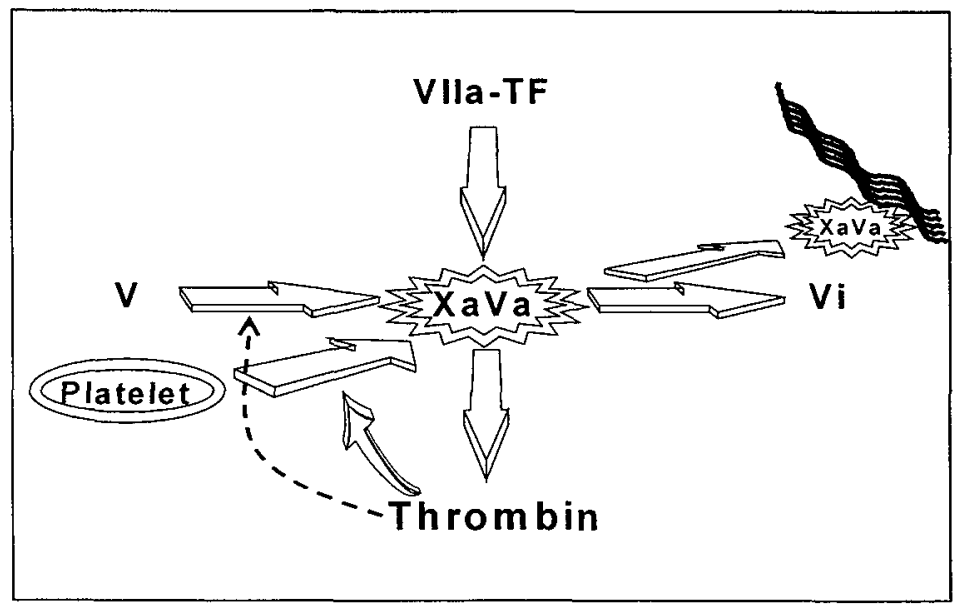

Fig. 5 The three axes of the clotting mechanism

Axis 1: Factor $\mathrm{Xa}$ is provided by the action of tissue factors and factor VII. Axis 2: Factor $\mathrm{Va}$ is provided by the action of thrombin on factor $\mathrm{V}$. It is subsequently inactivated by the APC system.

Axis 3: Procoagulant phospholipids are provided by activated platelets.

We will see that axis 1 makes thrombin generation possible, axis 2 makes that it occures explosively during a limited time and axis 3 confines thrombin generation to the wounded area.

Apart from that, the blood platelet is the only cell type capable, after triggering, to expose procoagulant phospholipids. The known physiological triggers are collagen, thrombin and fibrin.

Adhesion of platelets to collagen occurs when the blood comes into contact with the connective tissue matrix, i.e. upon wounding. This provides a layer of procoagulant platelets at the inside of a wound. Platelets also stick to each other (aggregation). In the interstices of the platelet aggregates, flow is minimal and conditions are optimal to build up a local thrombin pool.

The first traces of thrombin have a multiple action that first enhances and then quenches further thrombin formation, thus limiting thrombin formation in time. These actions can be summarized as follows: 
1) Activation of factor $V$. The interstices of a platelet aggregate must be rich in factor $\mathrm{V}$, because it is not only contained in plasma but also released by the activated platelet. Traces of thrombin activate this factor $\mathrm{V} .{ }^{10}$ Factor $\mathrm{Xa}$ is formed in large quantities in a wound because of the exposure of tissue factor. Procoagulant phospholipids are abundantly present. In fact factor $\mathrm{Va}$ is the rate-limiting component for prothrombinase formation, hence for thrombin generation.

2) In a similar manner factor VIII is activated that, together with factor IXa, forms an alternative factor $X$ activator. In the present context this is primarily of importance for the understanding of the mechanism behind the aPTT (see next chapter).

3) Thrombin is the most potent platelet activator known. It acts through specific thrombin receptors such as V1 (Vu et al., 1991). This receptor is a protein with seven transmembrane domains and an extracellular $\mathrm{N}$ terminus." Thrombin cleaves this receptor generating a new $\mathrm{N}$-terminal ("the tethered-ligand") that acts as a ligand and hence actiavtion of the receptor. Thrombin induces the full range of platelet reactions, i. e. release, change of shape etc. up to and inclusive membrane scrambling.

4) Thrombin forms fibrin. To fibrin vWF adsorbs and thus undergoes a conformational change. Platelet receptor GPIb binds to this altered $v W F$, which activates the platelet. This is an alternative pathway that also leads to membrane scrambling and microparticle formation.

Actions, 1-4, of thrombin together have strong positive feedback effect on prothrombinase activity. Interference with thrombin action, such as that with heparins, therefore also interferes with thrombin generation.

5) In the activated platelet, the heterodimer GPIIb/IIIa forms and binds fibrin. This binding leads to platelet procoagulant activity in a process in which vWF seems also to play a role.

6) For the sake of completeness we mention also an activation pathway in which thrombin is not involved. Collagen binds to the receptor GPVI and thus induces platelet procoagulant activity. This reaction does not play a role in blood (plasma) clotting ex vivo. 


\section{Heparin}

Heparin had been introduced to the medical theatre in the early 1920ies. ${ }^{16}$ Since then, extensive research line has been done on its structure, biochemical properties and pharmacological action.

A large amount of data has been published on different heparin preparations but a unifying theory on the structure function relation has not emerged. This is best illustrated by the fact that the FDA considers every heparin preparation as a different drug. This thesis presents some elements that might lead to the recognition of the principle mechanisms behind heparin action.

Heparin is a natural polysaccharide belonging to the family of glycosaminoglycans (GAG). Heparin occurs in connective tissue mast cells. Other common GAG compounds are chondroitin sulphate, dermatan sulphate, heparan sulphate, keratan sulphate, and hyaluronic acid. Heparan sulphate is structurally similar to heparin and occurs in blood vessel walls and brain. Dermatan sulphate is a connective tissue compound present in skin, blood vessels, and heart valves.

\section{Chemistry of Heparin}

Heparin is a mixture of unbranched heteropolysaccharides. It consists of alternating iduronic acid or glucoronate units and $N$-acetylglucosamine units joined by glycosidic 1-4 linkages. Five different monosaccharides were recognized as basic constituents of heparin molecule: D-glycosamine, D-glucoronic acid, iduronic acid, D-galactose, and D-xylose. N-sulfo groups replace most of the $\mathrm{N}$-acetyls of the glucosamine. Most iduronates are $O$-sulfated in their 2-position, so are glucosamines in their 6-position. Heparin is a product of subsequently enzymatic reactions in which the linear polysaccharides are suseptible to biosynthetic transformation.

\section{Preparation Methods for Heparin Derivatives}

Unfractionated heparin is a heterogeneous mixture of natural heparins obtained from pig intestinal mucosa or bovine lung, ranging in molecular mass from 4,000 to 35,000 Dalton. The basic procedure of heparin isolation is autolysis of the tissue, alkali extraction, precipitation of proteins by heating, and subsequent precipitation of a heparin-protein complex by acidification. Heparin is then recovered from the re-dissolved complex by precipitation with ethanol or/and acetone. Remaining traces of proteins and 
fats are removed eventually by trypsin and ethanol respectively. ${ }^{17}$ Low molecular weight heparin (LMWH) is a class of compounds derived from unfractionated heparin (UFH) by enzymatic or chemical depolymerization according to one of the following processes:

\section{Nitrous Acid Deamination}

A process in which UFH is hydrolysed with nitrous acid. ${ }^{18}$ It cleaves selectively the heparin chain glycosidic linkage between the 1-position of $\mathrm{N}$-sulphated glucoseamine and the 4-position of the adjacent uronate with formation of di-, tetra-, hexa- and higher saccharides terminated with 2,5anhydro-mannose $^{19.20}$ (fig. 6). The uronate remains intact in the nonreducing residue. By reduction of the terminal anhydromannose to anhydromannitol with sodium borohydride, the compound is stabilized.

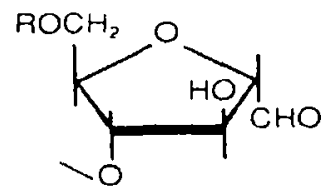

Fig. 6 Anhydromannose obtained by deaminative cleavage of heparin ( $R=H$ or $\mathrm{SO}_{3}{ }^{-}$).

\section{Heparinase Cleavage}

The enzymatic depolymerization proceeds usually via a heparinase, extracted from Flavobacterium heparinum, which breaks glycosidic bonds. ${ }^{21.22}$ Unlike in deaminative hydrolysis, the iduronate residue is dehydrogenated to form at the non-reducing domain an oligosaccharide having 4,5 unsaturated acid (fig. 7). The latter is readily detected by its u.v absorption at $227 \mathrm{~nm}$. ${ }^{22}$ Sulphated glucosamine remains intact at the reducing residue.

\section{B-Elimination of Heparin Esters}

At alkaline $\mathrm{pH}$, esterification of the iduronic carboxyl groups causes glycosidic cleavage, yielding of 4,5-dehydrouronate at the non-reducing end (fig. 7). 


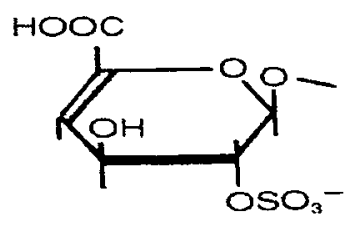

Fig. 7 The sulphated 4,5- unsaturated uronic acid produced by heparinase or $\beta$ elimination.

\section{Oxidative Depolymerization}

Heparin is depolymerized by peroxides at low $\mathrm{pH}$ resulting in an inactive material. ${ }^{24}$ The activity can be subsequently recovered by re- $\mathrm{N}$-sulfation.

Biological Actions of Heparin

\section{Heparin-AT Interaction}

The accelerating effect of heparin on antithrombin action is dependent upon a unique pentasaccharide sequence ( $A$-domain) present in the natural heparin molecule ${ }^{25}$ (fig. 8). The occurrence of this sequence in the molecules of a heparin preparation ranges from about $40 \%$ in UFH to $10 \%$ in some types of LMWH. This fraction we call the high affinity material (HAM). The remaining low affinity material is not completely devoid of biological effects, but does not significantly inhibit thrombosis.

Through the eminent work of the groups of Carrel, Olson, Petitou and others the biochemistry of the interaction of heparin with antithrombin is known in astonishing detail. Antithrombin circulates in a native, constrained form that is about a thousand-fold less active towards its target enzymes than the other members of the serpin family are. ${ }^{30}$ The alternative, active and unconstrained form is in equilibrium with the constrained form but the equilibrium greatly favors the latter. ${ }^{31}$ Binding of the specific pentasaccharide relieves the intramolecular constraints and makes the antithrombin molecule shifts to the alternative form that is tousand-fold more active, i.e. behaves as the other serpins do. The interaction of heparin with AT and the two forms of heparin can be described in terms of a classical allosteric reaction: 


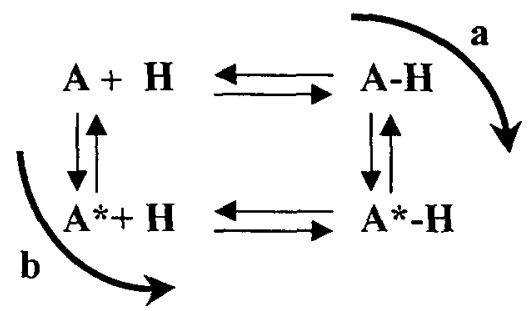

Scheme. 1 The allosteric interactions of Antithrombin and Heparin The * indicates the active form of Antithrombin. a: induced fit pathway; b: alternative pathway. (From ref. ${ }^{32}$ )

The functional molecular anatomy of this interaction is known in detail from X-ray, crystallography ${ }^{33.34}$, site directed mutagenesis ${ }^{3.5}$, synthesis of pentasaccharide derivatives ${ }^{32}$, fluorescence ${ }^{36-38}$ and other studies ${ }^{39-41}$ that will not be summarized here. The reader is referred to the original literature and appropriate reviews. ${ }^{30-41}$ An essential feature is that antithrombin and thrombin interact through their reactive sites only. ${ }^{35}$ Mutations brought about in thrombin that modify its reactivity to AT are all in the active site region and also modify its reactivity towards a tripeptide substrate like GlyPro-Arg-pNA (S2238). ${ }^{35}$ This lack of intimate interaction between these molecules probably is responsible for the fact that the active from of antithrombin, as it occurs in the presence of pentasaccharide, is hardly more active towards thrombin than the inactive form is. The recognition mechanism through the exosites of thrombin, that determines the specificity of thrombin towards its large molecular substrates such as fibrinogen, factors V and VIII, platelet receptors etc, ${ }^{42-45}$ is not operative in the case of antithrombin.

Thrombin binds to heparin through its exosite II that is not located in the neighborhood of its reactive site. ${ }^{40-50}$ Antithrombin interacts with the pentasaccharide through a specific cleft in the molecule that as such is not directly related to the reactive part that is responsible for inactivation reaction. $^{35}$ Three dimensional modelling of the thrombin - heparin antithrombin complex, clearly shows that a prolongation of the pentasaccharide to the left (i.e. non-reducing) end of the molecule is required to provide a matrix on which the two proteins can readily interact. ${ }^{32.36 .51 .52}$ Brilliant synthetic work of Petitou and colleagues ${ }^{53}$ has confirmed the concepts of these model studies. From this work it emerges that a tether of minimal 12 saccharide units is required for thrombin to bind. Six residues adjacent to the pentasaccharide function as a "spacer" and may 
be either neutral or charged. The six remaining ones need to be negatively charged in order to bind to thrombin.

Within the HAM fraction three classes are to be recognised. Molecules with a size of between 5 and 17 sugar units (1.7-5.4 KD), are effective catalysts of the inactivation of factor $\mathrm{Xa}$, but will not influence the inactivation of thrombin. ${ }^{54.55}$ For the action on thrombin a domain of 12 sugar units- without strict further structure requirements- is needed to the left of the A-domain. This is called the T-domain. The recognition of these structural requirements is due to synthetic re-constructions of natural heparin by Petitou et al.

As stated above, molecules with more than 17 sugar units (always including the $A$-domain) are capable to foster the AT-dependent- inhibition of both factor $\mathrm{Xa}$ and thrombin.

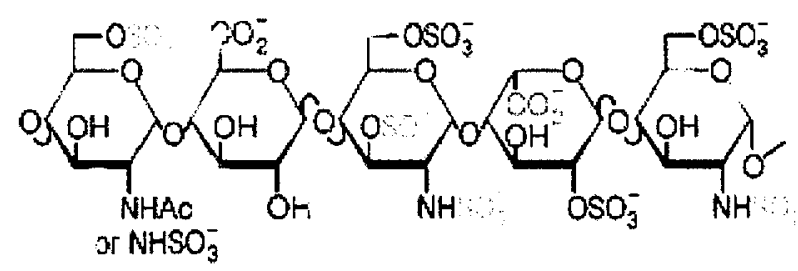

Fig. 8 Structure $\underset{5550}{o f}$ the pentasaccharide sequence, antithrombin- binding domain. From Refs ${ }^{5560}$.

By binding to such heparins, AT becomes a powerful inhibitor of free thrombin as it appears in clotting plasma, because they drain thrombin from the solution into the AT-trap. A secondary effect of this draining is that less free thrombin is available for the feedback activation of factor VIII and blood platelets.

Because 17 sugar units are the critical chain length required for the antithrombin action we called active heparin-molecules that are smaller "Below Critical Length Material" or BCLM. Active heparin molecules that catalyse both thrombin and factor $\mathrm{Xa}$ inactivation we call "Above Critical Length Material" or ACLM.

Active heparins longer than about 30 sugar units require special attention. We call them extra large material or XLM. Because XLM is above the 
critical chain length, it is a subspecies of ACLM. Unlike the smaller ones, these heparins have been reported to require $\mathrm{Ca}^{2+}$ ions for their full antifactor Xa activity (this subject will be treated in more detail in chapter V). The fraction of ACLM that is not XLM, i.e. the active heparins between 17 and 30 sugars we will call medium sized material (MSM). XLM has, on good grounds, been suspected to have special haemorrhagic properties.

\section{Heparin -Heparin Cofactor II Interaction}

Heparin cofactor II (HCII) is a serine protease inhibitor with a mass of $66 \mathrm{kDa}{ }^{63} \mathrm{HCII}$ inhibits thrombin and, unlike AT, does not exert any inhibitory potency towards the other activated clotting factors. The rate of thrombin inhibition is increased more than 1000 times by the glycosaminoglycans; heparin, heparan sulphate and dermatan sulphate. ${ }^{64}$ HCII, compared to AT, binds heparin with a low affinity and 10 fold more heparin is needed to induce the same rate of thrombin inhibition as with antithrombin. $^{64.65}$ No specific sequence, such as the pentasaccharide is required to the binding of HCII to heparin; thus heparin fractions with high and low affinity for AT are equally effective in accelerating this inhibitor. The global charge density of the polysaccharide molecule seems to be imperative in determining the HCII-related activity without specific structural requirements. ${ }^{66}$ At the heparin concentrations encountered in therapy, AT-mediated activity remains the main determinant of the anticoagulant activity. ${ }^{65,67}$

\section{The Difference between Unfractionated and Low Molecular Weight Heparins}

Heparin (UFH, LMWH) acts because it accelerates the interaction between AT and the activated clotting factors: IXa, XIa and particularly thrombin and factor $\mathrm{Xa}$. By this action less free thrombin becomes available in the body to exert prothrombotic actions and consequently the tendency to develop thrombosis diminishes. In this respect there is no difference between LMWH and unfractionated heparin (UFH).

The current opinion very much stresses that at equal antithrombin action, the aXa action of heparin is higher, the lower the molecular weight is. Thus the aXa/aIla ratio is high in LMWHs. From this observation to the assumption that aXa activity per se is an important and desirable activity in heparins seems a logical, small step. However we have good reasons to doubt whether it is legitimate. 
We could demonstrate that the aXa action does not significantly contribute to the inhibition of the coagulation system ${ }^{57}$ (see also Chapter V). In clotting plasma, the conversion of prothrombin to thrombin is hardly inhibited by any type of heparin. Only at high concentration of heparins that are (almost) without any anti-thrombin activity (both pentasaccharide and very low MW heparins), prothrombinase inhibition can be observed. Furthermore, the reputedly high aXa activity of LMWH can be demonstrated to be largely a laboratory artifact, dependent upon the absence of $\mathrm{Ca}^{2+}$ in the test medium.

Rather than the mechanism of action, we think that the favorable properties of LMWHs are due to the higher plasma concentration after subcutaneous injection (bioavailability, see below) and/ or to the absence of a putative haemorrhagic component present in UFH.

\section{Pharmacokinetic Properties of Heparin}

It is not possible to apply straightforward pharmacokinetics to heparins because they are inhomogeneous and both their biochemical and pharmacological properties vary with the molecular weight.

The pharmacokinetics of LMWH are plainly different from those of unfractionated heparin. Heparin is cleared through a combination of a cellular (rapid-saturable) mechanism and an exponential first-order (nonsaturable) mechanism. ${ }^{68-70}$ The mechanism of the rapid clearance is likely due to the binding to the surface endothelial cells ${ }^{71,72}$ and macrophages. There heparin is internalised and depolymerized, resulting in a loss in the anticoagulant activity. ${ }^{74.75}$ The elimination of heparin (at high doses) through the non-saturable mechanism is mediated via the kidneys. At the therapeutic doses, heparin is cleared through the rapid saturable phase in a dose- dependent manner; hence the pharmacokinetics of UFH are nonlinear. Contrary to UFH, the increased intake of LMWH probably does not modify its metabolism, because of the lower cellular uptake of LMWH compared to UFH. ${ }^{72.76 .77}$ The bioavailability of LMWH consequently is higher. It is thought to be roughly $90 \%$ compared with that $30 \%$ for low doses of UFH given subcutaneously.

In order to unravel the complicated pharmacology of LMWHs, a method has been established previously in our laboratory to determine the molar concentration of ACLM and BCLM in a plasma sample from its aXa and alla activities. ${ }^{62.79}$ In this way we are no longer dependent upon comparison with a standard and neither are we bothered by the complications that arise when impure preparations of different molecular weight comparison are to be compared upon a weight basis. 
The molar amount of active heparin in a given preparation can be determined by fluorescence titration. Its catalytic activity on AT-mediated decay of thrombin and factor Xa can be measured and expressed in the conventional ways of chemical kinetics. In this way the specific activities of the ACLM and the BCLM contained in a given heparin preparation can be determined exactly and expressed in standard independent units. Once these are known, it is possible to calculate the molar concentrations of ACLM and $\mathrm{BCLM}$ in a plasma sample from the aXa and aIIa activities.

Using this approach, the course of ACLM and BCLM was determined after injection of normal UFH and of a LMWH preparation in healthy volunteers. After injection of UFH no BCLM was found, because this fraction is not present in UFH and the ACLM rose to moderate levels. ${ }^{62}$ After injection of LMWH, high concentrations of BCLM were found but also the concentrations of ACLM were much higher than those seen after injection of conventional heparin.

Apart from the presence of BCLM, that we excluded to play a significant role, the most important difference between UFH and LMWH is the presence of XLM in UFH and its absence in LMWH. This led us to postulate that in fact the XLM fraction is responsible for the induction of bleeding. After intravenous injection of a bolus of UFH, there is a very rapid drop of activity, followed by a phase in which the disappearance is much slower. ${ }^{80}$ However, after subcutaneous injection, the apparent half-life of the ACLM from both types of heparin is comparable. ${ }^{62}$ We supposed that the XLM fraction disappears quickly from the circulation because it binds to the vessel wall and exerts a haemorrhagic function there. The remaining, circulating ACLM may not be very different between UFH and LMWH.

\section{Monitoring Heparins in the Clinical Practice}

The two current procedures for estimating heparin or the heparin effect are the activated partial thromboplastin time (aPTT) and measurement of the aXa activity. Both of them are less than ideal and better solutions are an urgent necessity.

The aPTT shows a large experimental variation and is strongly method and machine dependent. More important, the same amount of heparin activity produces very variable prolongation of the aPTT in different individuals. Its relation to the level of anticoagulation is strongly non-linear (see Chapter VI) and hence prolongation of the aPTT can be used as a primitive warning sign of overdosage but not for the control of therapy. 
The aXa measurement is useful to indicate the presence of heparin in plasma, but it does not give comparable results between different heparins. In practice, due to the $\mathrm{Ca}^{2+}$ effect discussed above, the heparin level of LMWHs is roughly two times overestimated.

There are good reasons to believe that the current practice could be improved significantly if not aXa, but alla measurements were carried out for the determination of drug levels and if a method measuring thrombin generation would replace the aPTT. ${ }^{5.83}$ In the chapter II, we give a critical review of the laboratory tests used to evaluate the efficiency of the anticoagulants (oral anticoagulant, heparin, etc.).

\section{Non-Anticoagulant Actions of Heparins}

The interaction of heparin with heparin-binding proteins can be categorized according to the nature of binding ${ }^{84}$ :

Non-specific complexation is basically a result of strong anionic interaction due to the presence of sulphate and carboxyl groups, and may depend upon the charge density, the structure or the length of the polysaccharide. Other compounds like heparan sulphate and chondroitin show the same type of binding. By such interactions HCII is potentiated, but AT binds specifically to heparin via the unique pentasaccharide sequence.

\section{Heparin-Tissue Factor Pathway Inhibitor (TFPI) Interaction}

TFPI is a transmembrane glycoprotein synthesised in the endothelial cells. It circulates in the plasma at concentration of 2-3 nM. ${ }^{85-87}$ TFPI exerts two anticoagulant roles a) inhibition of factor $\mathrm{Xa}$ and $\mathrm{b}$ ) blockage the activity of tissue factor in vivo by the TFPI-Xa complex. Heparin was found to increase in a $\mathrm{Mr}$-independent way $^{85-87}$ the circulating TFPl by displacement from the endothelium. This release is unrelated to the ATmediated activity of heparin.

\section{Heparin-Platelet Factor-4 Interaction}

Platelet factor 4 (PF-4) is stored with chondroitin sulphate proteoglycan in platelets. ${ }^{89}$ The affinity of heparin for PF-4 is remarkably higher than that of heparan sulphate, dermatan sulphate, and chondroitin respectively." Heparin fractions with different affinity for AT possess similar affinity for PF-4. ${ }^{92}$ Heparins of high molecular weight can bind two PF-4 molecules yielding complexes much stronger than those with the antithrombin 
molecule. ${ }^{93}$ Heparin-induced thrombocytopenia (HIT) is an immune thrombocytopenia induced by antibodies against the heparin-PF4 complex. ${ }^{94}$ ${ }^{95}$ HIT is less frequently induced by LMWH than by UFH. ${ }^{95}$ This might be explained by the fact that LMWHs bind PF4 with lower affinity than UFH does, or/and that the IgG antibodies hardly recognize the LMWH-platelet complex.

\section{Heparin-Lipoprotein Interaction}

Heparin complexes preferentially to low-density (LDL) and very lowdensity (VLDL) lipoproteins on the arginin-rich apoproteins. ${ }^{96.97}$ The affinity of heparin for lipoproteins increases proportionally with the degree of the sulfation. ${ }^{98}$ Heparin interacts with high-density (HDL) exclusively in the presence of $\mathrm{Mn}^{2+}$ ions.

\section{Heparin-Lipase Enzymes Interaction}

Heparin has a clearing effect on blood triglycerides via its capability of releasing lipoproteinlipase (LPL) and hepatic triglyceridelipase (HL) from the endothelial cells. ${ }^{100-103}$ The affinity of heparin fractions for LPL is independent of the affinity for antithrombin binding. LPL binds heparin with higher affinity than with dermatan sulphate and heparan sulphate.

\section{This Thesis}

This introduction clearly shows that there are still important gaps in our knowledge of the mode of heparin action. As a consequence, it is impossible to characterize a heparin preparation in terms of molecular biocatalysis. Neither is it possible to estimate the concentration of heparins in plasma routinely in molar units, nor to assess the precise effect of heparins in plasma on the function of the blood clotting system.

It is the purpose of the work presented here to find solutions for these problems. To this end, we present the following chapters:

a) A method to determine in an exact and simple way the aXa and alla activity in plasma samples. This approach, in combination with the data from chapters $(\mathrm{V}, \mathrm{VI})$, allows determination of molar plasma levels of ACLM and BCLM.

b) A method for determining the catalytic activity of heparin in standard independent units, i. e. as catalytic activity per mole per second. 
c) The molecular weight dependency of the catalytic aXa and alla activity in a purified system.

d) The molecular weight dependency of the catalytic aXa and alla activity in plasma.

\section{References}

1. Rijkers, D.T., Wielders, S.J., Tesser, G.I. \& Hemker, H.C. Design and synthesis of thrombin substrates with modified kinetic parameters. Thromb Res 79, 491-9 (1995).

2. Hemker, H.C. \& Béguin, S. Thrombin generation in plasma: Its assessment via the endogenous thrombin potential. Thromb Haemost 74, 134-138 (1995).

3. Rosing, J., Hemker, H.C. \& Tans, G. Molecular biology and pathophysiology of APC resistance: current insights and clinical implications. Semin Thromb Hemost 24, 329-35 (1998).

4. Nicolaes, G.A., Thomassen, M.C., Tans, G., Rosing, J. \& Hemker, H.C. Effect of activated protein $\mathrm{C}$ on thrombin generation and on the thrombin potential in plasma of normal and APC-resistant individuals. Blood Coagul Fibrinolysis 8, 28-38 (1997).

5. Wielders, S. et al. The routine determination of the endogenous thrombin potential, first results in different forms of hyper- and hypocoagulability. Thromb Haemost 77, 629-36 (1997).

6. Rotteveel, R., Roozendaal, K., Eijsman, L. \& Hemker, H. The influence of oral contraceptives on the time-integral of thrombin generation (thrombin potential). Thromb Haemost 70, 959-962 (1993).

7. Rosing, J. et al. Oral contraceptives and venous thrombosis: different sensitivities to activated protein $\mathrm{C}$ in women using second- and thirdgeneration oral contraceptives [see comments]. Br J Haematol 97, 233-8 (1997).

8. Bevers, E.M., Comfurius, P., van Rijn, J.L., Hemker, H.C. \& Zwaal, R.F. Generation of prothrombin-converting activity and the exposure of phosphatidylserine at the outer surface of platelets. Eur $J$ Biochem 122, 429-36 (1982).

9. Beguin, S. et al. Fibrin-dependent platelet procoagulant activity requires GPIb receptors and von Willebrand factor. Blood 93, 564-70 (1999).

10. Baruch, D., Hemker, H.C. \& Lindhout, T. Kinetics of thrombin-induced release and activation of platelet factor V. Eur J Biochem 154, 213-8 (1986). 
11. Vu, T.K., Hung, D.T., Wheaton, V.I. \& Coughlin, S.R. Molecular cloning of a functional thrombin receptor reveals a novel proteolytic mechanism of receptor activation. Cell 64, 1057-68 (1991).

12. Bevers, E.M., Comfurius, P. \& Zwaal, R.F. Platelet procoagulant activity: physiological significance and mechanisms of exposure. Blood Rev 5, 14654 (1991).

13. Zwaal, R.F. et al. Loss of membrane phospholipid asymmetry during activation of blood platelets and sickled red cells; mechanisms and physiological significance. Mol Cell Biochem 91, 23-31 (1989).

14. Reverter, J.C. et al. Platelet activation during hemodialysis measured through exposure of p- selectin: analysis by flow cytometric and ultrastructural techniques. $J$ Lab Clin Med 124, 79-85 (1994).

15. Kehrel, B. et al. Glycoprotein VI is a major collagen receptor for platelet activation: it recognizes the platelet-activating quaternary structure of collagen, whereas CD36, glycoprotein IIb/IIIa, and von Willebrand factor do not. Blood 91, 491-9 (1998).

16. Howell, W.H. The purification of heparin and its presence in blood. $A m$. J. Physiol 71, 553-562 (1925).

17. Charles, A.F. \& Scott, D.A. Biochem. J 30, 1927-1933 (1936).

18. Cifonelli, J., J, K. \& AD, C. The distribution of 2-acetamido-2deoxy-Dglucose residue in mammalian heparins. Carbohydrate Research 21, 173186 (1972).

19. Foster, A.B. \& Huggard, A.J. Adv. Carbohydr. chem 10, 335-368 (1955).

20. Cifonelli, J. Methods Carbohydr. Chem 7, 139-141 (1976).

21. Dietrich, C.P., Michelacci, M.C. \& Nader, H.B. In mechanism of saccharide polymerization and depolmerization. Academic press, New York , 317-329 (1980).

22. Linker, A. \& Hovingh, P. Methods Enzymol 28, 902-911 (1972).

23. Kiss, J. Adv. Carbohydr. Chem.Biochem 29, 229-303 (1974).

24. Cifonelli, J.A. \& King, J. The distribution of sulfated uronic acid and hexosamine residues in heparin and heparan sulfate. Connect Tissue Res 3, 97-104 (1975).

25. Choay, J. et al. Structure-activity relationship in heparin: a synthetic pentasaccharide with high affinity for antithrombin III and eliciting high anti-factor Xa activity. Biochem Biophys Res Commun 116, $492-9$ (1983).

26. Merton, R.E., Thomas, D.P., Havercroft, S.J., Barrowcliffe, T.W. \& Lindahl, U. High and low affinity heparin compared with unfractionated heparin as antithrombotic drugs. Thromb Haemost 51, 254-6 (1984).

27. Ockelford, P.A., Carter, C.J., Cerskus, A., Smith, C.A. \& Hirsh, J. Comparison of the in vivo hemorrhagic and antithrombotic effects of a low antithrombin-III affinity heparin fraction. Thromb Res 27, 679-90 (1982).

28. Zammit, A. \& Dawes, J. Low-affinity material does not contribute to the antithrombotic activity of Orgaran (Org 10172) in human plasma. Thromb Haemost 71, 759-67 (1994). 
29. Barrowcliffe, T.W. et al. Low-affinity heparin potentiates the action of high-affinity heparin oligosaccharides. Thromb. Res 34, 125-134 (1984).

30. Ersdal-Badju, E., Lu, A., Zuo, Y., Picard, V. \& Bock, S.C. Identification of the antithrombin III heparin binding site. J Biol Chem 272, 19393-400 (1997).

31. Pike, R.N. et al. Heparin-dependent modification of the reactive center arginine of antithrombin and consequent increase in heparin binding affinity. J Biol Chem 272, 19652-5 (1997).

32. Desai, U.R., Petitou, M., Bjork, I. \& Olson, S.T. Mechanism of heparin activation of antithrombin. Role of individual residues of the pentasaccharide activating sequence in the recognition of native and activated states of antithrombin. $J B C 273,7478-7487$ (1998).

33. Schreuder, H.A. et al. The intact and cleaved human antithrombin III complex as a model for serpin-proteinase interactions. Nat Struct Biol 1, 48-54 (1994).

34. Carrell, R.W., Skinner, R., Jin, L. \& Abrahams, J.-P. Haemostasis 77, 516519 (1997).

35. Tsiang, M., Jain, A.K. \& Gibbs, C.S. Functional requirements for inhibition of thrombin by antithrombin III in the presence and absence of heparin. J Biol Chem 272, 12024-9 (1997).

36. Meagher, J.L., Beechem, J.M., Olson, S.T. \& Gettins, P.G. Deconvolution of the fluorescence emission spectrum of human antithrombin and identification of the tryptophan residues that are responsive to heparin binding. J Biol Chem 273, 23283-9 (1998).

37. Nordeman, B., Danielsson, A. \& Björk, I. Eur. J. Biochm 90, 1-6 (1978).

38. Beeler, D., Rosenberg, R.D. \& Jordan, R. J. Biol. Chem 254, 2902-2913 (1979).

39. Nordenman, B. \& Bjork, I. Binding of low-affinity and high-affinity heparin to antithrombin. Ultraviolet difference spectroscopy and circular dichroism studies. Biochemistry 17, 3339-44 (1978).

40. Gettins, P. Antithrombin III and its interaction with heparin. Comparison of the human, bovine, and porcine proteins by $1 \mathrm{H}$ NMR spectroscopy. Biochemistry 26, 1391-8 (1987).

41. Gettins, P. \& Wooten, E.W. On the domain structure of antithrombin III. Tentative localization of the heparin binding region using $1 \mathrm{H}$ NMR spectroscopy. Biochemistry 26, 4403-8 (1987).

42. Bode, W., Turk, D. \& Karshikov, A. The refined 1.9-A X-ray crystal structure of D-Phe-Pro-Arg chloromethylketone-inhibited human alphathrombin: structure analysis, overall structure, electrostatic properties, detailed active-site geometry, and structure-function relationships. Protein Sci 1, 426-71 (1992).

43. Bode, W. \& Stubbs, M.T. Spatial structure of thrombin as a guide to its multiple sites of interaction. Semin Thromb Hemost 19, 321-33 (1993). 
44. Furie, B. et al. Computer-generated models of blood coagulation factor Xa, factor IXa, and thrombin based upon structural homology with other serine proteases. J Biol Chem 257, 3875-82 (1982).

45. Tsiang, M. et al. Functional mapping of the surface residues of human thrombin. J Biol Chem 270, 16854-63 (1995).

46. Church, F.C., Meade, J.B., Treanor, R.E. \& Whinna, H.C. Antithrombin activity of fucoidan. The interaction of fucoidan with heparin cofactor II, antithrombin III, and thrombin. J Biol Chem 264, 3618-23 (1989).

47. Sheehan, J.P. \& Sadler, J.E. Molecular mapping of the heparin-binding exosite of thrombin. Proc Natl Acad Sci U S A 91, 5518-22 (1994).

48. Gan, Z.R., Li, Y., Chen, Z., Lewis, S.D. \& Shafer, J.A. Identification of basic amino acid residues in thrombin essential for heparin-catalyzed inactivation by antithrombin III. $J$ Biol Chem 269, 1301-5 (1994).

49. Ye, J., Rezaie, A.R. \& Esmon, C.T. Glycosaminoglycan contributions to both protein $\mathrm{C}$ activation and thrombin inhibition involve a common arginine-rich site in thrombin that includes residues arginine 93, 97, and 101. J Biol Chem 269, 17965-70 (1994).

50. Sheehan, J.P., Tollefsen, D.M. \& Sadler, J.E. Heparin cofactor II is regulated allosterically and not primarily by template effects. Studies with mutant thrombins and glycosaminoglycans. $J$ Biol Chem 269, 32747-51 (1994).

51. Grootenhuis, P.D., Westerduin, P., Meuleman, D., Petitou, M. \& van Boeckel, C.A. Rational design of synthetic heparin analogues with tailormade coagulation factor inhibitory activity [letter]. Nat Struct Biol 2, 736-9 (1995).

52. Jin, J.e.a. The anticoagulant activation of antithrombin by heparin. Proc. Natl Acad. Sci. USA 94, 14683-14688 (1997).

53. Petitou, M. et al. Synthesis of thrombin-inhibiting heparin mimetics without side effects [see comments]. Nature 398, 417-22 (1999).

54. Lane, D.A., MacGregor, I.R., VanRoss, M., Cella, G. \& Kakkar, V.V. Molecular weight dependence of the anticoagulant properties of heparin: intravenous and subcutaneous administration of fractionated heparins to man. Thromb Res 16, 651-62 (1979).

55. Lane, D.A., Denton, J., Flynn, A.M., Thunberg, L. \& Lindahl, U. Anticoagulant activities of heparin oligosaccharides and their neutralization by platelet factor 4. Biochem J218, 725-32 (1984).

56. Hemker, C.H. \& Béguin, S. Mode of action of low molecular weight heparins in plasma and its consequences for the clinical laboratory. $E d$, Bounameaux, H. LMWHs in prophylaxis and therapy of thromboembolic diseases. Geneva, Switzeland. , 21-42 (1994).

57. Beguin, S., Lindhout, T. \& Hemker, H.C. The mode of action of heparin in plasma. Thromb Haemost 60, 457-62 (1988). 
58. Hemker, H.C. The mode of action of heparin in plasma. In: Thrombosis and Haemostasis. Eds. M. Verstraete, J. Vermylen, H. Rliynen, J. Arnout, University Press, Leuven, 17-36 (1987).

59. Beguin, S., Dol, F. \& Hemker, H.C. Factor IXa inhibition contributes to the heparin effect. Thromb Haemost 66, 306-9 (1991).

60. Ofosu, F.A. et al. The inhibition of thrombin-dependent positive-feedback reactions is critical to the expression of the anticoagulant effect of heparin. Biochem J 243, 579-88 (1987).

61. Beguin, S., Lindhout, T. \& Hemker, H.C. The effect of trace amounts of tissue factor on thrombin generation in platelet rich plasma, its inhibition by heparin. Thromb Haemost 61, 25-9 (1989).

62. Bendetowicz, A.V., Beguin, S., Caplain, H. \& Hemker, H.C. Pharmacokinetics and pharmacodynamics of a low molecular weight heparin (enoxaparin) after subcutaneous injection, comparison with unfractionated heparin--a three way cross over study in human volunteers. Thromb Haemost 71, 305-13 (1994).

63. Tollefsen, D.M., Majerus, D.W. \& Blank, M.K. Heparin cofactor II. Purification and properties of a heparin-dependent inhibitor of thrombin in human plasma. J Biol Chem 257, $2162-9$ (1982).

64. Tollefsen, D.M., Pestka, C.A. \& Monafo, W.J. Activation of heparin cofactor II by dermatan sulfate. J Biol Chem 258, 6713-6 (1983).

65. Tollefsen, D.M. Heparin Cofactor II. In: Heparin. Chemical and biological properties; Clinical applications. Eds DA Lane and U Lindhal. Edward Arnold, London. , 257-274 (1989).

66. Hurst, R.E., Poon, M.C. \& Griffith, M.J. Structure-activity relationships of heparin. Independence of heparin charge density and antithrombin-binding domains in thrombin inhibition by antithrombin and heparin cofactor II. $J$ Clin Invest 72, 1042-5 (1983).

67. Yamagishi, R., Koide, T. \& Sakuragawa, N. Binding of heparin or dermatan sulfate to thrombin is essential for the sulfated polysaccharideaccelerated inhibition of thrombin by heparin cofactor II. FEBS Lett 225 , 109-12 (1987).

68. de Swart, C.A., Nijmeyer, B., Roelfs, J.M. \& Sixma, J.J. Kinetics of intravenously administered heparin in normal humans. Blood 60, 12511258 .

69. Olsson, T.D., Lagergren, H. \& EK, S. The elimintaion from plasma of intravenous heparin: an expermintal study on dogs and humans. Acta. Med. Scand 173, 619-630 (1963).

70. Bjornsson, T.D., Wolfram, K.M. \& Kitchell, B.B. Heparin kinetics determined by three assay methods. Clin Pharmacol Ther 31, 104-113 (1982).

71. Glimelius, B., Busch, C. \& Höök, M. Binding of heparin on the surface of cultured human endothelial cells. Thromb Res 12, 773-782 (1978). 
72. Mahadoo, J., Heibert, L. \& Jaques, L.B. Vascular sequestration of heparin. Thromb Res 12, 79-90 (1978).

73. Friedman, Y. \& Arsenis, C. Studies on the heparin sulphamidase activity from rat spleen: intracellular distribution and characterization of the enzyme. Biochem. $J$ 139, 699-708 (1974).

74. Dawes, J. \& Papper, D.S. Catabolism of low-dose heparin in man. Thromb Res 14, 845-860 (1979).

75. Maallister, B.M. \& Demis, D.J. Heparin metabolism: isolation and characterization of uroheparin. Nature 212, 293-294 (1966).

76. Bara, L. \& Samama, M. Pharmacokinetics of low molecular weight heparins. Acta Chir Scand Supp 543, 65-72 (1988).

77. Rijn van, J.L.M.L., Trillou, M., Mardiguian, J., Tobelem, G. \& Caen, J. Celective binding of heparins to human endothelial cells. Implications for pharmacokinetics. Thromb Res 45, 211-222.

78. Bara, L., Billaud, E., Gramond, G., Kher, A. \& Samama, M. Comparative pharmacokinetics of a low molecular weight heparin (PK 10169) and unfractionated heparin after intravenous and subcutaneous administration. Thromb Res 39, 631-636 (1985).

79. Hemker, H.C. \& Beguin, S. Standard and method independent units for heparin anticoagulant activities [editorial] [published erratum appears in Thromb Haemost 1993 Dec 20;70(6):1072]. Thromb Haemost 70, 724-8 (1993).

80. Swart de, C. et al. Elimintaion of high affinity heparin fractions, their anticoagulant and lipase activity. Blood 6, 836-842 (1984).

81. Poller, L., Thomson, J.M. \& Yee, K.F. Heparin and partial thromboplastin time, an international survey. Brit. J. Haematol 44, 161-165 (1980).

82. van Putten, J.J., van de Ruit, M., Beunis, M. \& Hemker, H.C. Interindividual variation in relationship between plasma heparin concentration and the results of five heparin assays. Clin. Chim. Acta 122, 261-270 (1982).

83. Hemker, H.C., Weilders, S., Kessels, H. \& Béguin, S. Continuous registration of thrombin generation in plasma, Its use for the determination of thrombin potential. 1993 70, 617-624 (1993).

84. Lane, D.a. Heparin binding and neutralizing proteins. In: Heparin. Chemical and Biological properties; Clinical applications. Eds Lane D A , Edward Arnold. London. , 363-392 (1989).

85. Wun, T.Z. Lipoprotein-associated coagulation inhibitor (LACI) is a cofactor for heparin: synergistic anticoagulant action between $\mathrm{LACl}$ and sulphated polysaccharides. Blood 79, 430-438 (1992).

86. Kamikubo, Y. et al. A kinetic analysis of the interaction of human recombinant tissue factor pathway inhibitor with factor Xa utilizing and immunoassay and the effect of antithrombin III/heparin on the complex formation. Thromb Res 89, 179-86 (1998). 
87. Sandset, P.M., Abildgaard, U. \& Larsen, M.L. Heparin induces release of extrinsic coagulation pathway inhibitor (EPI). Thromb Res 50, 803-13 (1988).

88. Valentin, S., Larnkjer, A., Ostergaard, P., Nielsen, J.I. \& Nordfang, O. Characterization of the binding between tissue factor pathway inhibitor and glycosaminoglycans. Thromb Res 75, 173-83 (1994).

89. Barber, A.J., Glanzmann-Kaser, R., Jakabova, M. \& Luscher, E.F. Biochim. Biophys. Acta 286, 312-329 (1972).

90. Moore, S., Pepper, D.S. \& Cash, J.D. Platelet antiheparin activity. The isolation and characterisation of platelet factor 4 released from thrombinaggregated washed human platelets and its dissociation into subunits and the isolation of membrane-bound antiheparin activity. Biochim Biophys Acta 379, 370-84 (1975).

91. Handin, R.I. \& Cohen, H.J. Purification and binding properties of human platelet factor four. J Biol Chem 251, 4273-82 (1976).

92. Niewiarowski, S., Rucinski, B., James, P. \& Lindahl, U. Platelet antiheparin proteins and antithrombin III interact with different binding sites on heparin molecule. FEBS Lett 102, 75-8 (1979).

93. Jordan, R.E., Favreau, L.V., Braswell, E.H. \& Rosenberg, R.D. Heparin with two binding sites for antithrombin or platelet factor 4. $J$ Biol Chem 257, 400-6 (1982).

94. Shoenfeld, Y. Heparin-induced thrombocytopenia as an autoimmuno disease-idiotypic evidence for the role of anti-heparin/PF4 autoantibodies. Isr J Med Sci 33, 243-245 (1997).

95. warkentin, T.E. et al. Heparin-induced thrombocytopenia in patients treated with low-molecular weight heparin or unfractionated heparin. New England Journal of Medicine 332, 1330-1335 (1995).

96. Iverius, P.H. The interaction between human plasma lipoproteins and connective tissue glycosaminoglycans. J Biol Chem 247, 2607-13 (1972).

97. Mahley, R.W. \& Innerarity, T.L. Interaction of canine and swine lipoproteins with the low density lipoprotein receptor of fibroblasts as correlated with heparin/manganese precipitability. J Biol Chem 252, 39806 (1977).

98. Iverius, P.H. J. Biol. Chem 247, 2607-2613 (1972).

99. Srinivasan, S.R., Radhakrishnamurthy, B. \& Berenson, G.S. Studies on the interaction of heparin with serum lipoproteins in the presence of $\mathrm{Ca} 2+$, $\mathrm{Mg} 2+$, and Mn2+. Arch Biochem Biophys 170, 334-40 (1975).

100. Korn, E.D. J. Biol. Chem 215, 1-14, 15-26 (1955).

101. Olivecocrona, T., Egelrud, T., Iverius, P.H. \& Lindhal, U. Biochem. Biophys. Res Commun 43, 524-529 (1971).

102. La Rosa, J.C., Levey, R.I., Windmueller, G. \& Fredrickson, D. J. Lipid. Res 13, 356-363 (1972).

103. Hernell, O., Egelrud, T. \& Olivecrona. Biochim. Biophys. Acta 381, $233-$ 241 (1975). 
104. Bengtsson, G., Olivecrona, T., Hook, M., Riesenfeld, J. \& Lindhal, U. Interaction of lipoprotein lipase with native and modified heparin-like polysaccharides. Biochemical Journal 189, 625-633 (1980). 



\section{CHAPTER II}

A Critical Appraisal of the Control of Antithrombotic Therapy: Particularly of Heparin Therapy. 



\section{Introduction}

Two classes of anticoagulant agents are in current use today, the heparins and the oral anticoagulants. Within the heparin group, we distinguish unfractionated heparin (UFH) that accelerates the inactivation of both thrombin and factor $\mathrm{Xa}$ and low-molecular-weight heparins that lack the very high molecular weight fractions $(>10,000)$ and contain significant amounts of a component that only fosters the inactivation of factor Xa. Oral anticoagulants inhibit the synthesis of functionally active carboxylated vitamin-K-dependent coagulation factors (factors II, VII, IX, X, proteins C and $S$ ). During the last decade, a third class of substances has been developed: direct specific (factor $\mathrm{Xa}$ and thrombin) inhibitors, such as hirudin, hirulog, argatoban and several others.'

One of the key points in the clinical development of a new antithrombotic agent is to determine the optimal dosage. The proof of the pudding remains in the eating: i.e. the ultimate tests are clinical dose-finding studies that relate the antithrombotic effect to the plasma levels of the anticoagulant. Such studies are extremely costly in time and money and fairly inaccurate in determining the range of concentrations that enables adequate treatment. It is therefore of utmost importance to dispose of a laboratory model that can serve to relate pharmacokinetics to the anticoagulant effect.

There were two fundamentally different types of such models. The animal thrombosis model, in which thrombosis is provoked in any of a number of standardized ways, and the relationship between drug level and thrombosis prevention can be determined, if required to a high degree of accuracy. The problem with this approach is that the data on artificial thrombosis in an animal should be used to guess the dose relationship in clinical thrombosis in man. This chapter is not meant to discuss this problem further.

The second type of model is an ex vivo test that can be carried out on the blood of a patient and that varies with the level of anti-thrombotic action obtained on the pathogentic mechanism in patient. An ideal test would be that one that directly reflects the effect of the drug on the relevant pathogenic mechanism. Tests that only covariate with the antithrombotic action are still useful as long as the correlation with the pathogenetic mechanism is high and the tests meet general standards of reproducibility and accuracy. This raises the question of what indeed is the mechanism of action of the anticoagulant drugs. The fact that the three groups of drugs listed above each have an entirely different mode of action, facilitates an educated guess: it will not seem far fetched to surmise that the one thing 
that they have in common is the essential property that determines their antithrombotic action. That evidently is their capacity to diminish the amount of free thrombin that develops in clotting blood.

The next question, and the main one that we want to discuss in this review is: what are the relative merits of the currently used ex vivo tests for monitoring anticoagulant/anti-thrombotic treatment. ${ }^{2}$

\section{Thromboplastin Time or Prothrombin Time Test (PT)}

The principle of the PT is that it measures the time necessary to clot a plasma sample after recalcification in the presence of an excess of tissue factor and procoagulant phospholipid, i.e. the clotting time in the extrinsic system, in which the factors I, II, V, VII and X are involved. Since the introduction of oral anticoagulants in the early 1940s, the PT has been the primary means of monitoring the effectiveness and safety of oral anticoagulant therapy. Its results can be expressed in seconds, in the prolongation ratio (i.e. seconds in the sample over seconds in a normal control) or in present activity, i.e. the clotting factor concentration in diluted normal plasma that will cause an identical clotting time. The results vary with the type of thromboplastin used, no matter what way of expression is used. Also, as a rule, calibration curves of diluted normal plasma are not parallel to those of diluted samples of the anticoagulated blood and are dependent upon the dilution medium used. Hence, it is not possible to determine percent activity unequivocally. Therefore, the ratio method is commonly preferred. Variabilities in the results obtained with different thromboplastin reagents may cause oral anticoagulant therapy to be managed inappropriately. ${ }^{3}$ In response to these problems, the World Health Organization (WHO) recommends a mathematical correction of the PT results known as the International Normalized Ratio (INR). The INR relies upon the calibration of commercial thromboplastins against a standard reagent with a known sensitivity to the antithrombotic effect of oral anticoagulants. By reporting PT as INR, results from laboratory to laboratory can be compared with acceptable accuracy. Extensive studies have been carried out to express the level of safe and efficient oral anticoagulant therapy in terms of INR. ${ }^{4.5}$ Nevertheless, a number of potential problems with the INR were identified. On the one hand, even the most extensive studies leave large margins of uncertainty as to the relationship between INR and bleeding or rethrombosis. ${ }^{6}$ On the other hand, a lack of reliability was noticed at the onset of warfarin therapy. Also, the ISI provided by the manufacturer may be a source of error. On the other 
hand, a loss of accuracy was reported when thromboplastins with high INR values and /or automatic clot detectors were used. 'Finally, it should be noted that the PT is not sensitive to the effect of heparin. This in itself shows that it is a correlate to antithrombotic action only if this is obtained by oral anticoagulation, but cannot be the indicator of the pathophysiological mechanism behind it, otherwise it would have to react to heparin as well.

\section{Activated Partial Thromboplastin Time (aPTT)}

\section{Principle of the Test}

The aPTT represents the lag phase before explosive thrombin generation in an intrinsically triggered plasma sample, i.e. after recalcification in the presence of sufficient procoagulant phospholipid and a trigger of contact activation. The clotting factors involved are XII, XI, X, IX, VIII, V, II and I. The rate limiting step in this process in all probability is the feedback activation of factor VIII by thrombin. This makes it an indicator of antithrombin activity, at least in plasma in which the participating clotting factors are normally present. Factor VIII can not participate in the clotting cascade unless it is bound to phospholipid. Plasmatic, unactivated factor VIII does not bind to phospholipid because it is bound to von Willebrand factor. Its activation therefore can only be done by thrombin in free solution. The presence of heparin decreases the lifetime of thrombin in solution and hence makes it more difficult for thrombin to activate factor VIII and thus retards the thrombin burst and prolongs the lag time. ${ }^{8.9}$ Factor $\mathrm{V}$ can adsorb to phospholipid and can be activated by membrane-bound processes are essentially immune to heparin action. This explains why thromboplastin-induced clotting times are insensitive to heparin whereas the aPTT is.

\section{Performance}

APTT is an aspecific test, sensitive to all disturbances of the intrinsic clotting system. As a consequence of its mechanism of action, it is particularly sensitive to variations in the concentration and /or activity of factor VIII. It shows large interindividual variation and is strongly reagent and instrument dependent."

Interlaboratory variability of aPTT is excessive, as revealed by national and international surveys." A collaborative study was aiming to standarize aPTT monitoring of UFH by use of a reference aPTT reagent. The study essentially failed and concluded that each laboratory should perform its own 
local aPTT system calibration. This shows that aPTT standardization is obviously not simple, if at all possible. It is strongly felt that a reliable overall test to monitor heparin therapy is strongly needed ${ }^{12}$, but there is considerable doubt whether the approach that was successful with the PT in oral anticoagulant will serve a useful purpose in this case.

\section{aPTT in the Control of Heparin Therapy}

Despite these drawbacks, the aPTT is universally used as an indicator of the therapeutic level of heparin-mediated anticoagulation. As a rule of thumb, doubling the aPTT is thought to represent adequate heparin administration. This concept of a defined therapeutic range is based on experimental studies in animals ${ }^{13}$ and on a limited subgroup analysis of two prospective cohort studies in man. ${ }^{14.15}$ The results of these studies have led to the recommendation that the therapeutic range of heparin should be 1.5 to 2.5 times the control, which is equivalent to a heparin level (measured by protamine titration of the thrombin time) of $0.1-0.4 \mathrm{IU} / \mathrm{ml}$ or, in terms of anti-factor Xa activity, of $0.3-0.7 \mathrm{U} / \mathrm{ml}$. For the most commercial aPTT reagents in use at present, the lower limit of the therapeutic range is over 1.5 and close to 2.0 times prolongation.

How does the aPTT perform as a monitor of heparin administration? In a recent study, significant differences in respect of heparin responsiveness were found between six aPTT reagents. ${ }^{16}$ In addition, the limitation of aPTT for heparin monitoring was highlighted by the poor correlation between heparin concentration by protamine titration and aPTT ratio. ${ }^{16}$ In some cases, high aPTT values are associated with subtherapeutic heparin levels. ${ }^{17}$ This lack of association in these circumstances could be due to underlying diseases, which affect the aPTT.

It has been observed that a similar dosage of UFH produces significantly different prolongations in aPTT in different patients. The most likely explanation is the nonspecific binding of UFH to plasma proteins that neutralizes its anticoagulant effect. A number of these heparin-binding proteins are acute phase reactants that tend to be elevated in sick patients. Another protein that neutralizes heparin is platelet factor 4, a platelet constituent that is released during platelet activation in vivo (thrombosis!) and in vitro (blood handling and storage). In patients with heparin resistance as assessed by the aPTT, the heparin level measured by the anti-Xa assay is a more relevant marker of the effectiveness of the treatment, since this test is relatively unaffected by the high levels of procoagulants that shorten the aPTT. 
Recently, a formal review of the literature was performed on all available studies that provided information on the relationship between the risk of recurrent venous thromboembolism and the early aPTT response (within 24$48 \mathrm{~h}$ of initiation of treatment) to continuous intravenous heparin. More than 700 studies were identified, of which 50 were considered sufficiently informative for the overview. No convincing evidence shows that the risk of recurrent venous thromboembolism is critically dependent on achieving therapeutic aPTT result within $24-48 \mathrm{~h}^{17}$

\section{aPTT as a General Indicator of Anticoagulant Therapy}

The criterion of doubling the aPTT is sometimes, thoughtlessly, applied to other anticoagulants like direct thrombin inhibitors. This overlooks the fact that the mechanism by which such inhibitors prolong the aPTT is significantly different from that of heparin. Unlike heparin, such inhibitors do act on meizothrombin and therefore on the prothrombinase complex. This shows, even without going into details, that the dose-effect relationship must be quite different.

It is generally recognized that low-molecular-weight heparins with a high anti-factor Xa activity, and the synthetic pentasaccharides as a fortiori, exert their antithrombotic action at doses that hardly prolong the aPTT. This in the first place indicates that the aPTT does not directly represent the antithrombotic effect, so that it is not allowed to assume that two times prolongation of the aPTT can be used with other anticoagulants than with UFH.

\section{Thrombin Clotting Time (TCT)}

TCT is based on the fact that a certain amount of thrombin is required over a certain time in order to clot a fibrin-containing plasma sample. The more thrombin is present, the shorter the time. Thrombin added to plasma will disappear with a velocity dependent upon the antithrombin activity, i.e. upon the presence of heparin. Clotting will be faster when thrombin persists longer, i.e. the less heparin there is. This test is very sensitive and relatively specific for the antithrombin effect of heparin. There are differences in heparin sensitivity between various forms of TCT, that can be ascribed to variations in thrombin concentrations, thrombin type (bovine or human), and addition or not of calcium. ${ }^{18}$ Very low concentrations of UFH can be detected when a low thrombin concentration and no calcium is used. Conversely, high concentration of thrombin and addition of calcium is necessary to assess high concentrations of UFH. 
TCT is influenced by other factors than heparin, such as fibrin degradation products. Also variations in $\mathrm{pH}$ or temperature influence the results. ${ }^{20}$ The reliability of TCT in monitoring of heparin treatment has been a matter of dissention. It has been advocated by some authors, while others have underlined cautiousness and doubt. ${ }^{21.22}$ One point seems clear: if only one single thrombin concentration is used, only a narrow range of heparin concentrations can be accurately assessed. This range is somewhat enlarged by the addition of calcium.

\section{Activated Clotting Time}

The activated clotting time is a whole blood clotting time in the presence of a contact activator such as celite. ${ }^{24}$ It is a rapid and simple test that can be carried out at the bedside and in the operating theater. Indeed its widest use, in the USA, is to monitor heparin therapy during extracorpreal circulation and coronary angioplasty. ${ }^{25}$ The test is essentially an aPTT carried out on whole blood. Like the aPTT it covers an acceptable range of heparin levels. It carries the same drawbacks as the aPTT and is also strongly influenced by the conditions of blood sampling. ${ }^{26}$

\section{Ecarin Clotting Time}

Ecarin is a snake venom enzyme derived from the viper Echis Carinatus, which converts prothrombin into meizothrombin and other intermediates. The thrombin intermediates exhibit thrombin-like activity on the fibrinogen in the sample. While direct thrombin inhibitors are able to inhibit these thrombin intermediates, antithrombin has no effect and consequently heparin not either. Recently, ecarin-clotting time has been proposed for the specific measurement of the effect of hirudin and related direct antithrombin agents. ${ }^{27}$ This method is reported to show linear correlation with the anti-IIa activity of hirudin, to be highly reproducible, simple to perform and reliable for bedside monitoring of hirudin. ${ }^{28.29}$ Critical reviews of its performance in practice are still lacking.

\section{Heparin Anti-IIa and Anti-Xa Activities}

The specific action of heparin is that it accelerates the inactivation of thrombin and factor $\mathrm{Xa}$ in plasma by antithrombin. This property can be used to estimate these specific activities of heparin in a sample. These 
methods are based on inhibition of a known amount of factor $\mathrm{Xa}$ or thrombin, and are usually based on measuring residual factor $\mathrm{Xa}$ (thrombin) activity after a fixed incubation time, using a photometric determination with a synthetic peptide substrate to determine residual activities. The use of a photometer reduces the observer bias. These tests are as sensitive as and more specific than the aPTT. ${ }^{30}$ Assay of anti-Xa activity is the most widely used method for assessing low-molecular weight heparin ex vivo. The results are expressed in anti-Xa international units per milliliter of plasma. Here an important artifact must be noted. In plasma, in the presence of $\mathrm{Ca}^{2+}$ ions, the anti-factor $\mathrm{Xa}$ activity of $\mathrm{UFH}$, and hence of the international heparin standard, is twice higher than in an anti-Xa test situation where $\mathrm{Ca}^{2+}$ is absent. This is not the case, however, for low-molecular-weight heparins. Hence, the latter are measured against a 'handicapped' standard and overestimated. The effect causes 1.5-2.0 times too high anti-factor $\mathrm{Xa}$ values ${ }^{31.32}$. It should be noted that the use of the international standard for low-molecular-weight heparins does not abolish this error because the activity of that standard itself has been determined against the UFH standard. Amidolytic methods may differ as to the reagents used. The addition of purified antithrombin to the test plasma is recommended by some authors and rejected by others. ${ }^{33}$ A well-designed test renders, however, always the catalytic activity of the heparin present in the sample, independent of other components that may be present.

\section{Endogenous Thrombin Potential (ETP)}

The thrombin-generating capacity of plasma is one of the main determinants of hemostasis and thrombosis. ${ }^{34}$ Clotting times measure the onset of thrombin generation, the moment that about $1 \mathrm{unit} / \mathrm{ml}$ of thrombin ( $10 \mathrm{nM}$ ) is formed. Most thrombin, up to $100-250 \mathrm{nM}$, appears after the clot is formed. In vivo this thrombin will still act on its numerous substrates and exert a prothrombotic action. It has been shown that the enzymatic potency of generated thrombin is best expressed as the area under the thrombin generation curve, or ETP. The ETP can be determined from a classical thrombin generation curve, but this is unsuitable for routine purposes. A simplified and automated test has been described. ${ }^{35}$ This parameter might possibly be representing the essential variable decreasing in drug-induced hypocoagulability and increasing in hypercoagulability.

Preliminary results were obtained with this ETP assay as a routine procedure. The ETP appears to be decreased to between 20 and $40 \%$ of normal by oral anticoagulation in the therapeutic range (INR $=1.5-3.0)$ and 
by heparin administration in the therapeutic range (aPTT $=1.5-2.5$ control). It also indicates the hypocoagulability obtained in mixed treatment, common in the 1st week of treatment of venous thrombosis, and in which none of the currently used tests gives reliable guidelines. The ETP is increased in untreated subjects with congenital antithrombin deficiency and in women using contraceptives. It is also increased in patients with deep vein thrombosis and in coronary infarction after the acute phase. ${ }^{28}$ Extensive large-scale clinical trials will still be necessary to demonstrate the feasibility and the ability of the ETP as a general indicator of anticoagulation or hypercoagulable states.

\section{Conclusion}

Laboratory monitoring of anticoagulant therapy has its roots in the past, and is more often than not founded on tradition rather than on wellestablished data. Secondary rigorous standardization may (as in the case of PT) or may not (as in the case of aPTT) ameliorate the situation. In any case, the need of an adequate assay to monitor anticoagulant/antithrombotic therapy is obvious. This test should be easy and cheap and should represent an essential parameter of the coagulation system and therefore be applicable to all anticoagulants in the same way. No such test is available at this moment, but the ETP proposes as a candidate worthy of clinical testing.

\section{References}

1. Lefkovits, J. \& Topol, E.J. Direct thrombin inhibitors in cardiovascular medicine. Circulation 90, 1522-36 (1994).

2. FitzGerald, G.A. The human pharmacology of thrombin inhibition [published erratum appears in Coron Artery Dis 1997 Jan;8(1):A4]. Coron Artery Dis 7, 911 -8 (1996).

3. van Bergen, P.F. et al. Efficacy of long-term anticoagulant treatment in subgroups of patients after myocardial infarction. Br Heart $J 74,117-21$ (1995).

4. Azar, A.J. et al. Optimal intensity of oral anticoagulant therapy after myocardial infarction. $J$ Am Coll Cardiol 27, 1349-55 (1996).

5. Azar, A.J. et al. Assessment of therapeutic quality control in a long-term anticoagulant trial in post-myocardial infarction patients. Thromb Haemost 72, 347-51 (1994). 
6. Azar, A.J. et al. Risk of stroke during long-term anticoagulant therapy in patients after myocardial infarction. Ann Neurol 39, 301-7 (1996).

7. Hirsh, J., Dalen, J.E., Deykin, D., Poller, L. \& Bussey, H. Oral anticoagulants. Mechanism of action, clinical effectiveness, and optimal therapeutic range. Chest 108, 231S-246S (1995).

8. Béguin, S., Lindhout, T. \& Hemker, H.C. The mode of action of heparin in plasma. Thromb Haemost 60, 457-62 (1988).

9. Béguin, S., Dol, F. \& Hemker, H.C. Factor IXa inhibition contributes to the heparin effect. Thromb Haemost 66, 306-9 (1991).

10. Kitchen, S. \& Preston, F.E. The therapeutic range for heparin therapy: relationship between six activated partial thromboplastin time reagents and two heparin assays. (1996).

11. D'Angelo, A. et al. Effect of clot-detection methods and reagents on activated partial thromboplastin time (APTT). Implications in heparin monitoring by APTT. Am J Clin Pathol 94, 297-306 (1990).

12. Van der Velde, E.A. \& Poller, L. The APTT monitoring of heparin--the ISTH/ICSH collaborative study. Thromb Haemost 73, 73-81 (1995).

13. Chiu, H.M., Hirsh, J., Yung, W.L., Regoeczi, E. \& Gent, M. Relationship between the anticoagulant and antithrombotic effects of heparin in experimental venous thrombosis. Blood 49, 171-84 (1977).

14. Basu, D., Gallus, A., Hirsh, J. \& Cade, J. A prospective study of the value of monitoring heparin treatment with the activated partial thromboplastin time. N Engl J Med 287, 324-7 (1972).

15. Hull, R.D., Raskob, G.E. \& Hirsh, J. Continuous intravenous heparin compared with intermittent subcutaneous heparin in the initial treatment of proximal-vein thrombosis. $N$ Engl J Med 315, 1109-14 (1986).

16. Levine, M.N. et al. A randomized trial comparing activated thromboplastin time with heparin assay in patients with acute venous thromboembolism requiring large daily doses of heparin. Arch Intern Med 154, 49-56 (1994).

17. Anand, S., Ginsberg, J.S., Kearon, C., Gent, M. \& Hirsh, J. The relation between the activated partial thromboplastin time response and recurrence in patients with venous thrombosis treated with continuous intravenous heparin. Arch Intern Med 156, 1677-81 (1996).

18. Teien, A.N. \& Lie, M. Heparin assay in plasma: a comparison of five clotting methods. Thromb Res 7, 777-88 (1975).

19. Eika, C., Godal, H.C. \& Kierulf, P. Detection of small amounts of heparin by the thrombin clotting-time. Lancet 2, 376 (1972).

20. Godal, H.C. The assay of heparin in thrombin systems. Scand J Clin Lab Invest 13, 153-166 (1961).

21. Soloway, H.B. \& Cox, S.P. In vitro comparison of the thrombin time and activated partial thromboplastin time in the laboratory control of heparin therapy. Am J Clin Pathol 60, 648-50 (1973). 
22. Ts'ao, C.H., Raymond, J., Kolb, T. \& Lo, R. Effects of source and concentration of thrombin, and divalent cations, on thrombin time of heparinized plasma. Am J Clin Pathol 65, 206-12 (1976).

23. Denson, K.W. \& Bonnar, J. The measurement of heparin. A method based on the potentiation of anti- factor Xa. Thromb Diath Haemorrh 30, 471-9 (1973).

24. Hattersley, P.G. Progress report: the activated coagulation time of whole blood (ACT). Am J Clin Pathol 66, 899-904 (1976).

25. Blakely, J.A. A rapid bedside method for the control of heparin therapy. Can Med Assoc J 99, 1072-6 (1968).

26. Forman, W.B. \& Bayer, G. A simplified method for monitoring heparin therapy at the bedside: the activated whole blood clotting time. Am $J$ Hematol 11, 277-81 (1981).

27. Nowak, G. \& Bucha, E. A new method for the therapeutical monitoring of hirudin. Thromb Haemost 69, 1306-1314 (1993).

28. Esslinger, H.U., Dubbers, K., Radziwon, P. \& Breddin, H.K. Monitoring of the anticoagulant effects of PEG-hirudin administered as a continuous 24hour infusion following an I.V. bolus injection in healthy volunteers using the ecarin clotting time. Thromb Haemost suppl, 277-278 (1997).

29. Bode, C., Kohler, B., Steg, G., Parow, C. \& Rubsamen, K. The ecarin clotting time but not the aPTT is a reliable indicator for PEG-hirudin blood levels in patients with unstable angina pectoris. $J$ Am Coll Cardiol 29, 401 A-411 A (1997).

30. Teien, A.N., Lie, M. \& Abildgaard, U. Assay of heparin in plasma using a chromogenic substrate for activated factor X. Thromb Res 8, 413-6 (1976).

31. Schoen, P., Lindhout, T. \& Hemker, H.C. Ratios of anti-factor Xa to antithrombin activities of heparins as determined in recalcified human plasma. British Journal of Haematology 81, 255-262 (1992).

32. Hemker, H.C. \& Béguin, S. The activity of heparin in the presence and absence of $\mathrm{Ca}++$ ions; why the anti-Xa activity of $\mathrm{LMW}$ heparins is about two times overestimated. Thromb. Haemost 70(4), 717-718 (1993).

33. Walenga, J.M., Bara, L., Samama, M.M. \& Fareed, J. Amidolytic antifactor Xa assays in the laboratory evaluation of heparin and low molecular weight fractions. Semin Thromb Hemost 11, 100-7 (1985).

34. Hemker, H.C. \& Béguin, S. Thrombin generation in plasma: Its assessment via the endogenous thrombin potential. Thromb Haemost 74, 134-138 (1995).

35. Wielders, S. et al. The routine determination of the endogenous thrombin potential, first results in different forms of hyper- and hypocoagulability. ThrombHaemost 77, 629-36 (1997). 


\section{CHAPTER III}

Materials and Methods 



\section{Materials}

\section{Plasma}

Platelet poor plasma (PPP): Blood was pooled from 10-12 healthy donors on $0.13 \mathrm{M}$ trisodium citrate; nine parts of blood to one part of citrate solution. Neither suction nor pressure was applied, and the first blood drops were neglected. Plasma was obtained by two centrifugations at $15^{\circ} \mathrm{C}$, for 15 min at $3.000 \mathrm{~g}$, and a third centrifugation was made at $4{ }^{\circ} \mathrm{C}$, for $15 \mathrm{~min}$ at $23.000 \mathrm{~g}$. The platelet-poor plasma was stored at $-80{ }^{\circ} \mathrm{C}$. The clotting factors and the antiproteases were checked to be in the normal range.

\section{Proteins}

Euglobulin Fraction (thrombin): It was obtained from pooled plasma by acid precipitation ( $\mathrm{pH} \mathrm{5.2)} \mathrm{at} \mathrm{low} \mathrm{ionic} \mathrm{strength} \mathrm{as} \mathrm{described} \mathrm{in} \mathrm{ref.}{ }^{1}$ The precipitation was collected by centrifugation and dissolved in half the initial plasma volume of $21.6 \mathrm{mM}$ trisodium citrate in buffer A. In order to obtain thrombin, thrombin generation was triggered by adding 0.25 volume of diluted human thromboplastin in $100 \mathrm{mM} \mathrm{CaCl}_{2}$ to 1 volume of euglobulin fraction see ref. ${ }^{2}$

Recombinant Hirudin: It was a kind gift of Dr. R. B. Wallis (Ciba-Geigy, UK).

Bovine Antithrombin (AT): AT was isolated from frozen plasma. A modification of the procedure described by Thaler and Schmer was used." Plasma was stirred with Heparin-Agarose, the Agarose was poured into a column and washed with three column volumes $100 \mathrm{mM} \mathrm{NaCl}, 20 \mathrm{mM}$ $\mathrm{MES}-\mathrm{NaOH}$ (pH 6.5). The AT was eluted in a linear gradient (0.1-2 M $\mathrm{NaCl}$ ) with a rate of $4 \mathrm{ml} / \mathrm{min}$. Fractions containing $0.66-2 \mathrm{M} \mathrm{NaCl}$ were pooled. The buffer was changed into $100 \mathrm{mM} \mathrm{NaCl}, 20 \mathrm{mM}$ BisTris $(\mathrm{pH}$ $6.5)$ by gel filtration. The protein was applied to a DEAE-Fractogel column $\left(5 \mathrm{~cm}^{2} \times 28 \mathrm{~cm}\right)$ and eluted in a linear gradient of $100-600 \mathrm{mM} \mathrm{NaCl}(4$ $\mathrm{ml} / \mathrm{min}$ ) in $20 \mathrm{mM}$ BisTris-buffer ( $\mathrm{pH} \mathrm{6.5)}$. The AT eluted at about $280 \mathrm{mM}$ $\mathrm{NaCl}$ in a sharp peak. The AT was gel filtered to change the buffer into 175 $\mathrm{mM} \mathrm{NaCl}, 50 \mathrm{mM}$ Tris- $\mathrm{HCl}, \mathrm{pH}$ 7.9. The protein showed a single band on SDS-PAGE [Laemli] gels.

Human antithrombin $(A T)$ : The isolation procedure is a modification of the procedure described in ref ${ }^{3}$.

Bovine factor $X$ was purified and activated as described in refs ${ }^{4.5}$. 
Prothrombin was purified and activated as described. ${ }^{6.7}$ Both thrombin and FXa showed single bands on SDS-PAGE gels.

Recombinant human tissue factor and Actin $F S^{\otimes}$ were a gift of Dade productions (Düdingen, Switzerland). Actin $\mathrm{FS}^{\circledR}$ is a suspension of ellagic acid and soybean phosphotides.

Ancrod: The fibrinogen-clotting enzyme extracted from the Malayan pit Viper was the commercial preparation Arvin $^{(B)}$ (Knoll AG, Ludwigshafen, Germany). It was used at final concentration of $1 \mathrm{U} / \mathrm{ml}$, causing a clotting time of $50-60 \mathrm{~s}$ in normal plasma. It has been not reported to activate clotting factors in this system.

\section{Chemicals}

Buffers: Buffer A, $20 \mathrm{mM}$ Hepes, $150 \mathrm{mM} \mathrm{NaCl}, 0.5 \mathrm{mg} / \mathrm{ml}$ bovine serum albumin, pH 7.35. Buffer B, $20 \mathrm{mM}$ Hepes, $150 \mathrm{mM} \mathrm{NaCl}, 20 \mathrm{mM}$ EDTA, $0.5 \mathrm{mg} / \mathrm{ml}$ bovine serum albumin, pH 7.9. Buffer C, $20 \mathrm{mM}$ Hepes, $220 \mathrm{mM}$ $\mathrm{NaCl}, 20 \mathrm{mM}$ EDTA, $0.5 \mathrm{mg} / \mathrm{ml}$ bovine serum albumin, $\mathrm{pH}$ 7.9. Buffer Tris, $50 \mathrm{mM}$ Tris $\mathrm{HCl}, 0.1 \mathrm{M} \mathrm{NaCl}, \mathrm{pH} 7.5$.

Substrates: The chromogenic substrate for thrombin was H.D-phe-pip-Arg pNA (S-2238), for factor Xa it was Bz-Ile-Glu (piperdyl)-Gly-Arg-pNA) (S-2337) from Chromogenix, Sweden. The chromogenic substrate for ETP in intrinsic system was Malonyl $-\alpha$-aminoisobutyryl-arginin paranitroanilide methyl ester hydrochloride (SQ68) and synthesised by Serbio Laboratories, France. For extrinsic system, other chromogenic substrate; Msc-Val-arg-pNA ([methylsulfonylethyl]-oxycarbonyl-valyl-arginin-pnitroanilide) was synthesized in house by Dr. D. Rijkers. Pefachrome-FXa (methyloxycarbonyl-D-cyclohexyl-glycyl-glycyl-arginin-p-nitroanilide acetate) was obtained from Pentapharm, Basel, Switzerland. S2234 was purchased from Chromogenix, Sweden. Tris and ovalbumine (grade V) were obtained from Sigma, USA.

Heparins: Unfractionated heparin (UFH) was supplied by Organon. Clivarine $^{(\otimes)}$ (Reviparin sodium, a LMWH prepared from conventional heparin by deaminative cleavage) was supplied by (Knoll AG, Ludwigshafen, Germany). Logiparin ${ }^{(T i n z a p a r i n}$ sodium, a LMWH prepared from conventional heparin by enzymatic depolymerization) was supplied by (Novo Nordisk, Denmark). Clexane (Enoxaparin sodium, a LMWH from UFH by B-elimination of heparin esters) was supplied by (Rhone-Poulanc Rorer, France). Fraxiparin ${ }^{(N)}$ (Nadroparin sodium, a LMWH prepared from conventional heparin by deaminative cleavage) and Pentasaccharides (SR 90107 and SanOrg 34006) were a kind gift from 
(Sanofi-Recherche-, Gentilly, France). Synthetic heparin (17 sugar units) was a kind gift from Dr. Petitou (Sanofi-Recherche-, Gentilly, France).

\section{Methods}

\section{Defibrination of Plasma}

It was obtained by mixing an aliquot of plasma with 1: 50 volume of Arvin solution, letting a clot form for $10 \mathrm{~min}$ at $37^{\circ} \mathrm{C}$ and keeping the clotted plasma at $0{ }^{\circ} \mathrm{C}$ for $10 \mathrm{~min}$. The fibrin clot formed was discaried by winding it on a small spatula. The concentration of factors II, VII, VIII, IX, $\mathrm{X}, \mathrm{XI}$, and XII did not significantly change by the Arvin treatment."

\section{Gel filtration of Standard Heparin and Low-Molecular-Weight Heparin}

Unfractionated heparin was separated according to the molecular size by gel filtration. A preparative separation was obtained by chromatography on a Superdex 75 Prep Grade column $\left(5 \mathrm{~cm}^{2} \times 60 \mathrm{~cm}\right)$. The column was equilibrated with $0.5 \mathrm{M} \mathrm{NaCl}$ and $250 \mathrm{mg}$ heparin was applied (5 ml) each run. The elution rate was $45 \mathrm{ml} / \mathrm{hr}$, the heparin was detected at $206 \mathrm{~nm}$ and fractions of $1.3 \mathrm{ml}$ were collected. The molecular distribution of the heparin in the fractions was determined with high pressure size exclusion chromatography (HPSEC) with two columns coupled: TSK G (3000+ 2000) SW. The heparin was detected at $210 \mathrm{~nm}(0.1$ AUFS), the elution rate was $1.0 \mathrm{ml} / \mathrm{min}$, the eluent was $0.2 \mathrm{M} \mathrm{Na}_{2} \mathrm{SO} 4$ (pH 5.0), the run time $30 \mathrm{~min}$ and the injection volume $25 \mu \mathrm{l}$. The molecular weight distribution of heparin was determined by using a calibration curve, which was obtained by injection of 19 heparinoid with molecular weights varying from 35383 to 1181. The $\log \mathrm{Mr}$ was plotted against the retention time and the curve was fitted by using a 5 th order polynomial. The fractions with $\mathrm{Mr}$ above 15,000 were pooled according to molecular size. The fractions with Mr15,00010,000 were combined into two large pools. Then the heparin was precipitated in $\mathrm{NaCl}(5 \%, \mathrm{w} / \mathrm{v}$, final concentration in the aqueous solution) plus methanol (final concentration $75 \% \mathrm{v} / \mathrm{v}$ ) and lyophilized. The fractions with $\mathrm{Mr}>15,000$ were fine fractionated by chromatography on a Sephadex G75 fine column $\left(2 \mathrm{~cm}^{2} \times 92.5 \mathrm{~cm}\right)$. The column was equilibrated with $1 \mathrm{M}$ $\mathrm{NaCl}$ and applied about $60 \mathrm{mg}$ heparin dissolved in $2 \mathrm{ml} 1 \mathrm{M} \mathrm{NaCl}$, the elution rate was $30 \mathrm{ml} / \mathrm{hr}$. Fractions of $1 \mathrm{ml}$ were collected and the heparin was analyzed with HPSEC as above.

The heparin pool with $\mathrm{Mr}<10,000$ was fine fractionated by chromatography on a Sephadex G50 fine column $\left(5 \mathrm{~cm}^{2} \times 94.5 \mathrm{~cm}\right)$. The column was 
equilibrated with $1 \mathrm{M} \mathrm{NaCl}$, and a $300 \mathrm{mg}$ heparin dissolved in $5 \mathrm{ml} 1 \mathrm{M}$ $\mathrm{NaCl}$ was applied. The elution rate was $45 \mathrm{ml} / \mathrm{hr}$. Fractions of $1.65 \mathrm{ml}$ were collected and the heparin was analyzed with HPSEC as above.

The heparin pool with $15,000>\mathrm{Mr}>10,000$ was fine fractionated by chromatography on a Sephadex G75 fine column $\left(2 \mathrm{~cm}^{2} \times 93 \mathrm{~cm}\right)$. The column was equilibrated with $1 \mathrm{M} \mathrm{NaCl}$, and about a $150 \mathrm{mg}$ heparin dissolved in $2 \mathrm{ml} 1 \mathrm{M} \mathrm{NaCl}$ was applied. The elution rate was $30 \mathrm{ml} / \mathrm{hr}$. Fractions of $1.5 \mathrm{ml}$ were collected and the heparin was analyzed with HPSEC as above. This technique was also applied to Clivarine fragmentation.

\section{Determination of the High Affinity Material (HAM)}

This determination is based on the observation that the stoichiometric interaction between antithrombin and heparin causes a shift in fluorescence, one molecule of heparin containing the specific pentasaccharide binds to one molecule of antithrombin and thereby enhancing the fluorescence intensity of antithrombin molecule. 'In principle, antithrombin was first titrated with synthetic pentasaccharide so as to be sure of the concentration of active molecules of AT. Then this AT solution is titrated with each fraction (UFH, LMWH), so that its content of HAM can be expressed in molar units, see ref ${ }^{13}$. The measurements were conducted on a SLM Amino SPF-500 C spectrofluorometer (excitation $285 \mathrm{~nm}$, emission $345 \mathrm{~nm}$ ).

\section{Heparin Anti-Ila and Anti-Xa Activities}

Heparin accelerates the inactivation of thrombin and factor Xa in plasma by antithrombin. This property can be used to estimate the heparin activities in a sample. The determination is based on inhibition of a known amount of factor Xa or thrombin, and is usually based on measuring residual factor $\mathrm{Xa}$ (thrombin) activity after a fixed incubation time, using a photometric determination with a synthetic peptide substrate to determine residual activities. These tests are as sensitive as and more specific than the aPTT. ${ }^{14}$

\subsection{Determination of the Decay Constant of Thrombin}

The velocity of thrombin breakdown was undertaken by adding, at zero time, $10 \mu \mathrm{l}$ of human thrombin in buffer A (final concentration $100 \mathrm{nM}$ ), to $120 \mu \mathrm{l}$ of defibrinated plasma and $50 \mu \mathrm{l}$ of buffer $\mathrm{A}$ ( \pm heparin to be investigated), prewarmed at $37{ }^{\circ} \mathrm{C}$. At timed intervals, a $10 \mu \mathrm{l}$ sample was taken for determination of the amidolytic activity. The sampling was done 
with a push-button equipped pipette that recorded the moment of sampling on a personal computer. After about two minutes the amidolytic reaction was stopped by adding $300 \mu \mathrm{l}$ citric acid $(1 \mathrm{M})$. The moment of stopping was also recorded automatically. The amidolytic activities $(\mathrm{Ct})$ were fitted to the three parameter curve $\mathrm{Ct}=\mathrm{C} \infty+(\mathrm{C} 0-\mathrm{C} \infty) . \mathrm{e}^{-\mathrm{kdec} . \mathrm{t}}$, where $\mathrm{C} 0$ is the initial amidolytic activity and $\mathrm{C} \infty$ is the residual, steady end-level activity due to the $\propto 2$-macroglobulin-thrombin $(\propto 2 \mathrm{M}-\mathrm{T})$ complex. The decay constant $\left(\mathrm{k}_{\mathrm{dec}}\right)$ is the sum of the AT dependent part (k1) and the $\propto 2$ macroglobulin dependent part $(k 2)$. The ratio $R=k_{d c} / k 2$ is equal to $C 0 / C \infty$, i.e. the ratio of the amount of thrombin added and the amount of $(\propto 2 \mathrm{M}-\mathrm{T})$ complex at the end of the experiment. This ratio can be determined because of the persistent amidolytic activity of the $(\propto 2 \mathrm{M}-\mathrm{T})$ complex. The decay constant was measured for 4 different concentrations of heparin to be tested. The second order decay constant was expressed eventually in functional AT $\left(\mathrm{min}^{-1} / \mu \mathrm{M} \mathrm{AT}\right)$.

\subsection{Determination of the Decay Constant of Factor Xa}

Assay of anti-Xa activity is the most widely used method for assessing unfractionated and low-molecular weight heparin ex vivo.

\subsubsection{The Standard-Independent Method}

The determination of the biological (anti-FXa) activity of heparin by comparison to a standard is strongly method -dependent and therefore only gives reliable results if the conditions of the test are comparable to the conditions under which the drug is acting in vivo; using human clotting factors in the presence of $\mathrm{Ca}^{2+}$ ions. Activities may be over- or underestimated two-threefold if this is not taken into account.

Our procedure, however, for anti-factor Xa activity is the same as for antithrombin where it is undertaken in a standard-independent fashion; involving human plasma, human proteases, and the addition of $\mathrm{Ca}^{2+}$-ions.

A mixture of $120 \mu \mathrm{l}$ of defibrinated plasma, $10 \mu \mathrm{l}$ of r-hirudin $(25 \mathrm{nM}), 10$ $\mu \mathrm{l}$ of $\mathrm{CaCl}_{2}$ (final concentration $\left.15 \mathrm{mM}\right)$ and $30 \mu \mathrm{l}$ of buffer $\mathrm{A}( \pm 10 \mu \mathrm{l}$ of heparin in question) was prewarmed for $2-3$ minutes at $37^{\circ} \mathrm{C}$. A $10 \mu \mathrm{l}$ of human factor $\mathrm{Xa}(160 \mathrm{nM})$ was then added. At timed intervals, $10 \mu \mathrm{l}$ aliquot was sampled into disposal plastic cuvettes containing $490 \mu \mathrm{l}$ of a $200 \mu \mathrm{M}$ of $\mathrm{S} 2337$ in buffer $\mathrm{C}$. The velocity of factor Xa decay was then measured analogously to thrombin. 
Expression of Specific (aIIa, aXa) Activities: A standard independent unit (SIU) is defined as the amount of heparin that, in normal plasma, increases the decay constant of thrombin or factor Xa by $1 \mathrm{~min}^{-1}$ per $\mu \mathrm{M}$ of plasmatic AT. A plot of SIU activity against HAM content in molar units gives a slope that indicates the specific activity, see also refs ${ }^{16.17}$.

\subsection{The End-Point Assay of anti-Thrombin and anti-Factor Xa Activities}

We developed a method for quick and casy determination of heparin activity (anti-thrombin and anti-factor $\mathrm{Xa}$ ) in a standard independent way. This allows us to determine concentrations of active heparin in plasma expressed in molar units (see HAM determination).

The chromogenic assay is performed in the following way: to the reaction mixture containing purified AT, a suitable chromogenic substrate and the heparin-containing sample, thrombin or factor $\mathrm{Xa}$ is added. The reaction is started by the addition of thrombin or factor Xa. The amount of enzyme added is less than that of the AT present, so that, in the end, the enzyme is inactivated completely. The velocity of inactivation depends upon the amount of heparin added. During its lifetime the enzyme converts a limited amount of chromogenic substrate, i.e. an end-level of product (paranitroaniline) is obtained. This level is shown to be directly proportional to the half-life time of the enzyme, hence to the amount of active heparin added. Unlike other anti-thrombin and anti-FXa tests, the assay is not dependent upon timed sampling and therefore both easier and more accurate. Large numbers of samples can be tested at the same time by carrying out the reaction in wells of a micro titre plate, which can be read at the end in a simple plate reader. The method allows the direct determination of the molar concentration of active heparin. By using a traditional calibration curve, expression of the result in conventional units is also possible.

The reaction constant $\left(\mathrm{k}_{\mathrm{dec}}\right)$ was calculated from the formed pNA with the formula: $\mathrm{k}_{\mathrm{dec}}=\mathrm{k}_{\mathrm{cal}} / \mathrm{K}_{\mathrm{m}} * \mathrm{~S} / \mathrm{pNA} * \ln [\mathrm{A} /(\mathrm{A}-\mathrm{E})]$, in which $\mathrm{k}_{\mathrm{coal}}$ is the catalytic constant of the chromogenic substrate, $\mathrm{K}_{\mathrm{m}}$ is the Michaelis constant of the chromogenic substrate, $S$ is the concentration of the chromogenic substrate, pNA is the liberated para-nitroaniline, $A$ is the initial AT concentration and $\mathrm{E}$ is the initial thrombin or FXa concentration. The formula is valid only when the amount of hydrolyzed substrate is less than $10 \%$ or S is constant for practical purposes during the whole time course. During the life of the enzyme in the reaction mixture two reactions take place, (i) $E$ is irreversibly inactivated by AT in a second order reaction and (ii) $E$ hydrolyzes $S$ with 
Michaelis-Menten kinetics. When all $\mathrm{E}$ has been inactivated by $\mathrm{AT}$ hydrolysis of $S$ stops and no pNA will be formed anymore. The formula given above is integral of the formula valid for a second order inactivation reaction of an enzyme and simultaneous hydrolysis of a substrate by the enzyme.

\section{Performance}

All reaction components were diluted in $175 \mathrm{mM} \mathrm{NaCl}, 50 \mathrm{mM}$ Tris- $\mathrm{HCl}$, $0.02 \% \mathrm{NaN}_{3}, 2 \mathrm{mg} / \mathrm{ml}$ ovalbumin ( $\mathrm{pH} 7.9$ ).

Both the anti-thrombin and the anti-FXa activity assays were done in wells of micro-titre plates at room temperature. Each well was composed of 100 $\mu \mathrm{l}$ AT-chromogenic substrate mixture, $100 \mu \mathrm{l}$ sample and $100 \mu \mathrm{l}$ thrombin or FXa (the enzyme: E). The reaction was started with $\mathrm{E}$ and after $30 \mathrm{~min}$ the plate was read at $405 \mathrm{~nm}-492 \mathrm{~nm}$.

\section{The Thrombogram (the Thrombin Generation Curve)}

The thrombin-generating capacity of plasma is one of the main determinants of haemostasis and thrombosis. ${ }^{18}$ Clotting times measure the onset of thrombin generation, the moment that about 1 unit $/ \mathrm{ml}$ of thrombin $(10 \mathrm{nM})$ is formed. Most thrombin, up to $100-250 \mathrm{nM}$, appears after the clot is formed. In vivo this thrombin will still act on its numerous substrates and exert a prothrombotic action. It has been shown that the enzymatic potency of generated thrombin is best expressed as the area under the thrombin generation curve, also called the endogenous thrombin potential (ETP). The thrombin generation curve we call the thrombogram. The ETP can be determined from a classical thrombin generation curve, but this is unsuitable for routine purposes. A simplified and automated test has been described. ${ }^{8.11}$ This parameter might possibly be representing the essential variable decreasing in drug-induced hypocoagulability and increasing in hypercoagulability.

The ETP test was performed in the absence and the presence of heparin. In brief, the reactions are carried out in a laboratory automaton capable of measuring the optical density at $405 \mathrm{~nm}$ at $30 \mathrm{~s}$ intervals during 12 to 15 min. The Cobas Fara centrifugal analyser (F. Hoffmann-La Roche, Basel, Switzerland) was used for most experiments. The reaction mixture consists of four parts of defibrinated plasma, one part of trigger solution and one part of start solution. As a trigger for extrinsic system we used r.TF in a final concentration of about $300 \mathrm{pM}$. For the intrinsic system 1: 2.5 diluted contact activator (Actin $\mathrm{FS}^{\circledR}$ ) was used. In Cobas machines the volumes were $80 \mu \mathrm{l}$ of defibrinated plasma (or $75 \mu \mathrm{l}$ plasma with $5 \mu \mathrm{l}$ of heparin to 
be tested) and $20 \mu \mathrm{l}$ of r.TF (or the contact activator ), without $\mathrm{Ca}^{2+}$. After $30 \mathrm{~s}$ of incubation, which is sufficient for temperature equilibration, thrombin generation is started by adding $20 \mu \mathrm{l}$ of a prewarmed start solution containing $0.1 \mathrm{M} \mathrm{CaCl}_{2}$ and $3 \mathrm{mM}$ of substrate. After the start of the reaction the optical density at $405 \mathrm{~nm}$ is recorded at intervals of maximally $30 \mathrm{~s}$ for at least $12 \mathrm{~min}$. Data handling and calculation of ETP were undertaken on a personal computer connected to the centrifugal analyser see refs $^{8.19}$.

\section{Activated Partial Thromboplastin Time (aPTT)}

aPTT is an aspecific test, sensitive to all disturbances of the intrinsic clotting system. It is universally used as an indicator of the therapeutic level of heparin-mediated anticoagulation. As a consequence of its mechanism of action, it is particularly sensitive to variations in the concentration and /or activity of factor VIII. It shows large inter-individual variation and is strongly reagent and instrument dependent.

Performance of the Test:

aPTT was determined on the ACL300R (Automated Coagulation Laboratory) by mixing $100 \mu \mathrm{l}$ of plasma with $100 \mu \mathrm{l}$ of Actin $\mathrm{FS}^{\circledR}$, stirring and incubating for $3 \mathrm{~min}$ at $37^{\circ} \mathrm{C}$ and recalcifying with $100 \mu \mathrm{l}$ of a $25 \mathrm{mM}$ $\mathrm{CaCl}_{2}$ solution.

\section{References}

1. Josso, F. \& Prou-Wartelle, O. Exploration de l' hémostase. In: Techniquea en hématolgie. Alagille D et al.,eds. Paris. Flammarion , 101-8 (1972).

2. Béguin, S., Kessels, H., Dol, F. \& Hemker, H.C. The consumption of antithrombin III during coagulation, its consequences for calculation of prothrombinase activity and the standarisation of heparin activity. Thromb Haemost 68, 136-142 (1992).

3. Thaler, E. \& Schmer, G. A simple two-step isolation procedure for human and bovine antithrombin II/III (heparin cofactor): A comparison of two methods. Br J Haematol 31, 233-43 (1975).

4. Fujikawa, K., Legaz, M.E. \& Davie, E.W. Bovine factor X 1 (Stuart factor). Mechanism of activation by protein from Russell's viper venom. Biochemistry 11, 4892-9 (1972). 
5. Fujikawa, K., Legaz, M.E. \& Davie, E.W. Bovine factors X 1 and X 2 (Stuart factor). Isolation and characterization. Biochemistry 11, 4882-91 (1972).

6. Owen, W.G., Esmon, C.T. \& Jackson, C.M. The conversion of prothrombin to thrombin. I. Characterization of the reaction products formed during the activation of bovine prothrombin. J Biol Chem 249, 594 605 (1974).

7. Wagenvoord, R., Hendrix, H., Soria, C. \& Hemker, H.C. Localization of the inhibitory site(s) of pentosan polysulphate in blood coagulation. Thromb Haemost 60, 220-5 (1988).

8. Hemker, H.C., Weilders, S., Kessels, H. \& Béguin, S. Continuous registration of thrombin generation in plasma, Its use for the determination of thrombin potential. Thromb Haemost 70, 617-624 (1993).

9. Chan, K.E., Rizza, C.R. \& Henderson, M.P. A study of the coagulant properties of Malayan pit-viper venom. Br J Haemat 11, 646-57 (1965).

10. Davey, M.G. \& Luscher, E.F. Actions of some coagulant snake venoms on blood platelets. Nature 207, 730 (1965).

11. Hemker, H.C., Willems, G.M. \& Béguin, S.A. A computer assisted method to obtain the prothrombin activation velocity in whole plasma independent of thrombin decay processes. Thromb Haemost 56, 9-17 (1986).

12. Andersson, L.O., Barrowcliffe, T.W., Holmer, E., Johnson, E.A. \& Sims, G.E. Anticoagulant properties of heparin fractionated by affinity chromatography on matrix-bound antithrombin iii and by gel filtration. Thromb Res 9, 575-83 (1976).

13. Schoen, P., Wielders, S., Petitou, M. \& Lindhout, T. The effect of sulfation on the anticoagulant and antithrombin III- binding properties of a heparin fraction with low affinity for antithrombin III. Thromb Res 57, 415-23 (1990).

14. Teien, A.N., Lie, M. \& Abildgaard, U. Assay of heparin in plasma using a chromogenic substrate for activated factor X. Thromb Res 8, 413-6 (1976).

15. Hemker, H.C. \& Beguin, S. Standard and method independent units for heparin anticoagulant activities [editorial] [published erratum appears in Thromb Haemost 1993 Dec 20;70(6):1072]. Thromb Haemost 70, 724-8 (1993).

16. Bendetowicz, A.V., Pacaud, E., Beguin, S., Uzan, A. \& Hemker, H.C. On the relationship between molecular mass and anticoagulant activity in a low molecular weight heparin (enoxaparin). Thromb Haemost 67, 556-62 (1992).

17. Bendetowicz, A.V., Beguin, S., Caplain, H. \& Hemker, H.C. Pharmacokinetics and pharmacodynamics of a low molecular weight heparin (enoxaparin) after subcutaneous injection, comparison with unfractionated heparin--a three way cross over study in human volunteers. Thromb Haemost 71, 305-13 (1994). 
18. Hemker, H.C., Wielders, S. \& Béguin, S. The thrombin potential. A parameter to assess the effect of antithrombotic drugs on thrombin generation. In: Fraxiparine, seconde international symposium recent pharmacological and clinical data. Eds. H. Bounameaux, M. Samama and J. W. ten Cate. Schattauer. Stuttgart-New York 1990, 89-101 (1990).

19. Wielders, S. et al. The routine determination of the endogenous thrombin potential, first results in different forms of hyper- and hypocoagulability. Thromb Haemost 77, 629-36 (1997).

20. Kitchen, S. \& Preston, F.E. The therapeutic range for heparin therapy: relationship between six activated partial thromboplastin time reagents and two heparin assays. (1996). 


\section{CHAPTER IV}

An end-point assay to determine the decay constant of enzyme inactivation by an inhibitor, its application in measuring the catalytic activity of heparin. 



\section{Summary}

The determination of the decay constant of enzyme inactivation by an inhibitor usually requires monitoring of the enzyme concentration in time. By including a substrate during the inactivation reaction and monitoring the development of product, the inactivation can be observed directly. The level of product, after completion of the inactivation reaction, is proportional with the inverse of the decay constant of the inactivation reaction.

This principle is used for determining the decay constant of thrombin or factor Xa by AT and the influence of heparin. We show that the amount of formed product is proportional with the inverse of the decay constant, provided that substrate depletion does not play a role.

On the assumption that substrate conversion follows Michaelis-Menten kinetics and that enzyme inactivation by the inhibitor is a second order reaction we derived the formula for the course of product formation. It is validated by the close similarity of predicted and recorded course of product formation.

Heparin strongly accelerates thrombin and FXa inactivation by AT. At low heparin concentration the decay constant increases proportionally with the heparin concentration and for that reason the test system can be used to measure heparin activity. The method allows to determine catalytic heparin activity of large numbers of samples with high accuracy.

\section{Introduction}

In order to determine the decay constant of an enzyme that reacts with an irreversible inhibitor, the activity of the enzyme should be measured in time. This usually involves time-dependent sampling, which is both laborious and a source of error. We developed an assay which measures the decay constant of an inactivation reaction in a time independent way by including a substrate of the enzyme.

Heparins and heparin derivatives are widely used in the prevention and treatment of thrombosis. They enhance the action of antithrombin on activated clotting factors and therefore decrease the activity of thrombin in clotting blood. In a patient receiving heparin, the anticoagulant response is dependent upon the concentration of heparin in his plasma and the properties of that plasma. For that reason the accurate determination of heparin activity is of critical importance. 
Heparin is a mixture of polysaccharides with molecular weights varying from 2 to more than 40.' Active heparin molecules contain a specific pentasaccharide that provides the binding site for AT. ${ }^{1}$ Upon binding to AT the inactivation rate of FXa or thrombin is significantly increased. Active heparin molecules with a chain-length above 5.400 (Above Critical Length Material, ACLM) enhance the inactivation of both thrombin and FXa, those below that critical chain-length enhance the inactivation of factor $\mathrm{Xa}$ only (BCLM). To fully characterize the activity of functional heparin in a sample, therefore both anti-thrombin and anti-FXa activity should be measured. A large number of tests are available for this purpose. ${ }^{2-7}$ Other tests, such as the activated partial thromboplastin time (aPTT) are sensitive to both the heparin concentration and properties of the patients' plasma ${ }^{8-12}$, see chapter II. The outcome of these tests varies with the heparin concentration in an essentially unknown way, so calibration against a standard heparin is required.

Up till now no heparin test is described which measures the absolute activity of heparin. In many cases a chromogenic substrate is used, but this substrate is used to measure indirectly the action of heparin, i.e. enhancing thrombin or FXa inactivation by added AT or AT present in plasma.

In this study we describe a chromogenic assay, which measures the absolute activity of heparin. The assay is performed in reaction mixtures containing purified AT, a suitable chromogenic substrate and the heparin sample. Then the reaction is started by the addition of thrombin or FXa. The enzyme is completely inactivated by the AT present with a velocity dependent upon the amount of heparin added. During its lifetime in the mixture the enzyme converts only a limited amount of chromogenic substrate. This amount is shown to be inversely proportional to the decay constant of the enzyme, hence to the amount of active heparin added. Because this is an end-level assay, it is not dependent upon timed sampling like other anti-thrombin and anti-FXa tests. This makes the assay both easier and more accurate and also allows large numbers of samples to be tested at the same time and in a simple micro-titre plate reading. Because the reaction kinetics of the test are known, the results can be expressed in absolute terms (= reaction constant of thrombin or FXa inactivation per moles per second). However, by using a calibration curve, expression of the result in conventional units is also possible. 


\section{The Mathematical Model}

When enzyme $\mathrm{E}$ (FXa or thrombin) is added to a mixture of AT plus a chromogenic substrate, two reactions occur simultaneously. The enzyme will react with the substrate according to Michaelis-Menten kinetics and the enzyme will be irreversibly inactivated by AT. The Michaelis-Menten equations are:

$$
\mathrm{E}_{\mathrm{b}}=\mathrm{E}_{\mathrm{l}} \cdot[\mathrm{S}] /\left[\mathrm{K}_{\mathrm{m}}+\mathrm{S}\right] \quad \text { and } \mathrm{dP} / \mathrm{dt}=\mathrm{k}_{\text {ciat }} \cdot \mathrm{E}_{\mathrm{h}}=\mathrm{k}_{\mathrm{cat}} \cdot \mathrm{E}_{\mathrm{l}} \cdot[\mathrm{S}] /\left[\mathrm{K}_{\mathrm{m}}+\mathrm{S}\right] \text {, }
$$

In which $E_{b}$ is the enzyme bound to $S, E_{1}$ the total enzyme, dP/dt the hydrolysis rate of $S$ and $k_{\text {cat }}$ the catalytic constant of the enzymatic reaction. We further define $E_{i}$ as the enzyme not bound to the substrate, so that $E_{t}=$ $E_{\mathrm{h}}+\mathrm{E}_{\mathrm{f}}$ and $\mathrm{E}_{\mathrm{f}}=\left[\mathrm{K}_{\mathrm{m}}\right] /\left[\mathrm{K}_{\mathrm{m}}+\mathrm{S}\right]$.

Antithrombin $(A)$ only reacts with free enzyme $\left(E_{f}\right)$ to form the inactive antithrombin-enzyme complex. We will name this complex $\mathrm{X}$. In case $\mathrm{A}>$ $\mathrm{E}$, the following equations apply:

$$
\begin{aligned}
& A+E_{f}=X \text { and } d X / d t=(A-X) \cdot\left(E_{1}-X\right) . k^{\prime} \\
& \text { in which } k^{\prime}=k_{d e c} .\left[K_{m}\right] /\left[K_{m}+S\right] .
\end{aligned}
$$

Solving for $\mathrm{X}$ we obtain:

$$
X=\left[A \cdot E \cdot\left(e^{(A-E) \cdot k^{\prime} \cdot t}-1\right)\right] /\left[A \cdot\left(e^{(A-E) \cdot k \cdot t}-1\right)\right]
$$

This holds at any moment $t$, independent of the amounts of $A$ and $E$ that have interacted.

The integral of $X$ in time is:

$$
{ }_{0} \int^{\prime} X \cdot d t=A \cdot t-\ln \left(A \cdot e^{(A-E) \cdot k^{\prime} \cdot t}-E\right) / k^{\prime}+\ln (A-E) / k^{\prime}
$$

We are interested in the total amount of product formed, i.e. in the integral in time of $\mathrm{dP} / \mathrm{dt}=\mathrm{k}_{\mathrm{cat}} \cdot \mathrm{E}_{1} \cdot[\mathrm{S}] /\left[\mathrm{K}_{\mathrm{m}}+\mathrm{S}\right]$.

$\mathrm{E}_{1}=\mathrm{E}$ in time

Because $E_{1}=E-X$, we obtain:

${ }_{0} \int^{t} v \cdot d t=k_{\text {cat }} \cdot[S] /[K m+S] \cdot\left\{E . t-A \cdot t+\ln \left(A \cdot e^{\left[(A-E) \cdot k^{\prime} \cdot t\right]}-E\right) / k^{\prime}-\ln (A-\right.$ E)/k'

At $\mathrm{t}=0$ the integral is zero and at infinite time the integral is:

$$
P_{\text {end }}=\left(k_{\mathrm{cal}} . S\right) /\left(K_{\mathrm{m}} \cdot \mathrm{k}_{\mathrm{dec}}\right) . \ln [\mathrm{A} /(\mathrm{A}-\mathrm{E})]
$$

The model predicts that in an experiment with a given amount of substrate $\mathrm{A}$ and $\mathrm{E}, \mathrm{P}_{\mathrm{end}}$ is proportional to $1 / \mathrm{k}_{\mathrm{dec}}$ with a proportionality factor of $\mathrm{k}_{\mathrm{cal}} /$ $K_{m} . S \cdot \ln [A /(A-E)]$. It has been shown that $k_{\text {dec }}$ increases linearly with low heparin concentration.

We assume that the reaction is complete, i.e. that the end-level of product is reached, after ten half lives $\left(0.1 \%\right.$ remaining enzyme). The half-life $\left(\mathrm{t}^{1 / 2}\right)$ of the enzyme in the mixture is given by:

$$
\mathbf{t}^{1 / 2}=\{\ln ((2 \mathrm{~A}-\mathrm{E}) / \mathrm{A})\} /\left\{(\mathrm{A}-\mathrm{E}) \cdot \mathrm{K}_{\mathrm{m}} /\left(\mathrm{K}_{\mathrm{m}}+\mathrm{S}\right)\right\} / \mathrm{k}_{\mathrm{dec}}
$$


This shows that the time at which the end level is reached is dependent upon the kinetic properties of the substrate. It will be shown that special substrates are required to attain the end level in a reasonable reaction time.

\section{Results}

\section{Use of chromogenic substrates}

Theoretically there are no restrictions to the chromogenic substrates that can be used in this method, because equation (iii) is generally applicable. However, because of practical considerations we have to use substrates with low affinity for thrombin and FXa. Enzyme (thrombin or FXa) bound to the substrate is immune to the action of AT. The amount of enzyme free in solution is determined by the $\mathrm{K}_{\mathrm{m}}$ and the substrate concentration. The free enzyme is the fraction $K_{n} /\left(K_{m}+S\right)$ times the total enzyme and thus the halflife time is increased by the inverse of this fraction. In practice we prefer that the reaction is completed within $30 \mathrm{~min}$, that means that the half -life time should not exceed $3 \mathrm{~min}$. The half-life time of thrombin in plasma is about 16 seconds and the half-life time of FXa about 72 seconds. This means that for anti-FXa determination and working with about $1 \mu \mathrm{M} \mathrm{AT}$, $\left(\mathrm{K}_{\mathrm{m}}+\mathrm{S}\right) / \mathrm{K}_{\mathrm{m}}$ should not increase 2.5. To set one's mind this means that in a $0.5 \mathrm{mM}$ solution the $\mathrm{K}_{\mathrm{m}}$ should not be below $0.33 \mathrm{mM}$. For the antithrombin determination we may use a substrate with lower $\mathrm{K}_{\mathrm{m}}$, because the half-life time is shorter.

Besides the demands for the $K_{m}$ we have requirements for sensitivity of the assay. In the absence of heparin we need an amount of chromogenic substrate converted that produces colour with an absorption between 0.2 and $2.0 ; 0.2$ being the lowest level to allow accurate measurement of a substantial, heparin-related decrease and 2.0 being the upper limit of measurement in many photometers. These figures indicate that the amount of converted substrate has to be between 0.02 and $0.2 \mathrm{mM}$. Equation (iii) is only valid when $\mathrm{S}$ is practically constant, so the amount of converted substrate should be only a fraction (about 10\%) of present substrate. This sets the lower limit of the concentration of the substrate to $0.2 \mathrm{mM}$, whereas the upper limit is determined by other considerations: a signal with an OD below 2.0, effective use of materials, etc. According to equation (iii) the total amount of hydrolysed substrate is proportional with substrate efficiency $\left(\mathrm{k}_{\text {cal }} / \mathrm{K}_{\mathrm{m}}\right)$. The requirements for the $\mathrm{K}_{\mathrm{m}}$ set the limits for the $\mathrm{k}_{\text {cat }}$. In order to be in the range of $0.02-0.2 \mathrm{mM}$ converted substrate, the $\mathrm{k}_{\mathrm{cat}}$ should be in the order of 0.5-5 per second. So we need substrates which are slow compared to $\mathrm{S} 2238\left(\mathrm{~K}_{\mathrm{m}}=2.11 \mu \mathrm{M}, \mathrm{K}_{\mathrm{cat}}=79 \mathrm{~s}^{-1}\right)$ 
Fig. 1 shows that we can determine the decay constant with a "good" substrate for thrombin (S2234), but that the reaction was not completed within the time-course of the experiment $(50 \mathrm{~min})$. The decay constant could be determined only by curve fitting. Because the end-level could not be read, it was impossible to calculate the decay constant with equation (iii).

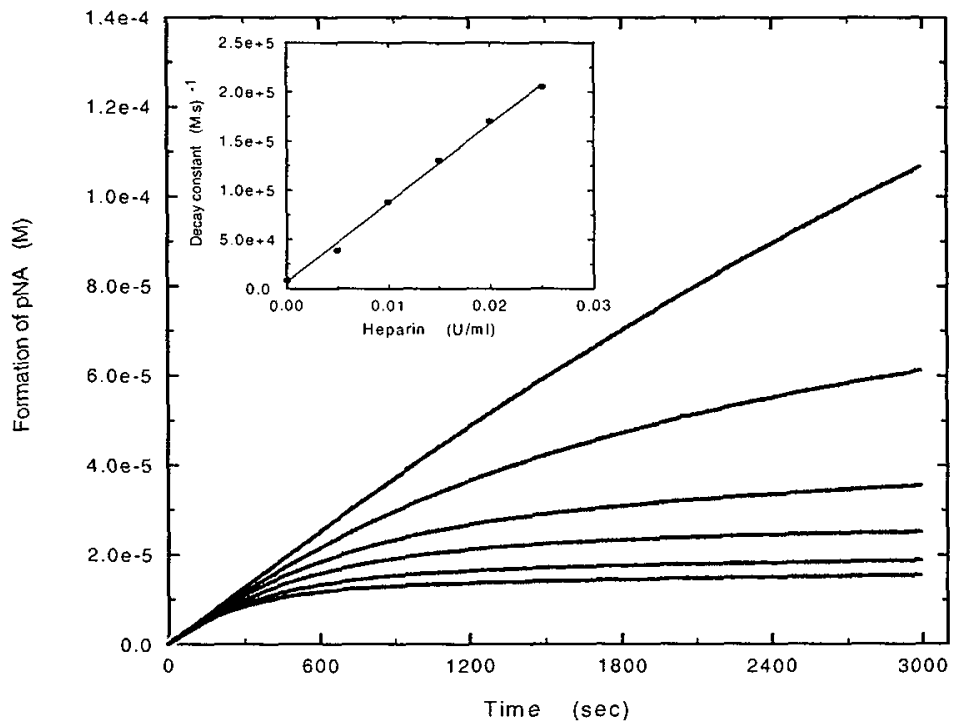

Fig. 1 Formation of $p N A$ in a mixture containing $A T, S 2234$, heparin and thrombin. The reaction mixture contained $1 \mu \mathrm{M}$ bovine-AT, $0.862 \mathrm{mM} \mathrm{S} 2234,0$ $0.025 \mathrm{U} / \mathrm{ml} 4^{\text {th }} \mathrm{ISH}$ and $250 \mathrm{pM}$ bovine-thrombin. The reaction was started with thrombin and done at $37{ }^{\circ} \mathrm{C}$. The pNA formation was calculated from the increase in absorption at $405 \mathrm{~nm}$, using a molar extinction coefficient of 9920 . The decay constant was obtained by curve fitting using equation (ii). The following kinetic constants were used: $K_{\mathrm{m}}=13.3 \mu \mathrm{M}, \mathrm{k}_{\mathrm{c} \text { :at }}=171 \mathrm{~s}^{-1}$. In the inset the decay constant is plotted against the heparin concentration.

In Fig. 2 we show that when we use a slow reacting substrate, Msc-val-argpNA, the survival time of the enzyme is much shorter. In this experiment the AT concentration was varied and no heparin was present. The inactivation reaction was completed within $10 \mathrm{~min}$. When heparin is present the rate of enzyme inactivation accelerates and the time required for complete enzyme inactivation is shorter. 


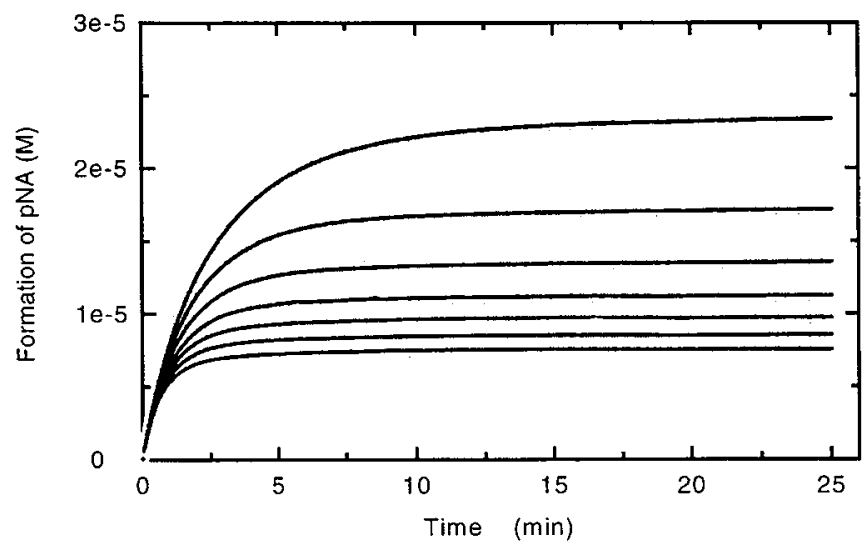

Fig. 2 The time course of $p N A$ formation in a reaction mixture containing Mscval-arg-pNA, thrombin and variable $A T$ concentrations, Comparison of the actual course with the fit. The reaction mixture contained $1 \mathrm{mM}$ Msc-val-argpNA, $0.8,1.0,1.2,1.4,1.6,1.8,2.0 \mu \mathrm{M}$ bovine-AT and $0.5 \mu \mathrm{M}$ bovine-thrombin. The reaction was started with thrombin and carried out at $37^{\circ} \mathrm{C}$. The black points give the measured pNA concentrations and the gray lines give the data obtained by fitting with equation (ii). The kinetic constants we used were: $\mathrm{K}_{\mathrm{m}}=1.58 \mathrm{mM}$ and $\mathrm{k}_{\mathrm{cat}}=1.059 \mathrm{~s}^{-1}$.

\section{Verification of the model}

Equation (iii) predicts that the total amount of formed pNA is proportional with the natural logarithm of $A /(A-E)$. To verify this, we have prepared mixtures containing Msc-val-arg-pNA or Pefachrome-Xa, thrombin or FXa and various AT concentrations. In Fig. 3 we show that in all four combinations the formed pNA is proportional with $\ln [\mathrm{A} /(\mathrm{A}-\mathrm{E})]$.

To check our calculation we monitored the concentration of pNA in time and compared it to the predicted values according to the equation. In all cases we found an almost compatible match. In Fig. 2 an example is shown for Msc-Val-Arg-pNA + thrombin.

The reaction constant of thrombin or FXa inactivation by AT can be determined from the amount of pNA formed at infinite time, from the slopes in Fig. 3 and from curve fitting as in Figs. 1 and 2. In Table I the results for the three procedures are given. In all three cases similar reaction constants are found. This indicates that, as predicted by theory, the end level of pNA contains the required information. 
Equation (iii) predicts that the end level of pNA is proportional with the substrate concentration. In the experiments shown in Fig. 4 we have varied $\mathrm{S}$ at fixed AT and thrombin or FXa concentrations. It is seen that indeed [S] is proportional to the end level of pNA in both cases. By rewriting formula (iii) we obtain $\mathrm{k}_{\mathrm{dec}}=\mathrm{k}_{\text {call }} / \mathrm{K}_{\mathrm{m}} \cdot \ln [\mathrm{A} /(\mathrm{A}-\mathrm{E})] /$ Slope. When we fill in the relevant constants we find 14280 (M.s) ${ }^{-1}$ for thrombin inactivation by AT and 4760 (M.s) ${ }^{-1}$ for FXa inactivation by AT. These constants are lower than the ones shown in Table I, because this experiment was done at room temperature.

Equation (iii) predicts that $P_{\text {end }}$ is proportional with $k_{c a t} / K_{m} \cdot \ln [A /(A-E)]$. The $\mathrm{k}_{\mathrm{cat}} / \mathrm{K}_{\mathrm{m}}$ can vary by more than 4 orders of magnitude. To obtain conditions at which less than $10 \%$ of the substrate is hydrolyzed, $\ln [\mathrm{A} /(\mathrm{A}-\mathrm{E})]$ must be varied with the inverse of their $\mathrm{k}_{\mathrm{cal}} / \mathrm{K}_{\mathrm{n}}$ values. In Table II some examples are given to illustrate that the product of $k_{\text {cal }} / K_{m}$ and $\ln [A /(A-E)]$ is proportional with formed $\mathrm{pNA}$ at constant substrate concentration.

From all the points given above we conclude that the theoretical equations render the experimental situation sufficiently.

Table I Reaction (decay) constants of thrombin or FXa inactivation by AT. The reaction constants were determined by curve fitting (see Figs. 1 and 2 ), by calculation according to formula (iii), or from the slopes in Fig. 3. The following kinetic constants were used, Msc + thrombin: $\mathrm{K}_{\mathrm{m}}=1.58 \mathrm{mM}$ and $\mathrm{k}_{\mathrm{cal}}=1.059 \mathrm{~s}^{-\mathrm{f}}$; Msc + FXa: $\mathrm{K}_{\mathrm{m}}=4.11 \mathrm{mM}$ and $\mathrm{k}_{\mathrm{cat}}=2.07 \mathrm{~s}^{-1}$; Pefachrome-Xa + thrombin: $\mathrm{K}_{\mathrm{m}}=$ $71.5 \mu \mathrm{M}$ and $\mathrm{k}_{\text {cat }}=23.1 \mathrm{~s}^{-1}$; Pefachrome-Xa $+F X a: \mathrm{K}_{\mathrm{m}}=142 \mu \mathrm{M}$ and $\mathrm{k}_{\mathrm{cat}}=$ $386 \mathrm{~s}^{-1}$; SQ68 + thrombin: $\mathrm{K}_{\mathrm{m}}=322 \mu \mathrm{M}$ and $\mathrm{k}_{\mathrm{cat}}=0.421 \mathrm{~s}^{-1}$; SQ68 + FXa: $\mathrm{K}_{\mathrm{m}}=$ $1.61 \mathrm{mM}$ and $\mathrm{k}_{\mathrm{cat}}=1.37 \mathrm{~s}^{-1} ; \mathrm{S} 2234+$ thrombin: $\mathrm{K}_{\mathrm{m}}=13.3 \mu \mathrm{M}$ and $\mathrm{k}_{\mathrm{cat}}=171 \mathrm{~s}^{-1}$; $\mathrm{S} 2234+\mathrm{FXa}: \mathrm{K}_{\mathrm{m}}=3.361 \mathrm{mM}$ and $\mathrm{k}_{\mathrm{cat}}=258 \mathrm{~s}^{-1}$.

\begin{tabular}{|c|c|c|c|c|c|c|}
\hline Experiment & & $\begin{array}{c}\text { AT } \\
(\mu \mathrm{M})\end{array}$ & $\begin{array}{c}\mathrm{E} \\
(\mathrm{nM})\end{array}$ & $\begin{array}{l}\text { Reaction constant } \\
\text { By curve fitting }\end{array}$ & $\begin{array}{l}{\left[(\mathrm{M} . \mathrm{s})^{-1} \times 10^{-3}\right] \mathrm{d}} \\
\text { From end-level }\end{array}$ & $\begin{array}{l}\text { etermined } \\
\text { From slope }\end{array}$ \\
\hline $\mathrm{Msc}-\mathrm{V}-\mathrm{R}-\mathrm{pNA}$ & $\begin{array}{l}+ \text { thrombin } \\
+ \text { FXa }\end{array}$ & $\begin{array}{l}0.8-2.0 \\
0.8-2.0\end{array}$ & $\begin{array}{l}500 \\
500\end{array}$ & $\begin{array}{l}24.8 \pm 0.59 \\
8.6 \pm 0.41\end{array}$ & $\begin{array}{l}23.8 \pm 0.84 \\
8.6 \pm 0.48\end{array}$ & $\begin{array}{l}24.5 \\
10.8\end{array}$ \\
\hline Pelichrome-Xa & $\begin{array}{l}+ \text { thrombin } \\
+ \text { FXa }\end{array}$ & $\begin{array}{l}0.6-2.0 \\
0.6-2.0\end{array}$ & $\begin{array}{l}2.1 \\
0.2\end{array}$ & $\begin{array}{l}16.9 \pm 0.44 \\
11.5 \pm 0.29\end{array}$ & $\begin{array}{l}15.2 \pm 0.48 \\
11.0 \pm 0.26\end{array}$ & $\begin{array}{l}15.5 \\
10.2\end{array}$ \\
\hline SQ68 & $\begin{array}{l}+ \text { thrombin } \\
+\mathrm{FX}_{\mathrm{a}}\end{array}$ & $\begin{array}{l}0.8-2.0 \\
0.8-2.0\end{array}$ & $\begin{array}{l}500 \\
500\end{array}$ & $\begin{array}{l}32.0 \pm 4.35 \\
13.9 \pm 1.65\end{array}$ & $\begin{array}{l}30.8 \pm 5.28 \\
13.5 \pm 1.54\end{array}$ & $\begin{array}{l}35.8 \\
14.4\end{array}$ \\
\hline S22.34 & $\begin{array}{l}+ \text { thrombin } \\
+ \text { FXa }\end{array}$ & $\begin{array}{l}1.0-4.0 \\
1.0-4.0\end{array}$ & $\begin{array}{l}0.25 \\
12.0\end{array}$ & $\begin{array}{l}15.4 \pm 0.30 \\
6.7 \pm 0.18\end{array}$ & $\begin{array}{c}14.7 \pm 0.53 \\
6.9 \pm 0.32\end{array}$ & $\begin{array}{l}15.1 \\
6.85\end{array}$ \\
\hline
\end{tabular}


Table II Product of $k_{c a r} / K_{m}, \ln [A /(A-E)]$ and $1 /$ end-level. The reaction vessels contained the indicated substrate and variable amounts of AT, thrombin or FXa. The reaction temperature was $37^{\circ} \mathrm{C}$. At appropriate times the formed $\mathrm{pNA}$ was read.

\begin{tabular}{llcc}
\hline Enzyme and substrate & $k_{\mathrm{cal}} / \mathrm{K}_{\mathrm{m}}(\mathrm{s} \cdot \mathrm{mM})^{-1}$ & $\times \ln [\mathrm{A} /(\mathrm{A}-\mathrm{E})] /[\mathrm{pNA}]$ & $\begin{array}{c}= \\
\text { "Product" } \\
(\mathrm{s} . \mathrm{mM} . \mathrm{M})^{-1}\end{array}$ \\
\hline Thrombin & & & \\
Msc-Val-Arg-pNA & 0.670 & 36500 & 24500 \\
SQ-68 & 1.31 & 27.300 & 35700 \\
Pefachrome-FXal & 323 & 96.05 & 31000 \\
S2234 & 12860 & 2.34 & 30100 \\
\hline Faclor Xa & & & \\
Msc-Val-Arg-pNA & 0.504 & 21450 & 10800 \\
SQ-68 & 0.641 & $22800)$ & $14600)$ \\
Pefachrome-FXa & 2720 & 7.49 & 20400 \\
S2234 & 76.9 & 178 & 13700 \\
\hline
\end{tabular}
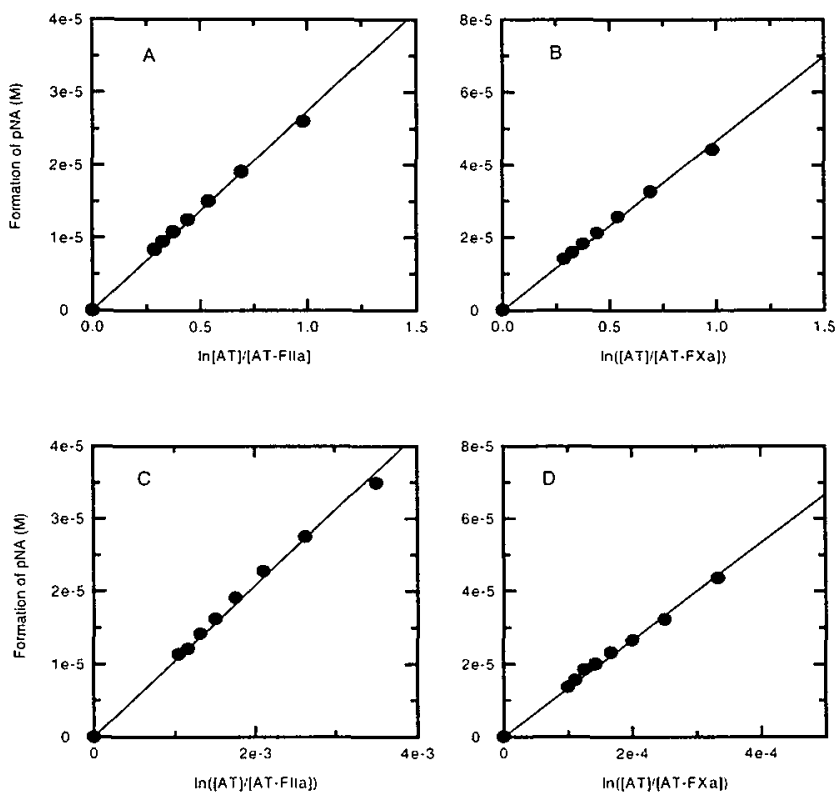

Fig. 3 Dependency of the amount of formed $p N A$ on the $A T$ concentration in reaction mixtures containing a chromogenic substrate and thrombin or $F X a$ The reaction vessels of panels $\mathrm{A}$ and $\mathrm{B}$ contained $0.8,1.0,1.2,1.4,1.6,1.8,2.0$ $\mu \mathrm{M}$ bovine-AT, $1 \mathrm{mM}$ Msc-val-arg-pNA and $500 \mathrm{nM}$ bovine-thrombin (panel A) or $500 \mathrm{nM}$ bovine-FXa (panel $\mathrm{B}$ ). The reaction vessels of panels $\mathrm{C}$ and $\mathrm{D}$ contained $0.6,0.8,1.0,1,2,1.4,1.6,1.8,2.0 \mu \mathrm{M}$ bovine-AT, $0.5 \mathrm{mM}$ Pefachrome-FXa and $2.1 \mathrm{nM}$ bovine-thrombin (panel C) or $0.2 \mathrm{nM}$ bovine-FXa (panel D). The reaction was started with the enzyme and done at $37^{\circ} \mathrm{C}$. The OD $(405 \mathrm{~nm}$ ) was read after $25 \mathrm{~min}$ (panels $\mathrm{A}$ and $\mathrm{B}$ ) or 50 min (panels $\mathrm{C}$ and D) to determine formed pNA. 


\section{Determination of heparin}

In the presence of heparin the inactivation reaction of thrombin or FXa by AT is faster than in its absence. Fig. 5 shows that the increase in reaction constant is proportional with the concentration of the added heparin. By addition of $0.033 \mathrm{U} / \mathrm{ml}$ the anti-thrombin activity increases about 10 -fold, whereas about twice as much heparin is needed to increase the anti-FXa activity with the same factor. This effect is not dependent of the AT concentration. By increasing the AT concentration the end level of pNA decreases, but the same amount of heparin causes the same increase of the reaction constant.

Heparin can also be determined in wells of micro-titre plates at room temperature. In that case a similar result is found: the increase of the reaction constant is proportional with the added heparin, but the reaction constants are about half of the values found at $37^{\circ} \mathrm{C}$.
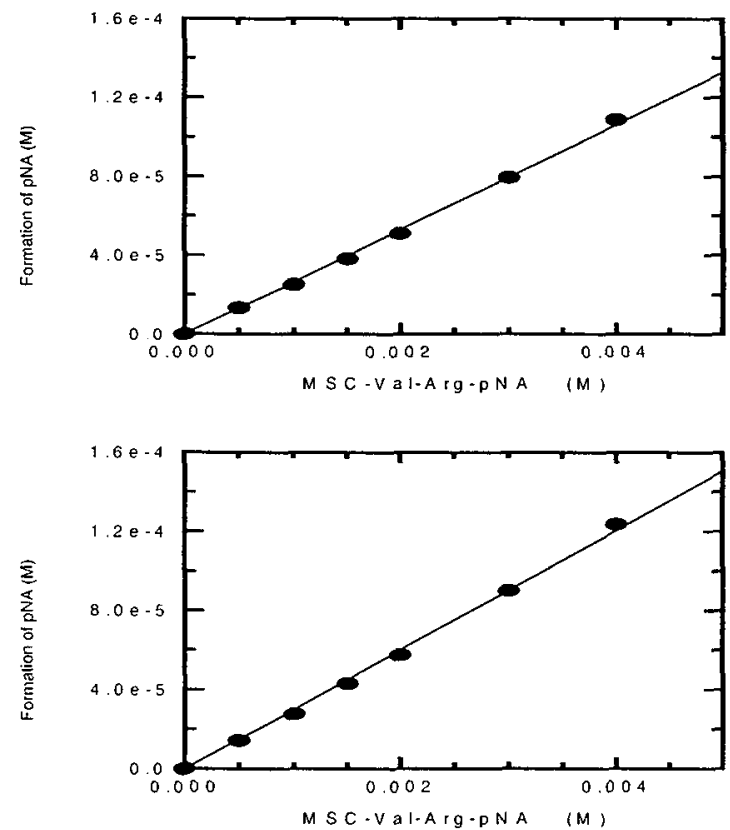

Fig. 4 Dependency of the formed $p N A$ on the substrate concentration. The reaction was started with the enzyme and carried out in micro-titre plate wells at room temperature. Each well contained $1 \mu \mathrm{M}$ AT, Msc-val-arg-pNA as indicated and $505 \mathrm{nM}$ thrombin (upper panel), or $400 \mathrm{nM} \mathrm{FXa} \mathrm{(lower} \mathrm{panel).}$ 

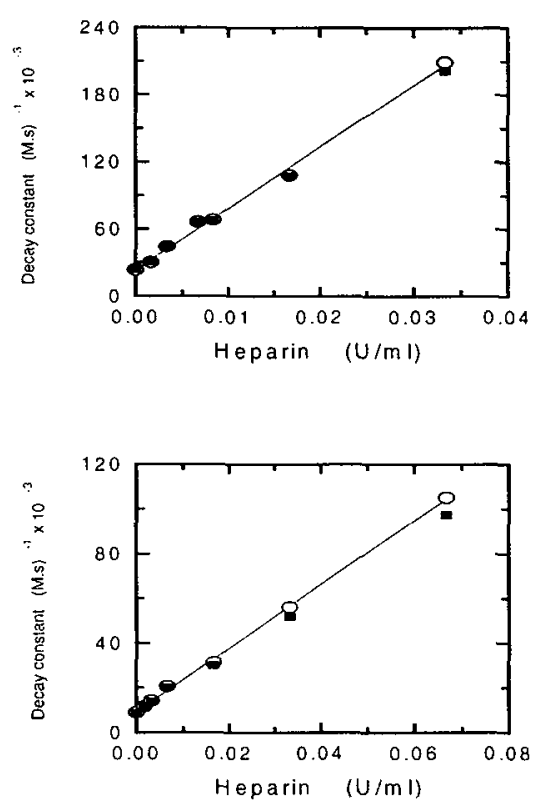

Fig. 5 Dependence of the decay constant on the heparin concentration. The reaction mixture contained $1.0 \mu \mathrm{M} \mathrm{AT}, 2 \mathrm{mM}$ Msc-val-arg-pNA and heparin as indicated. The reaction was started with $600 \mathrm{nM}$ thrombin (upper panel) or 400 $\mathrm{nM}$ FXa (lower panel). The pNA formation was measured during $25 \mathrm{~min}$. The reaction constants were determined by curve fitting (o), or calculated from the optical density at $25 \mathrm{~min}(\mathbf{m})$.

The reaction constant of thrombin or FXa inactivation by $A T$ saturated with heparin:

When we know the reaction constant of thrombin or FXa inactivation by AT saturated with heparin, we have the tool to calculate the molar concentration of active heparin added. In Figs. 1 and 5 we show that when heparin is present in concentration far below the AT concentration $(0.02$ $\mathrm{U} / \mathrm{ml}$ corresponds to about $10 \mathrm{nM}$ ), the increase of the reaction constant, is proportional with the added heparin. In a mixture of heparin and AT the following equilibrium is present: 


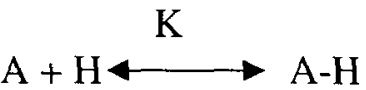

In which $\mathrm{K}$ is the dissociation constant, $\mathrm{A}$ is the $\mathrm{AT}$ concentration, and $\mathrm{H}$ is the heparin concentration.

The amount of bound heparin is given by:

$$
\mathrm{A}-\mathrm{H}=0.5(\mathrm{~A}+\mathrm{H}+\mathrm{K})-0.5\left[(\mathrm{~A}+\mathrm{H}+\mathrm{K})^{2}-4 \mathrm{AH}\right]^{1 / 2}
$$

If we assume that the amount of bound heparin does not change during the course of the inactivation reaction (i.e. heparin binds to free AT with the same affinity as to the AT-E complex), the actual reaction constant is composed of two components:

$$
\mathrm{k}_{\mathrm{d}} \mathrm{l} \cdot \mathrm{K}_{\mathrm{m}} /\left(\mathrm{K}_{\mathrm{m}}+\mathrm{S}\right) \cdot(\mathrm{l}-\mathrm{n})+\mathrm{k}_{\mathrm{d}} 2 \cdot \mathrm{K}_{\mathrm{m}} /\left(\mathrm{K}_{\mathrm{m}}+\mathrm{S}\right), \mathrm{n} \text { in which }
$$

$\mathrm{k}_{\mathrm{d}} \mathrm{l}$ is the reaction constant of thrombin/FXa inactivation by AT (no heparin)

$\mathrm{k}_{\mathrm{d}} 2$ is the reaction constant of thrombin/FXa inactivation by AT saturated with heparin

$I-n$ is the fraction of AT to which no heparin bound

$\mathrm{n}$ is the fraction of AT to which heparin is bound

$\mathrm{K}_{\mathrm{m}}$ is the Michaelis constant, (as above)

$\mathrm{S}$ is the substrate concentration, (as above).

To find the decay constant of thrombin or FXa inactivation by AT saturated with heparin, we prepared reaction mixtures with heparin concentration of the same order as AT. In order to hydrolyse sufficient substrate during the short survival time of the enzyme under these conditions, we had to use the rather "good" substrate S2234. In the presence of high heparin concentrations, the end-level of pNA is reached within 1 min. and the amount of liberated pNA is $40-50 \mu \mathrm{M}$. In Fig. 6 we have plotted the inverse of the reaction constant against the inverse of the heparin concentration. A straight relationship was found. The decay constant was $1.13 \times 10^{7}(\mathrm{M} . \mathrm{s})^{-1}$ and the dissociation constant $0.19 \mathrm{U} / \mathrm{ml}$. We also have measured the reaction constant of FXa inactivation by AT, under these conditions. A similar result was found, the reaction constant was $5.66 \times 10^{6}$ $\left(\mathrm{M} . \mathrm{s}^{-1}\right.$ and the dissociation constant $2.0 \mathrm{U} / \mathrm{ml}$. We notice that the affinity of thrombin for the AT-heparin complex is higher than the affinity of FXa for this complex.

With these data we can calculate the amount of heparin, expressed in molar units, bound to AT under the condition of Fig. 5; i.e. with a large excess of AT. Fig. 5 shows that $0.033 \mathrm{U} / \mathrm{ml}$ causes an increase of the decay constant of $180,000(\mathrm{M} . \mathrm{s})^{-1}$, which corresponds to $16 \mathrm{nM} \mathrm{AT-heparin} \mathrm{complex.} \mathrm{Thus}$ the ratio free AT, AT-heparin complex is 984/16. The $\mathrm{Kd}=\mathrm{AT}_{\text {iree }} /$ AT-heparin $\cdot$ Heparin $_{\text {free }}=0.19 \mathrm{U} / \mathrm{ml}$. The bound heparin is about $30 \mathrm{mU} / \mathrm{ml}$ 
and thus $1 \mathrm{U} / \mathrm{ml}$ heparin corresponds to $533 \mathrm{nM}$ heparin. For the anti-FXa case the same type of calculation can be made: we find $1 \mathrm{U} / \mathrm{ml}$ corresponds to $292 \mathrm{nM}$ heparin.

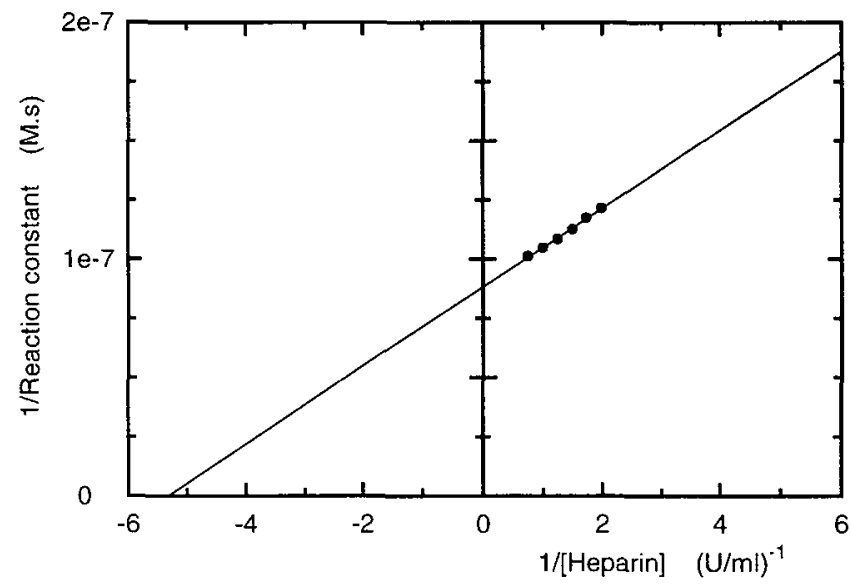

Fig. 6 The decay constant of thrombin inactivation by $A T$ at saturating amounts of the heparin (double reciprocal plot). The reaction mixtures contained $1 \mu \mathrm{M}$ AT, $0.5 \mathrm{mM} \mathrm{S} 2234$, heparin as indicated and $75 \mathrm{nM}$ thrombin. The reaction was done at $37^{\circ} \mathrm{C}$. The decay constants were calculated from the end-level of pNA and the inverse of the decay constants were plotted against the inverse of the heparin concentrations. The points were on a straight line. The intercept at the ordinate represents the inverse of the decay constant at infinite heparin concentration. The decay constant is $1.13 \times 10^{7}(\mathrm{M} . \mathrm{s})^{-1}$. The intercept on the abscissa is the inverse of the dissociation constant. The $\mathrm{Kd}$ is $0.19 \mathrm{U} / \mathrm{ml}$.

\section{Discussion}

We have developed a test system, which allows accurate measurement of the reaction constant of thrombin and FXa inactivation by AT from and end-level OD measurement. The reaction mixture contains purified AT, a chromogenic substrate and a heparin sample and the reaction is started by addition of thrombin or FXa. In the mixture two reactions take place simultaneously: (i) the enzyme hydrolyses the chromogenic substrate and (ii) the AT inactivates the thrombin or FXa. Theory predicts the course of pNA production and we have shown that indeed the product formation measured follows the predictions from the theoretical model within the limits of experimental accuracy. The end level is proportional with the $\mathrm{k}_{\mathrm{cat}} / \mathrm{K}_{\mathrm{m}}$, with the substrate concentration (Fig. 4), with the natural logarithm 
of AT/(AT-E) (Fig. 3) and with the inverse of the reaction constant (cf. results shown in Fig. 5).

In theory any substrate can be used in this assay, but for practical reasons we must use chromogenic substrates with a low affinity for the enzyme (i.e. the $K_{m}$ is in the $m M$ range), because only in those cases the end-level is reached within acceptable time (see Figs. 1 and 2). The order of the $\mathrm{k}_{\mathrm{cat}}$ of the substrates must be in the order of 1 per second, because the amount of hydrolysed substrate must be less then $10 \%$, in order to provide the condition that the substrate is not depleted during the whole time course. To produce sufficient product (pNA) with these slow reacting substrates, we need enzyme concentrations in the range of 20 to $600 \mathrm{nM}$. With faster reacting chromogenic substrates as S2234 and Pefachrome-Xa (see figs. land 3 respectively) we have to use much lower enzyme concentrations. By using such low concentration, we introduce the risk of enzyme denaturation, which reduces the reproducibility of the test.

However, highly reactive chromogenic substrates for thrombin and FXa are required to measure the reaction constant of thrombin or FXa inactivation by AT in the presence of saturating amounts of heparin (i.e. in the range of $1 \mathrm{U} / \mathrm{ml}$ ). Because under those conditions thrombin or FXa is inactivated very rapidly by AT, one needs a reactive chromogenic substrate in order to measure any hydrolysis in the short time that the enzyme exists. In the presence of saturating amounts of heparin (the same molar concentration as AT), thrombin is inactivated about 500 times faster than in the absence of heparin. A comparable difference is seen with FXa.

A remarkable finding is that the affinity of heparin for AT is dependent on the presence of the enzyme to be inactivated. When measured by detecting thrombin inactivation the affinity of heparin for AT is higher than when it is detected by FXa inactivation. This suggests that the mechanism by which heparin accelerates thrombin inactivation by AT is different from the mechanism by which heparin accelerates FXa inactivation by AT.

We showed that the assay is sensitive for heparin in the range of 0-0.05 $\mathrm{U} / \mathrm{ml}$ and that concentrations as low as $0.002 \mathrm{U} / \mathrm{ml}$ can be measured accurately (Fig. 5). For that reason we have to dilute plasma samples containing $0.2-1.0 \mathrm{U} / \mathrm{ml}$ heparin at least 100 times in order to be in the optimal range for heparin detection.

For practical applications it is very important that this assay does not require time dependent sampling steps and for that reason we can determine large numbers of samples in micro-titre plates. 


\section{References}

1. Casu, B. Structure and biological activity of heparin. Adv Carbohydr Chem Biochem 43, 51-134 (1985).

2. Larsen, M.L., Abildgaard, U., Teien, A.N. \& Gjesdal, K. Assay of plasma heparin using thrombin and the chromogenic substrate H- D-Phe-Pip-ArgpNA (S-2238). Thromb Res 13, 285-8 (1978).

3. Teien, A.N., Lie, M. \& Abildgaard, U. Assay of heparin in plasma using a chromogenic substrate for activated factor X. Thromb Res 8, 413-6 (1976).

4. Teien, A.N., Abildgaard, U., Hook, M. \& Lindahl, U. Anticoagulant activity of heparin: assay of bovine, human and porcine preparations by amidolytic and clotting methods. Thromb Res 11, 107-17 (1977).

5. Teien, A.N. \& Lie, M. Evaluation of an amidolytic heparin assay method: increased sensitivity by adding purified antithrombin III. Thromb Res 10, 399-410 (1977).

6. Handeland, G. Simplified chromogenic substrate assay for low molecular weight heparin. Thromb Res 42, 105-8 (1986).

7. Walenga, J.M., Bara, L., Samama, M.M. \& Fareed, J. Amidolytic antifactor Xa assays in the laboratory evaluation of heparin and low molecular weight fractions. Semin Thromb Hemost 11, 100-7 (1985).

8. Chen, A.L., Hershgold, E.J. \& Wilson, D.E. One-stage assay of heparin. $J$ Lab Clin Med 85, 843-54 (1975).

9. Bara, L., Combe-Tamzali, S., Conard, J., Horellou, M.H. \& Samama, M. Laboratory monitoring of a low molecular weight heparin (enoxaparin) with a new clotting test (Heptest). Haemostasis 17, 127-33 (1987).

10. Delahousse, B., Gruel, Y., Moalic, P., Toulemonde, F. \& Leroy, J. Comparative efficacy of a new clot-based anti-Xa/IIa assay and an amidolytic anti-Xa method during a very low molecular weight heparin fragment (CY 222) treatment. Thromb Res 46, 405-7 (1987).

11. Harenberg, J., Giese, C., Knodler, A. \& Zimmermann, R. Comparative study on a new one-stage clotting assay for heparin and its low molecular weight derivatives. Haemostasis 19, 13-20 (1989).

12. Abildgaard, U. et al. Monitoring therapy with LMW heparin: a comparison of three chromogenic substrate assays and the Heptest clotting assay. Haemostasis 20, 193-203 (1990).

13. Craig, P.A., Olson, S.T. \& Shore, J.D. Transient kinetics of heparincatalyzed protease inactivation by antithrombin III. Characterization of assembly, product formation, and heparin dissociation steps in the factor Xa reaction. J Biol Chem 264, 5452-61 (1989).

14. Nesheim, M.E. A simple rate law that describes the kinetics of the heparincatalyzed reaction between antithrombin III and thrombin. $J$ Biol Chem 258, 14708-17 (1983). 


\section{CHAPTER V}

The mechanism of interaction of the antithrombin-heparin complex with thrombin and activated factor $X$. 



\section{Introduction}

Heparins are glycosaminoglycans of variable length, composed of alternating $\mathrm{N}$-sulfated-D-glucosamine and L-iduronic acid of varying degrees of sulfation. The major disaccharide sequence is $\alpha-1,4$ linked $\mathrm{L}$ iduronic acid 2 sulfate - D-glucosamine N,6-disulfate '. Occasionally under- or oversulfation occurs, resulting in irregular sequences. One such irregular sequence is the pentasaccharide; called the A-domain that allows tight binding of antithrombin (A). The structure of this pentasaccharide was recognized and synthesized by the Choay group ? The binding to the Adomain causes an allosteric transition in the protein which increases its reaction velocity with blood clotting factor $\mathrm{Xa}$ about one thousand times ${ }^{3}$. It hardly changes its reactivity towards thrombin however, a phenomenon that may be explained by the fact that thrombin and antithrombin, in the absence of heparin only interact via the active- and vulnerable sites and that no accessory binding sites, influenced by the allosteric change, are involved 4.

For heparin to become an efficient catalyst of thrombin inactivation, it needs a minimal length of 12 sugar units in addition to the pentasaccharide. Recently Petitou synthesized a heparin by binding 6 regular disaccharide units (the T-domain) to the non-reducing end of the A-domain ${ }^{5}$. The combined T-A domain was shown to be the minimal structural requirement for anti-thrombin activity. The need for a T-domain is explained by the fact that it interacts with exosite 2 of thrombin and thus allows for the formation of an antithrombin-heparin-thrombin complex via accessory binding sites of both antithrombin (through the A-domain) and thrombin (through the Tdomain). The hepta-decasaccharide formed by the combined $A$ - and $T$ domains we will call the Choay- or C-domain in honor of the late Jean Choay who inspired the structural and synthetic work on heparins in the early 1980ies ${ }^{2}$.

Heparins prepared from natural sources (unfractionated heparin, UFH) are fragments of natural proteo-glycosaminoglycans that occur in many animal tissues and are usually prepared from pig intestine or bovine lung. Their lengths vary from a few to over a hundred saccharide units and they may or may not contain the A-domain. Further fragmentation by enzymatic breakdown, $\beta$-elimination or nitrous acid treatment yields the so-called low molecular weight heparins (LMWHs). They have around one third of the length of UFH and show improved pharmacological properties. A large variety of these preparations exists and is registered for medical use. The standard pharmacological- and haematological activity tests show 
differences between these preparations. Quantitative structure - function relationships in heparins cannot be established by these tests for two reasons. In the first place the preparations are very heterogeneous as to molecular size, covering a range of 5,000 $\mathrm{Mr}$ or more between the smaller and the larger molecules. Moreover, the sub-population with anticoagulant activity, i.e. the $10-50 \%$ containing the A-domain, does not show the same molecular distribution as the bulk material. In the second place the standard pharmacological tests do not determine absolute catalytic activities but measure activity relative to a standard that itself is a very heterogeneous heparin preparation. Such a procedure is valid only if like is compared to like and therefore essentially unsuitable for the detection of fundamental differences that may occur in heparins of different Mr. It has indeed been shown that serious systematic errors are introduced by this procedure ${ }^{6-8}$.

In an attempt to study the structure function relation in a more systematic way we developed tests that determine the specific activity of a heparin in terms of inactivations per minute per molecule of A-domain. Then we prepared a series of heparins of precisely defined $\mathrm{Mr}$, both from UFH and from LMWH preparations. Of each of these fractions we determined the specific catalytic activity towards antithrombin-mediated inactivation of thrombin and factor $\mathrm{Xa}$. In this way we established the relation between specific activity and the length of the heparin molecule.

\section{Method}

The catalytic activities (anti-thrombin and anti-FXa) of heparin fractions were determined in the presence of isolated antithrombin by the end-point measurement described in detail in Chapters III and IV.

In short, thrombin and factor $\mathrm{Xa}$ are added to a solution of antithrombin $(1 \mu \mathrm{M})$ and a chromogenic substrate that has a low affinity for the enzyme added. The velocity of conversion of the substrate is proportional to the amount of active enzyme present. The concentration of the product (pNA) reaches the end level when all enzyme is inactivated. We showed that the end level is inversely proportional to the pseudo-first order rate constant of enzyme decay $\left(k_{\mathrm{dec}}\right)$, and $\mathrm{k}_{\mathrm{dec}}$ expressed in $\mathrm{s}^{-1}$, can be determined if the concentrations of the reactants and the kinetic constants of the substrate are known. It is a pseudo-constant because it is still dependent upon the concentrations of both heparin and antithrombin. Concentrations of heparin fractions of precise molecular weight were obtained by gel filtration. The concentration of heparin solutions was determined by fluorescence titration of antithrombin. By determining $\mathrm{k}_{\mathrm{dec}}$ at varying concentrations of heparin $(\mathrm{H})$ the relation between $\mathrm{k}_{\mathrm{dec}}$ and $\mathrm{H}$ was determined for all heparin fractions. 


\section{Results}

At a fixed concentration $(1 \mu \mathrm{M})$ of antithrombin (A), the double reciprocal plot of $\mathrm{k}_{\mathrm{dec}}$ against the concentration of heparin is linear (fig. 1). This holds for all heparin fractions that we tested and for thrombin as well as for factor Xa. From these graphs two constants can be derived: The intercept with the ordinate gives the inverse decay constant $\left(k_{\mathrm{dec}}\right)$ of the enzyme at saturation of antithrombin with heparin, i.e. at $1 \mu \mathrm{M}$ of the A-H complex. Its dimension is (M.s. $)^{-1}$.

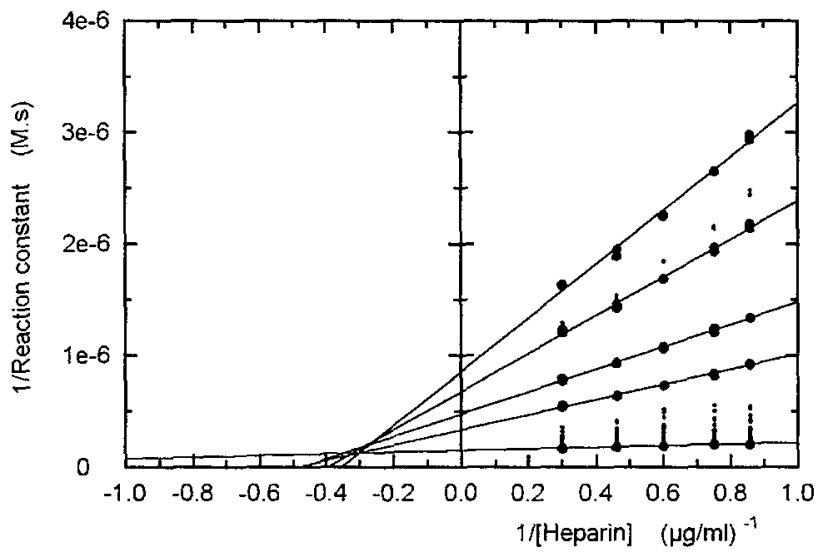

Fig. I Double reciprocal plot of $k_{\text {dec }}$ of thrombin and concentration of heparin. Reactants: bovine $\mathrm{A}(1 \mu \mathrm{M})+\mathrm{S} 2234(0.5 \mathrm{mM})$, fractionated heparin (varying conc.) and bovine thrombin $(10 \mathrm{nM})$. The different sets of points indicate results obtained by different $\mathrm{Mr}$ fractions of heparin.

The intercept with the abscissa gives the inverse of the heparin concentration $(\mathrm{Kd})$ at which the antithrombin-enzyme complex is half saturated with heparin.

The concentration of heparins can be expressed in two ways. From the fluorescence titrations we obtain the molar concentration of A-domains. This A-concentration is relevant for those reactions in which antithrombin is involved. The concentration of a heparin can also be expressed as the molar concentration of monosaccharide units. This is the S-concentration that is relevant for the interactions in which the A- or C-domain is not involved, such as the initial binding of the enzyme by the antithrombin-heparin complex (see later). The S-concentration is calculated by multiplying the Aconcentration by the number of monosaccharide units per antithrombin- 
binding molecule. The latter is calculated from the mean molecular weight divided by an assumed mean $\mathrm{Mr}$ of a monosaccharide unit of 320 .

In fig. 2 it is seen that the binding constants $(\mathrm{Kd})$ of all heparins, whether derived from the decay of $\mathrm{Xa}$ or from thrombin decay, do no longer show a systematic variation with $\mathrm{Mr}$ when expressed in terms of the Sconcentration. For factor Xa decay we calculate a $\mathrm{Kd}$ of $20.2 \pm 1.5 \mu \mathrm{M}$; for thrombin the $\mathrm{Kd}$ is $1.86 \pm 0.13 \mu \mathrm{M}$. This shows that the antithrombinheparin- binds thrombin roughly ten times tighter than factor Xa.
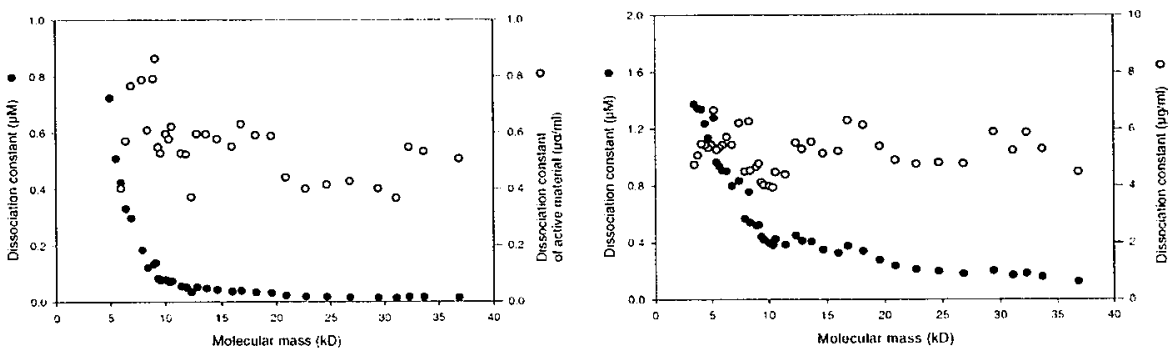

Fig. 2 The Kd of thrombin (left) and factor Xa (right) as a function of heparin Mr. Open circles; data expressed per weight. Closed circles; data expressed per A-domain.

The variation of the decay constant for thrombin inactivation with $\mathrm{Mr}$ is shown in fig.3. It represents thrombin inactivations per second per mole of A-H complex. Not every A-H complex is necessarily capable to inactivate thrombin because not every complex does contain the $\mathrm{C}$-domain. We therefore corrected for the C-domain content (see discussion). It is seen that after this correction the variation of $\mathrm{k}_{\mathrm{dec}}$ with $\mathrm{Mr}$ is much reduced and cannot be distinguished from being constant within the limits of experimental error (see discussion). Thrombin binding is near complete under our experimental conditions so the data were not corrected for the amount of thrombin bound (see discussion). 


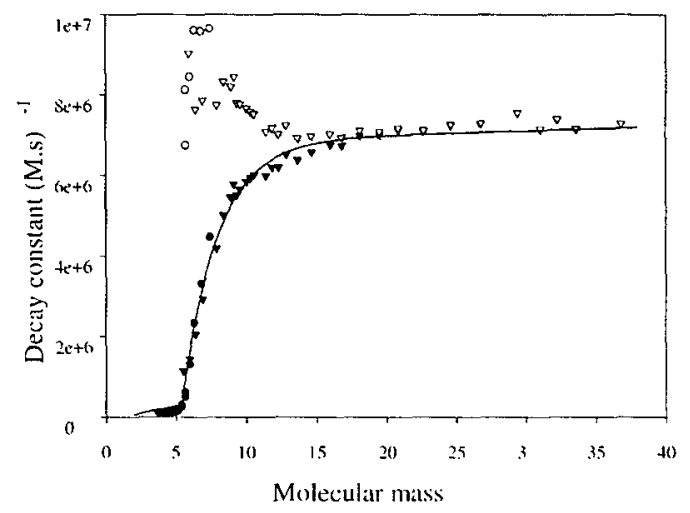

Fig. 3 The decay constant ( $k_{d e d}$ ) for thrombin as a function of heparin Mr.

Filled symbols: experimental $\mathrm{k}_{\mathrm{dec}}$, Open symbols: Corrected for the content of Cdomain.Triangle; UFH-derived fractions, circle; LMWH-derived fractions.

In fig. 4 the variation of the decay constant for factor $\mathrm{Xa}$ inactivation with $\mathrm{Mr}$ is shown. In the upper panel it is seen that $\mathrm{k}_{\text {dec }}$ increases linearly with $\mathrm{Mr}$ up to about 10,000 , then reaches a top and decreases.
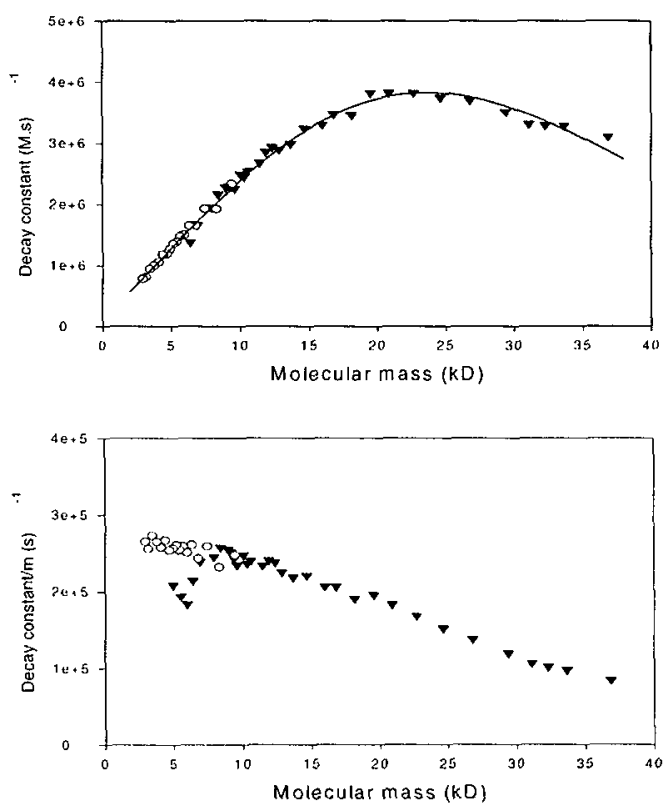

Fig. 4 The decay constant ( $k_{\text {ded }}$ ) for factor Xa as a function of heparin Mr. Upper curve: Experimental data. Lower curve: Corrected for bound factor Xa. Triangle; UFH-derived fractions, circle; LMWH-derived fractions. 
Taking into account that binding of factor $\mathrm{Xa}$ to the $\mathrm{A}-\mathrm{H}$ complex increases proportional with the number of sugar units (fig.2), we also expressed $\mathrm{k}_{\text {dec }}$ in terms of the $\mathrm{S}$-concentration (lower panel). Expressed in that manner, $\mathrm{k}_{\mathrm{dec}}$ appears roughly constant at $\mathrm{Mr}<10,000$ and at higher $\mathrm{Mr}$ decreases slowly.

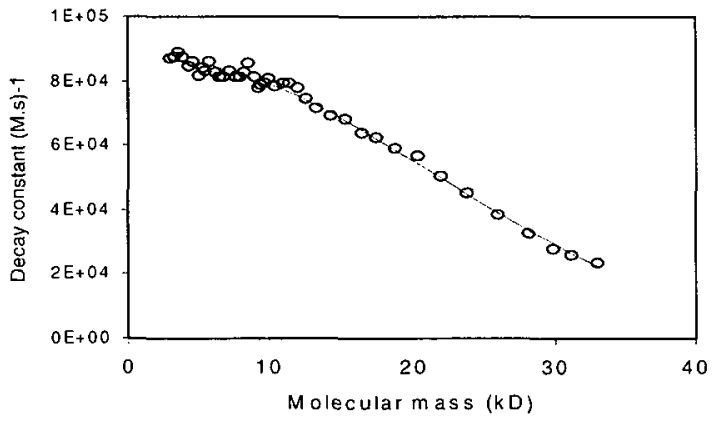

Fig. 5 The decay constant $\left(k_{\text {ded }}\right)$ for factor Xa fitted to a normal distribution curve. (See text)

In fig. 5 we present the same experimental data as in the lower panel of fig. 4 but smoothed via a moving average $(n=3)$ of both $\mathrm{Mr}$ and $\mathrm{k}_{\mathrm{dec}}$. It is shown that the points fit to the right half of a Gaussian distribution curve, with its top at $\mathrm{Mr}=1,900$ and a "standard deviation " of $\mathrm{Mr} \sim 19,000$, i.e. 60 sugar units.

\section{Discussion}

Interpretation of the constants found.

Our experimental procedure measures the decay constant $\left(\mathrm{k}_{\mathrm{dcc}}\right)$ of the semi-logarithmic disappearance of $10 \mathrm{nM}$ of enzyme $(E=$ thrombin or factor $\mathrm{Xa}$ ) in the presence of $1 \mu \mathrm{M}$ of antithrombin (A) and a varying concentration of different heparins of well defined $\mathrm{Mr}$, in the range of 5,000 to $40,000 . \mathrm{k}_{\mathrm{dec}}$ is dependent upon the type of enzyme that is being inactivated, upon the concentration of antithrombin and upon the molecular weight and concentration of heparin. From the double reciprocal plot of $\mathrm{k}_{\mathrm{dcc}}$ against $[\mathrm{H}]$, we calculated $\mathrm{Kd}$, i.e. the heparin concentration at which $\mathrm{k}_{\mathrm{dec}}$ attains half its maximum value, as well as $\mathrm{k}_{\mathrm{dec}}$, which is the decay constant of the enzyme in the presence of $1 \mu \mathrm{M}$ of the saturated A-H complex. From the work of Olson ${ }^{3}$, Bjork, Petitou ${ }^{5}$ and others (see further in Chapter I), much is known about the interaction between heparin and antithrombin. Because our data probe the situation at a constant concentration of the A-H complex, the formation of this complex is no longer involved in our data 
and our results are to be interpreted in terms of the interaction of the enzyme with the A-H complex.

The A-H complex consists of the A-domain, i.e. the pentasaccharide domain to which antithrombin adsorbs, on both ends of which a polysaccharide chain of variable length may be attached. Each monosaccharide contributes $\sim 320$ to $\mathrm{Mr}$, so that the total number of monosaccharides equals $\mathrm{Mr} / 320$. We assume that in (fractions of) natural heparins the A-domain is located randomly within the total chain. Of particular importance is the Choay domain (C-domain). This is an A-domain with twelve sugar units (the Tdomain) attached to its non-reducing end. From the synthetic work of Petitou et al. it is known that this is the minimal heparin that shows antithrombin activity ${ }^{5}$. Thrombin as such can only interact with antithrombin through its active site ${ }^{4}$. For adequate interaction of thrombin with protein substrates interaction through exosites 1 or 2 is required. From the simulation work of Grootenhuis et al. , it can be understood that the Adomain within the $\mathrm{C}$-domain serves to bind antithrombin and that the remaining part serves to interact with exosite 2 of thrombin and in this way provides the required juxtaposition of thrombin and antithrombin.

The concentration of a heparin preparation can be expressed in three ways: as the concentration of sugar units, as the concentration of A-domains and as the concentration of $\mathrm{C}$-domains. If a reaction constant is invariant with respect to one of these types of concentration, this indicates the nature of the interaction that determines the rate-limiting step in the reaction.

For instance, we observed that $\mathrm{Kd}$ is $1.86 \pm 0.13 \mu \mathrm{M}$ for thrombin and $20.2 \pm 1.5 \mu \mathrm{M}$ for factor $\mathrm{Xa}$ when expressed in terms of the molar concentration of sugar units. Kd thus is dependent upon the type of enzyme and independent of the chain length of the heparin that is used. This can only mean that this $\mathrm{Kd}$ concerns the interaction of the enzyme and the heparin-monosaccharide units, independent of the chain-length into which they are incorporated.

The interaction between thrombin and heparins has been studied by Fenton et al. ${ }^{10}$ via the inhibition, in the absence of antithrombin, of the clotting of fibrinogen. In a series $(n=22)$ of heparins that differed in average $\operatorname{Mr}(2,7-20)$ but that were not fractionated to narrow molecular weight distribution. From their observations one can calculate a $\mathrm{Ki}$ for thrombinfibrinogen interaction of $1.1 \pm 0.4 \mu \mathrm{M}$ over a range of between 2.700 and $20.000 \mathrm{Mr}$, which is close to our value of the $\mathrm{Kd}$ of thrombin binding to heparin $(1.86 \pm 0.13 \mu \mathrm{M})$.

It may appear counter-intuitive that saturating antithrombin with heparin reveals the interaction between the enzyme and heparin. One realizes however that the inactivation reaction that we measure is the 
formation of the irreversible E-A complex under the influence of heparin. The E-A form is necessarily a split product of a ternary complex of the three reactants: the enzyme, antithrombin and heparin. Two types of such complexes can be imagined: those in which the enzyme and antithrombin are bound to different parts of the long, chainlike heparin molecule and those in which the enzyme and antithrombin are in juxtaposition. Only the latter is a productive complex, in the sense that can render the product A-E. For short we will call the unproductive complex E-H-A and the productive complex H-E-A*, the asterix indicating the bonds between antithrombin and heparin. The situation is not unlike the formation of a two-substrate Michaelis complex in classical enzymology, heparin playing the role of the enzyme and antithrombin as well as thrombin (or factor $\mathrm{Xa}$ ) that of substrates. The formation of the complex follows the laws of saturation kinetics, hence the rectilinearity of the double-reciprocal plot. Under our circumstances, the reactant that plays the catalytic role (heparin) is not the one present in excess. This does not invalidate the analogy, because the roles of enzyme and substrate in the derivations of the Michaelis-Menten formula are symmetrical until the moment that one of the two is assumed to be in excess over the other ${ }^{\prime \prime}$.

Like $\mathrm{K}_{\mathrm{m}}$ in classical enzymology, $\mathrm{Kd}$ is the concentration of heparin in which half of the tripartite complex is formed, independent whether it is in the productive or in the alternative form (see ref 11 , pp 104,105), i.e. both E-H-A and $\mathrm{H}-\mathrm{E}-\mathrm{A}^{*}$ count. Although we probe the situation through the concentration of $\mathrm{A}-\mathrm{H}-\mathrm{E}^{*}$, we measure the binding of enzyme to the whole of the heparin molecule.

The reaction velocity is determined by the concentration of $\mathrm{H}-\mathrm{E}-\mathrm{A}^{*}$ and the intrinsic first order reaction of the breakdown of this complex

$\mathrm{H}-\mathrm{E}-\mathrm{A}^{*} \longrightarrow \mathrm{E}-\mathrm{A}+\mathrm{H}, \quad$ hence $\mathrm{k}_{\mathrm{dec}}=\mathrm{k}_{\mathrm{imIr}} \cdot\left[\mathrm{H}-\mathrm{E}-\mathrm{A}^{*}\right]$

There are two different types of H-E-A* complex: 1) that between the heparin C-domain, thrombin and antithrombin and 2) that between the heparin A-domain, factor $\mathrm{Xa}$ and antithrombin. One can easily conceive that $\mathrm{k}_{\text {intr }}$ is different in these two cases, but it is hard to imagine that the part of the heparin that does not contact the proteins will influence this constant. Variations in $\mathrm{k}_{\mathrm{dec}}$ are therefore primarily to be interpreted in changes of the concentration of $\mathrm{H}-\mathrm{E}-\mathrm{A}^{*}$. Under our experimental conditions, i.e. at $1 \mu \mathrm{M}$ of $\mathrm{A}-\mathrm{H}$, this means that variations of $\mathrm{k}_{\mathrm{dec}}$ with the chain-length of the heparin are to be interpreted in terms of the amount of thrombin or factor $\mathrm{Xa}$ bound and the partition between the E-H-A form and the H-E-A* form of bound enzyme. 


\section{The Mechanism of Thrombin Inactivation}

As demonstrated by Petitou et al. ${ }^{5}$, the C-domain (i.e. the combined Aand $\mathrm{T}$-domains) is the minimal structure to enhance the inactivation of thrombin by antithrombin. Among the large series of natural heparin fractions that we tested, we found none with a specific activity that was higher than this construct. It therefore seems that the C-domain may be not only the necessary but also the sufficient condition for optimal antithrombin activity.

To test this hypothesis we calculated the content of C-domain in our heparin fractions. If we imagine a heparin with a length of 20 sugar units, of which 5 are the A-domain, then there are only 4 positions of the A domain within the total molecule that allow a length of minimally 12 sugar units to its non reducing end. In general, at a length of $n$ sugar units, there are $n-16$ possibilities to accommodate the $\mathrm{C}$-domain. If the A-domain is positioned randomly along a heparin of $\mathrm{n}$ sugar units, then the fraction which contains the $\mathrm{C}$-domain is $\mathrm{f}=\mathrm{n}-16 / \mathrm{n}$. Because $\mathrm{n}=\mathrm{Mr} / 320$, an antithrombin-binding heparin fraction will contain a fraction $\mathrm{f}=(\mathrm{Mr}-5120) / \mathrm{MW}$ of $\mathrm{C}$-domains.

If we multiply the observed $k_{\text {dec }}$ by $1 / f$ we obtain the value of $k_{\text {dec }}$ at 1 $\mu \mathrm{M}$ of $\mathrm{A}-\mathrm{H}$ that contains the $\mathrm{C}$-domain. At low $\mathrm{Mr}$, this procedure involves multiplication of a low $\mathrm{k}_{\mathrm{dec}}$ with a large number and consequently the experimental error is large. From fig. 3 we see that within the limits of experimental error $k_{\text {dec }}$ can not be distinguished from a constant of $\sim 7.106$ (M.s) $)^{-1}$.

For thrombin, $\mathrm{Kd}$ is $1.86 \pm 0.13 \mu \mathrm{M}$ of monosaccharide units of heparin. At $1 \mu \mathrm{M}$ of $\mathrm{A}-\mathrm{H}$, the concentration at which $\mathrm{k}_{\mathrm{dec}}$ is measured, the concentration of monosaccharide units varies from 12 to $100 \mu \mathrm{M}$, depending upon $\mathrm{Mr}$ of the heparin. So over the range $\mathrm{Mr}$ tested, $86 \%$ to $99 \%$ of the thrombin present must be bound to heparin. The fact that $\mathrm{k}_{\text {dec }}$ is constant per $\mathrm{C}$-domain, independent of the heparin size, also indicates that the concentration of the productive complex must be constant (see formula a). So at any length of heparin molecule tested, there exists the same steady state concentration $\mathrm{H}-\mathrm{E}-\mathrm{A}^{*}$, i.e. the production of inactivated thrombin equals the velocity with which the thrombin in the complex is replenished by lateral diffusion along the heparin molecule.

So even in long heparins ( $>120$ sugar units, $\mathrm{Mr}>40000$ ) containing the C-domain, the observed decay constant hardly differs from much smaller ones (fig.3). So thrombin diffusion along the heparin molecule never becomes rate-limiting. The alternative explanation, i.e. that thrombin binds directly to the C-domain, can be excluded because in that case $\mathrm{Kd}$ would have to be constant in terms of the C-concentration and not of the S- 
concentration, as observed. If diffusion of the enzyme along the heparin molecule is so fast as not to become rate limiting in the saturation of the antithrombin-C-domain entity, the concentration of the productive complex therefore must approach $1 \mu \mathrm{M}$ and $\mathrm{k}_{\text {dec.intr }}$ must be in the order of $7.10^{6} \mathrm{~s}^{-1}$.

\section{The Mechanism of Factor Xa Inactivation}

In the case of factor $\mathrm{Xa}$, like in the case of thrombin, the $\mathrm{Kd}$ is constant in terms of sugar units, but it is about ten times as high as in the case of thrombin: $20.3 \pm 1.5 \mu \mathrm{M}$ of monosaccharide units. Under our conditions (1 $\mu \mathrm{M}$ of antithrombin saturated with heparin of a chain-length from 12 to 100 sugar units), between 37 and $83 \%$ of the factor $\mathrm{Xa}$ must be bound to heparin. So, contrary to thrombin, there is a considerable fraction of factor $\mathrm{Xa}$ in free solution.

From fig.4 it is clear that at $\mathrm{Mr}<10,000, \mathrm{k}_{\mathrm{dec}}$, expressed per mole of Abinding heparin increases almost linearly with $\mathrm{Mr}$. When expressed per mole of monosaccharide unit, however, it appears to be constant. Given the fact that a diffusional current from the solution to a thread-like object is roughly proportional to its length ${ }^{12}$, this in all probability reflects a situation in which adsorption of enzyme onto the heparin part of the A-H complex determines the reaction rate. Once adsorbed, the enzyme starts a unidimensional, random walk along the heparin. During this process it may collide with the antithrombin that is bound to the A-domain of the heparin and "click" into the tripartite complex, to be inactivated. It may however also dissociate before it can react with the antithrombin.

At equilibrium, the mean time of stay of an enzyme molecule on a heparin strand is determined by the dissociation constant of the complex. Within this finite time, the enzyme molecule by unilateral diffusion covers a certain length of the heparin molecule. The enzyme lands at a random site on the molecule and also the A-domain, i.e. the antithrombin is located at a random site. The distance covered during the random walk is independent of the length of the heparin molecule, because $\mathrm{Kd}$ is independent of the length. The longer the heparin molecule, the broader the range of possible distances between the landing site and the A-domain and the lower the probability that the reaction between antithrombin and the enzyme shall take place.

If the heparin consists of the A-domain only, $(\mathrm{Mr}$ 1700) the probability of collision between antithrombin and the enzyme is $100 \%$. At greater length of the heparin the probability decreases, to reach zero at infinite heparin length, according to the normal distribution curve. In fig.5 it is seen that the experimental points of $\mathrm{k}_{\mathrm{dec}}$, expressed per concentration of sugar units, perfectly fits a normal distribution with $\mu=1.9$ and $\sigma=19(\mathrm{kD})$. 
Half the optimal value is found at $\mathrm{Mr}=24,000$, i.e. at a chain-length of about 75 sugar units.

This model also fits to the observations with thrombin. Because the Kd of thrombin is roughly 0.09 of that of factor $\mathrm{Xa}$, its mean time of stay on the heparin is roughly 11 times as long. This apparently suffices to ensure meeting with antithrombin.

\section{Comparison between our Model and Current Theory}

The present day view of heparin action on thrombin is very well summarized by Petitou et al. "....binding of heparin to antithrombin causes a conformational change in the inhibitory loop of the protein (allosteric activation) resulting in recognition and inhibition of factor $\mathrm{Xa}$. Thrombin is inhibited through a template mechanism (entropic activation): it is electrostically attracted by heparin and collides with heparin bound antithrombin. Thus thrombin inhibition requires a longer heparin chain...."

This does indeed explain the need for a T-domain in thrombin inactivation. Implicitly it suggests that the allosteric change in antithrombin does not suffice to increase thrombin inactivation. Indeed the A-domain not more than doubles the $\mathrm{k}_{\mathrm{dec}}$ of thrombin, which is in accordance with this suggestion. A possible explanation may come from the observation that thrombin and antithrombin only interact via the thrombin active site, i.e. that no exosites seem to be involved ${ }^{4}$. A minimal-contact scenario for thrombin inactivation might lead to a minimal effect of allosteric changes on thrombin inactivation. Probably the allosteric effect does play a role also with thrombin, as soon as the heparin is long enough to allow the entropic mechanism.

Factor $\mathrm{Xa}$, in the accepted view, interacts directly with the antithrombin that, by heparin, is kept in a favorable allosteric form (see further introduction). From our results it becomes clear, however, that the entropic mechanism, i.e. the interaction between heparin and the enzyme that leads to an enhanced possibility of antithrombin -enzyme interaction must be common to both thrombin and factor $\mathrm{Xa}$.

The variation of $k_{\text {dec }}$ of factor $\mathrm{Xa}$ with $\mathrm{Mr}$ suggests a model in which the enzyme first binds to the heparin part of the A-H complex and then, by a random walk along the heparin molecule (one dimensional diffusion) may or may not encounter the antithrombin, that is bound to the A-domain. The fact that $\mathrm{Kd}$ is constant in terms of the concentration of sugar monomers indicates that the probability of adsorbing an enzyme molecule increases linearly with the length of the molecule, as is to be expected from theory ${ }^{12}$. When the enzyme comes into contact with the antithrombin that is adsorbed onto the A-domain it may "click" into a productive HAE" complex and be 
inactivated. Whether the enzyme encounters the antithrombin depends on the time that it remains bound on the heparin and the distance it has to cover before reaching the antithrombin-A-domain complex by diffusion. So the length of the heparin has two conflicting effects. The longer a heparin, the more readily will it adsorbs an enzyme-molecule, but the longer it will take, on the mean, before this molecule has diffused to the antithrombin-A domain complex. This mechanism is common to both thrombin and factor $\mathrm{Xa}$, there are quantitative differences however.

In the case of factor $\mathrm{Xa}$, binding is loose ( $\mathrm{Kd}$ is high) so that the conflicting properties can show. At low $\mathrm{Mr}(<10,000)$ the specific activity of a heparin, expressed per mole, increases linearly with the length of the molecule because the probability of "catching" a heparin molecule is proportional with the length of the molecule; i.e. the specific activity per concentration of sugar units remains constant. At higher $\mathrm{Mr}$ there is an increasing proportion of ineffective binding, because the enzyme detaches from the molecule before it has diffused to the antithrombin-binding site.

This means anyhow that the effect of heparin on the antithrombinfactor Xa interaction is not explained by the allosteric effect alone; "sliding" or better unidimensional diffusion, does play a role in the mechanism, contrary to the accepted view. More important: the properties of the sliding mechanism determine the variation of the specific activity with $\mathrm{Mr}$.

With thrombin, there is in the first place the necessity of a T-domain that is adjacent to the A-domain on the heparin, as found by modelling and synthetic studies 9.5 . Beyond this requirement, binding of thrombin to heparin is still dependent upon the chain length of the heparin, i.e. binding is constant per concentration of sugar units. This binding is ten times tighter than that with factor $\mathrm{Xa}$. Because of this tight binding the enzyme will not readily release from the heparin molecule before it meets with the $T$-domain and antithrombin. This makes that the sliding mechanism, although present, does not influence the apparent decay constant. The rate-limiting processes are entirely in the tripartite complex of thrombin, C-domain and antithrombin. Therefore the anti-thrombin activity of a heparin is entirely determined by the content of C-domain. This is corroborated by the observation that no natural heparin (-fraction) exceeds the specific activity of the synthetic C-domain.

\section{No differences between different sources of heparin}

The molecular weight distribution in the heparin fractions that we used was sufficiently narrow to consider them as representative for the heparin species of their mean molecular weight. Most of the fractions that we tested were obtained from unfractionated heparin and from a low molecular weight 
heparin, prepared from UFH by deamination. A limited number of fractions was tested that originated from LMWHs prepared by chemical or enzymatic breakdown. Under no circumstances we found significant differences between fractions that had been prepared from different sources as long as they had a comparable Mr. We conclude that the anticoagulant properties of a heparin fraction are defined by the presence of an A-domain and by the size of the molecule in which the A-domain resides and not by the chemical changes due to fractionation to which the heparin preparation has been subjected.

\section{Additional remarks}

In the development of the model it is implicit that enzyme decay is always first order with respect to the enzyme. This derives from the fact that the experimental $k_{d e c}$ values are obtained from the product formation during the entire life-span of the enzyme, in presence of an excess of antithrombin. That is, over a continuum of enzyme concentrations, that ranges from the initial activity added $(10 \mathrm{nM})$ to zero at complete inactivation of the enzyme. In all cases the course of product formation followed the course predicted by the formula that is derived on basis of semi-logarithmic decay (Chapter IV).

Also it is implicit in our model that the enzyme remains active towards small substrates when it is bound to heparin but not to antithrombin. In control experiments (not shown) we found that, under our experimental conditions, the binding of the enzyme to heparin did not influence its enzymatic activity on the chromogenic substrate. This is in accordance with earlier observations in the literature ${ }^{10}$.

\section{References}

1. Perlin, A.S., Mackie, D.M. \& Dietrich, C.P. Evidence for a (1 leads to 4)linked 4-O-(-L-idopyranosyluronic acid 2- sulfate)-(2-deoxy-2-sulfoaminoD-glucopyranosyl 6-sulfate) sequence in heparin. Long-range $\mathrm{H}-\mathrm{H}$ coupling in 4-deoxy-hex-4-enopyranosides. Carbohydr Res 18, 185-94 (1971).

2. Choay, J. et al. Structure-activity relationship in heparin: a synthetic pentasaccharide with high affinity for antithrombin III and eliciting high anti-factor Xa activity. Biochem Biophys Res Commun 1 16, 492-9 (1983).

3. Olson, S.T. et al. Role of the antithrombin-binding pentasaccharide in heparin acceleration of antithrombin-proteinase reactions. Resolution of the antithrombin conformational change contribution to heparin rate enhancement. J Biol Chem 267, 12528-38 (1992). 
4. Tsiang, M., Jain, A.K. \& Gibbs, C.S. Functional requirements for inhibition of thrombin by antithrombin III in the presence and absence of heparin. $\mathrm{J}$ Biol Chem 272, 12024-9 (1997).

5. Petitou, M. et al. Synthesis of thrombin-inhibiting heparin mimetics without side effects. Nature 398, 417-22 (1999).

6. Hemker, H.C. A standard for low molecular weight heparin? [editorial]. Haemostasis 19, 1-4 (1989).

7. Hemker, H.C. \& Beguin, S. Standard and method independent units for heparin anticoagulant activities. Thromb Haemost 70, 724-8 (1993).

8. Hemker, H.C. \& Beguin, S. The activity of heparin in the presence and absence of $\mathrm{Ca}^{2+}$ ions; why the anti-Xa activity of LMW heparins is about two times overestimated [letter]. Thromb Haemost 70, 717-8 (1993).

9. Grootenhuis, P.D., Westerduin, P., Meuleman, D., Petitou, M. \& van Boeckel, C.A. Rational design of synthetic heparin analogues with tailormade coagulation factor inhibitory activity [letter]. Nat Struct Biol 2, 736-9 (1995).

10. Fenton, J.W., Witting, J.I., Pouliott, C., Fareed, J. Thrombin anion-binding exocite interactions with Heparin and various Polyanions. Ann. New York Acad. Scie. 556, 158-165 (1989).

11. Fersht, A. Enzyme structure and mechanism. Freeman \& Co, New York (1984).

12. Berg, H. Random walks in biology. Princeton University Press (1983). 


\section{CHAPTER VI}

On the relation between the molecular weight of heparins and their specific anticoagulant activity, an in vitro study in plasma. 



\section{Introduction}

Clinical practice of heparin administration is based on rule of thumb procedures rooted in the definition of a unit of heparin in the 1920ies, now more precisely defined and calibrated via the international standard heparin (ISH). The calibration is primarily based on the influence of heparin on different types of clotting time that are sensitive to this drug, such as the activated partial thromboplastin time (aPTT) but not the thromboplastin time. This entirely empirical approach has been remarkably successful. A large number of different heparins either unfractionated (UFH) or low molecular weight type (LMWH) is now available to the clinician. Of each of them the therapeutic window has been established in clinical dose finding studies reinforced by clinical trials. These different heparins share the enhancement of antithrombin (AT) activity as a common mode of action but they differ in molecular weight (MW) distribution and, concomitantly, in biological properties such as the ratio of anti-thrombin (alla) to anti-factor $X$ a action, inhibitory action on the coagulation process and bioavailability. The empirical approach, however, does not allow to decide what is the relevant common denominator in this family and consequently they are all to be regarded as different drugs.

Nevertheless it is difficult to imagine that further progress in the heparin field will be fast if this empirical approach is to be continued. The chemistry and biochemistry of heparins are far advanced. Purely synthetic and semisynthetic heparins are being developed. If each of the products is to be tested in clinical studies, it is necessary for the clinician to have an accurate estimate of the relation between heparin concentration and MW on the one hand and the relevant clotting parameters in the plasma of the patient on the other. As a first step it is necessary to establish the relation between these variables in vitro, i.e. under conditions where heparin $\mathrm{MW}$ and concentration are precisely known.

There are extensive semi-quantitative data on the relation between MW distribution and several biological properties. The specific pentasaccharide sequence that is responsible for binding to antithrombin has a $\mathrm{Mr}$ of $\sim 1700$. $^{2}$ It is well established that heparin molecules of below $5400 \mathrm{D}$ have only anti factor $\mathrm{Xa}$ (aXa) activity and no anti-thrombin (alla) activity. ${ }^{3.4}$ It was observed (previous chapter) that the antithrombotic activity of a heparin depends upon its chemical composition and chain length. This makes it possible to decide on basis of what (physico-)chemical properties heparin 
preparations should be compared and if these properties do indeed differ sufficiently to maintain that all heparins are different drugs 5.6 .

Admittedly, the antithrombotic activity of any anticoagulant is related to its ability to decrease thrombin formation when plasma clots. This phenomenon is observed with oral anticoagulation, with heparins, with direct inhibitors of thrombin, factor Xa and factor VIIa and we know of no exception to this rule.

As a quantitative measure for anticoagulant activity we previously introduced the endogenous thrombin potential (ETP), which is defined as the area under the thrombogram, i.e. the course of thrombin concentration in time in clotting blood or plasma. The ETP quantifies the amount of enzymatic activity that thrombin develops during its transient existence in clotting plasma. We conjecture that it is the essential correlate to the anticoagulant effect.

It is the purpose of this chapter to establish, under conditions prevailing in plasma, the precise relation between the size of the heparin molecule and its catalytic activities on the decay of factor Xa and thrombin on the one hand and its influence on thrombin formation on the other.

Hitherto, these relations have been difficult to establish exactly, because neither the molar concentration nor the exact catalytic activity could be determined.

Heparin is a heterogeneous mixture of molecules that contain the antithrombin-binding pentasaccharide (high affinity material, HAM) and those that do not (low affinity material, LAM). The exact concentration of the HAM can not be established from the weight amount of heparin. Also the MW distribution of the HAM and LAM species within a heparin may differ considerably ${ }^{7}$ and only the mean $\mathrm{MW}$ of the bulk material is determined by physicochemical methods. Heparin molar concentrations therefore as a rule are difficult to obtain. Here we use heparin fractions of narrow MW distribution $( \pm 0.5 \mathrm{kD})$ and we determined the molar concentration of HAM by fluorescence titration.

Usually heparin activity is expressed relative to an arbitrary standard. It thereby remains undefined on the molecular level and dependent upon the assumption that, under the conditions of measurement, heparins of widely different molecular weight react similarly. We express the activity of heparin as the number of thrombin or F.Xa molecules inactivated per second per molecule (antithrombin or AT-heparin), i.e. by the turnover number as it is used in enzyme kinetics, independent of comparison with a standard. 
We found (Chapter $\mathrm{V}$ ) a strong dependence of the specific activity on molecular weight, which is different for thrombin and for factor $\mathrm{Xa}$ inactivation. The specific activity was found to be independent of the source of the heparin or of the method used for its fractionation. Identical specific activities were found in fractions of equal $\mathrm{Mr}$ from unfractionated heparin (UFH) or from low molecular weight heparins of different origin; i.e. prepared by either enzymatic breakdown (Logiparin ${ }^{(B)}$ ), deaminative cleavage (Clivarine ${ }^{(B)}$, Fraxiparin ${ }^{(\otimes)}$ ) or $\beta$-elimination of heparin esters $\left(\right.$ Clexane $\left.^{(B)}\right)$. The inhibition of the clotting system, expressed as inhibition of the ETP, is dependent upon the anti-thrombin activity, i.e. molar concentration times specific anti-thrombin activity. Preparations of identical specific activity inhibit the ETP in a quantitatively identical manner, again independent of the type of the heparin.

\section{Results}

\section{Determination of HAM Content}

From the concentration of HAM obtained from the antithrombintitration, we calculated the relation between HAM content and MW. It cannot be distinguished from linear, as could be surmised from earlier observations.' The content differs with the source of the material. At comparable MW it is higher in the preparations derived from LMWHeparins than in those from UFH (fig. 1).

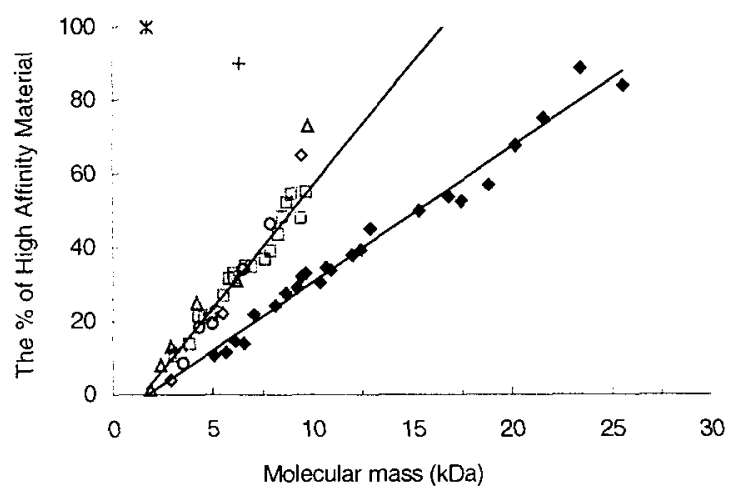

Fig. I The percentage of high affinity material of heparin fractions as a function of the molecular mass. (Open symbol: LMWHs, closed symbol: UFH). $\exists$ : Clivarine; o: Fraxiparin; $\diamond$ : Logiparin; $\Delta$ : Clexane; $\bullet$ : UFH fractions; $\leftrightarrow$ Pentasaccharide; +: Synthetic-heparin (17 sugar units). 


\section{Determination of the Specific Activity}

Heparin increases the decay constant (i.e. decreases the half-life time) of thrombin (or factor $\mathrm{Xa}$ ) in plasma. There is a linear relation between the observed increase of decay constant $\left(\mathrm{k}_{\mathrm{dec}}\right)$ and the concentration of heparin $([\mathrm{H}]){ }^{8}$. We confirmed this relation for all the fractions of each of heparin that we tested (not shown). The slopes of these $\mathrm{k}_{\mathrm{dec}} /[\mathrm{H}]$ lines indicate how much $\mathrm{k}_{\text {dec }}$ increases per mole of heparin added. From previous work we also know that there is a linear relationship between the antithrombin concentration of the plasma and $k_{d c c}$ both in absence and in presence of heparin. ${ }^{9.10}$ This was confirmed also for heparins with molecular weights ranging from 1.700 (pentasaccharide) to 20.000 (data not shown). In order to make the results comparable between plasmas, we normalized the experimental constants to an antithrombin concentration of $1 \mu \mathrm{M}$. Thus we obtained the normalized specific activity of each of the heparin fractions. The dimension of the decay constant is inverse time $\left(\mathrm{s}^{-1}\right)$, so the normalized specific activity is expressed as $s^{-1}$ per Mole of heparin, i.e. as $s^{-1} M^{-1}$. Previously we defined the standard independent unit (SIU) as that amount of heparin that increases the normalized decay constant by one inverse minute. We continue to use this unit here and consequently express the normalized specific activity in SIU/Mole.

\section{Molecular Weight Dependence of Specific anti-Thrombin Activity:}

In figure 2 the molecular weight dependence of the specific anti-thrombin activity of heparin is illustrated. It is confirmed that no significant activity is observed below a molecular mass of around $5 \mathrm{kD}$. Between 5 and $8 \mathrm{kD}$ the specific activity increases steeply to a plateau of around $450 \mathrm{SIU} / \mu \mathrm{M}$. It is seen that the specific activity is dependent upon MW only and does not seem to be influenced by fractionation. We did not find a significant influence of $\mathrm{Ca}^{2+}$-ions on the specific anti-thrombin activity for any of the fractions tested (table 1). It can be seen (fig. 2) that the synthetic heparin (17 sugar units) demonstrated the highest anti-thrombin activity compared with the other fractions. 
Table 1 The influence of $\mathrm{Ca}^{2+}$ ions on the anti-thrombin activity of heparin. The decay constant is expressed in $\mathrm{min}^{-1}$.

\begin{tabular}{ccc}
\hline $\mathrm{Mr}$ & $\left(-\mathrm{Ca}^{2+}\right)$ & $\left(+\mathrm{Ca}^{2+}\right)$ \\
\hline 5.64 & $2.7 \pm 0.1$ & $2.5 \pm 0.1$ \\
6.09 & $2.9 \pm 0.1$ & $2.7 \pm 0.1$ \\
8.13 & $4.4 \pm 0.2$ & $4.2 \pm 0.2$ \\
8.65 & $5.7 \pm 0.2$ & $5.4 \pm 0.2$ \\
\hline
\end{tabular}

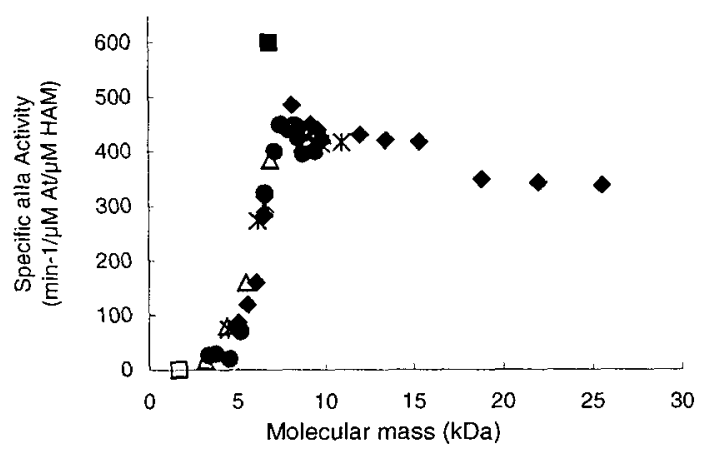

Fig. 2 The specific anti-thrombin activity of heparins prepared differently as a function of the molecular mass (in the absence of $\mathrm{Cat}^{2+}$ ). $\bullet$ : UFH-derived fractions; - Clivarine-derived fractions; $\Delta$ : Logiparin-derived fractions; Clexane-derived fractions; $\square$ : Pentasaccharide; $\mathbf{m}$ : Synthetic heparin.

\section{Molecular Weight Dependence of Specific anti-FXa Activity:}

The pattern of anti-factor Xa-activity differs significantly from that of anti-thrombin activity (fig. 3). In the presence of $\mathrm{Ca}^{2+}$-ions, there is a linear increase with molecular mass from 2-20 kD. In the absence of $\mathrm{Ca}^{2+}$-ions, in the range of $2-8 \mathrm{KD}$ the activity is roughly half of that in its presence, to reach a plateau at around $10 \mathrm{kD}$. Like the anti-thrombin activity, the factor $\mathrm{Xa}$ activity does not seem to be influenced by the method used for the fractionation of the heparin. The synthetic heparin, unlike its action on alla, showed an aXa activity similar to that of UFH and LMW fractions of the same Mr. 


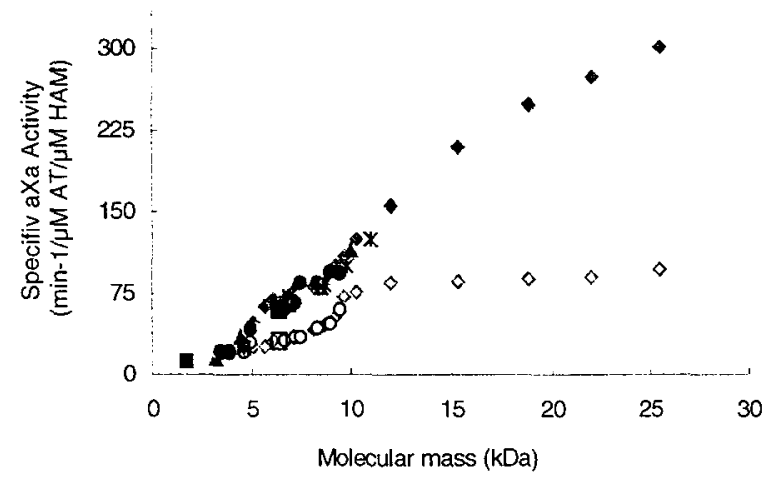

Fig. 3 The specific anti-factor Xa activity of heparins prepared differently as a function of the molecular mass. (open symbol: $-\mathrm{Ca}^{2+}$, closed: $+\mathrm{Ca}^{2+}$ ). (o, UFH-derived fractions; $(O, \bullet)$ : Clivarine-derived fractions; $\Delta$ : Logiparin-derived fractions; *: Clexane-derived fractions; ( $\square$, - $)$ Synthetic heparin; a: Pentasaccharide.

\section{Influence of Heparin on Thrombin Generation}

The net effect of heparin, like that of any other anticoagulant is a diminution of the amount of active thrombin that appears in plasma when the coagulation process is triggered. This effect is sometimes reflected in prolongation of the clotting times but can only be accurately assessed by measuring the thrombin generation curve (the "thrombogram"). The endogenous thrombin potential (ETP), i.e. the area under the curve quantifies the amount of enzymatic action that thrombin develops during the coagulation process and therefore is a good candidate for being the essential variable that is influenced by anticoagulant action.

In figure 4 it is seen that fractions of similar Mr but of different origin inhibit the ETP in a similar way. The relation between the amount of heparin added and the inhibition is hyperbolically like. In figure 5 we see the relation between heparin concentration and inhibition of the ETP for $\mathrm{UFH}$, for a LMWH, for pentasaccharide, and for a synthetic heparin. 


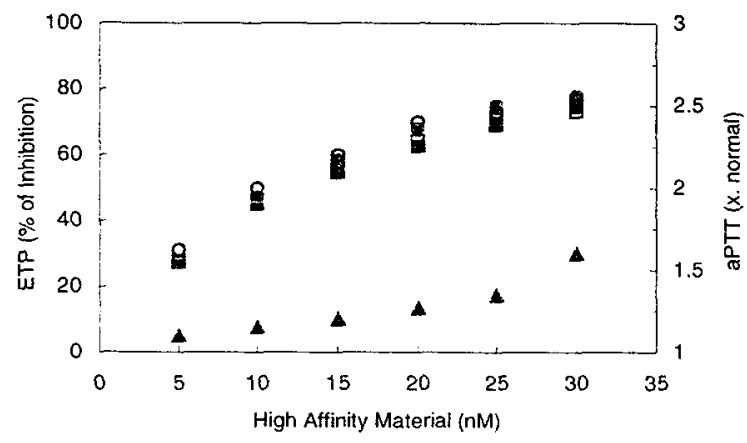

Fig. 4 The responsiveness of the ETP and of the aPTT to the active heparin concentration. (open symbol: extrinsic system, closed: intrinsic). $(\square$. Clivarine $8 \mathrm{kD}$ fraction; $(\circ, \bullet)$ UFH $8 \mathrm{kD}$ fraction; $\mathbf{\Delta}$ : aPTT (UFHfraction).

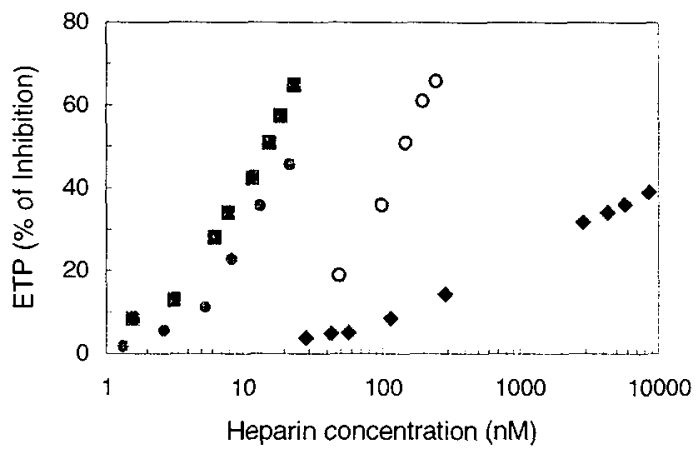

Fig. 5 Inhibition of thrombin generation versus heparin concentration. - Synthetic heparin (17 sugar units); : International Standard Heparin (15 kD); o: LMWH (Logiparin; $4.1 \mathrm{kD}) ;$ : Pentasaccharide (1.7 kD).

It is seen that, on a molar basis, the LMWHs are less active, but also that the activity of pentasaccharide is by far the lowest. The synthetic heparin exerted the highest capability of ETP inhibition, like it showed the highest anti-thrombin potency (fig.2). This suggests that the inhibitory power of a heparin is closely linked to its specific anti-thrombin activity. To investigate this point further, we determined, at two fixed HAM concentrations, the relation between ETP inhibition and MW (fig. 6). The pattern is very similar to that of the specific anti-thrombin activity of the heparin fractions (fig. 2) but dissimilar to that of the anti-factor Xa action (fig. 3). 
Finally we investigated the relation between $\mathrm{MW}$ and the prolongation of the aPTT. In the first place it is obvious that a concentration of LMWH that causes significant inhibition of thrombin generation, hardly influences the aPTT. In fact significant prolongation of the aPTT is seen only when the ETP is inhibited over 70\% (fig. 7). Essentially similar results were obtained with different types of aPTT tested, although the prolongation obtained at a fixed heparin concentration appeared to be strongly dependent upon the method used (results not shown).

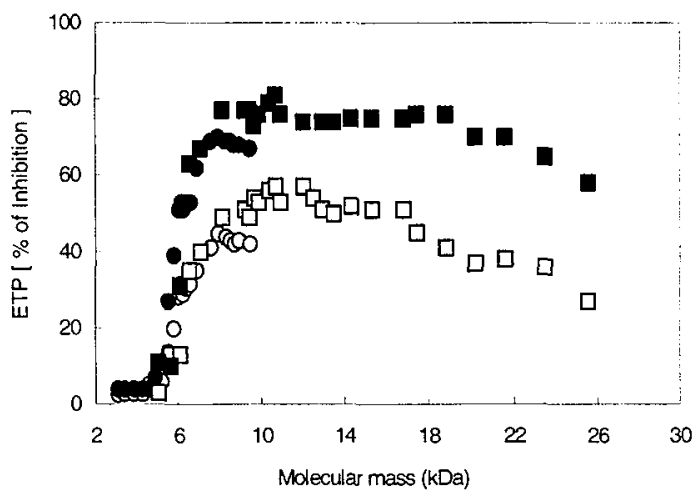

Fig. 6 Inhibition of the ETP as a function of $M W$. Two fixed concentrations $(10,25 \mathrm{nM})$ of HAM were used (open symbol: $10 \mathrm{nM}$, closed: $25 \mathrm{nM})$. ( 0 , •) Clivarine-derived fractions; $(\square, \square)$ UFH-derived fractions.

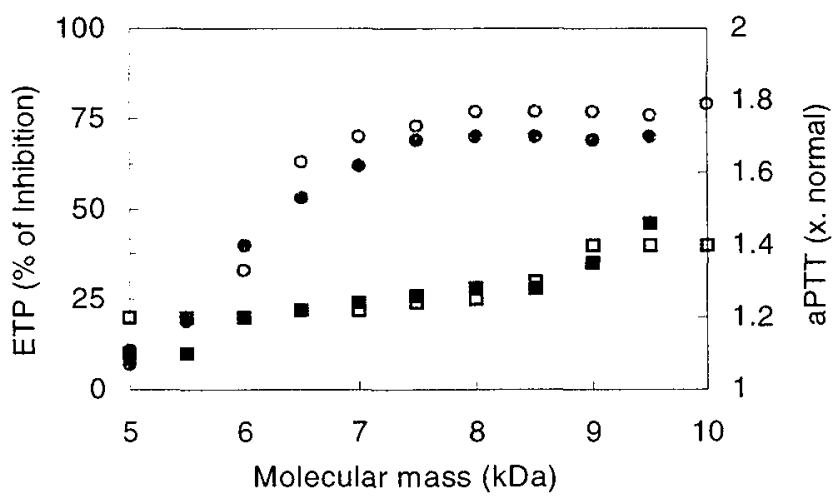

Fig. 7 Dependency of ETP inhibition and aPTT prolongation upon the $M W$. $25 \mathrm{nM}$ HAM (Clivarine or UFH fractions) was added to normal pooled plasma. (․ -) aPTT data of (UFH, Clivarine)-derived fractions respectively; $(0, \bullet)$ ETP data of (UFH, Clivarine)-derived fractions, respectively. 


\section{Discussion}

\section{1: The HAM Content}

It is known that UFH is prepared from fragments of natural molecules of over $100 \mathrm{kD}$." In these molecules the pentasaccharide sequence does not occur often. During preparation the large molecules are fragmented, some of the fragments will contain the pentasaccharide, other will not. It is logical that, the smaller the fragments, the less likely it is that they will contain the pentasaccharide domain. LMWHs stem from further, intentional, fragmentation. Such fragments may or may not contain the pentasaccharide domain. From fig. 1 it can be concluded that there is a rectilinear relationship between the MW and the percentage of HAM. The regression lines cut the abscissa at $1.45 \mathrm{kD}$ for LMWH and $1.75 \mathrm{kD}$ for UFH. If 320 is taken arbitrarily as the $\mathrm{Mr}$ of a monosaccharide unit, this corresponds roughly to a pentasaccharide. Indeed no activity can be expected below this chain-length. By extrapolation it seems that, in UFH, at a molecular mass of around $25 \mathrm{kD}$, every heparin molecule contains a pentasaccharide sequence, in low MW heparin this point is reached at around $13.6 \mathrm{kD}$. This corresponds to an approximate chain-length of 90 and 50 sugar units respectively. A possible explanation would be that in the natural heparins from which these preparations are obtained, the pentasaccharide is found on the mean every 90 or 50 saccharide units. In fractions that are smaller than this repeated length, the pentasaccharide will occur the less often, the smaller the length of the molecule is. This may explain the relation that we observed. In order to obtain a high yield of HAM, it seems necessary to start from a heparin with a low repeat length, which stands to reason.

\section{2: The Specific Activity}

As long as a biological activity is the only known property of a biomolecule, quantification is only possible by comparison to a standard preparation. If the nature of the substance becomes known, it becomes possible to shift from standard units to weight or molar units (cf. vitamins, hormones). If the reaction mechanism is known, activities can be expressed in terms of the influence on reaction rates (cf. enzymes). A standard may remain useful for inter- and intra-laboratory comparison, but concentrations and activities should preferably be defined in normal chemical notation. 
In the case of heparin the original standard-based unit was defined in 1927 by Howell. $^{12}$ The definition of the unit has not essentially changed since then.

In the meantime the reaction mechanism became known: heparins catalyze the reaction between a molecule of antithrombin and a molecule of thrombin or other activated clotting factor. There is good reason to assume that this mode of action is at the basis of their antithrombotic effect, i.e. that this catalytic activity is the relevant, or at least the most relevant, action of heparins. It therefore is natural to define heparin activity in terms of its influence on this reaction, i.e. to express the potency of heparin in terms of the acceleration of thrombin (and/or factor $\mathrm{Xa}$ ) breakdown. Hence our definition of a standard independent unit (SIU): One SIU is that concentration of heparin that brings about an increase of the decay constant of thrombin (factor Xa) of $1 \mathrm{~min}^{-1}$.

We observed that in plasma the effect of heparin is proportional to the concentration of antithrombin. ${ }^{9}{ }^{10}$ Therefore we normalize our observations to a plasma containing $1 \mu \mathrm{M}$ antithrombin and redefine the SIU as that amount of heparin that brings about an increase of the decay constant of thrombin (factor Xa) of $1 \mathrm{~min}^{-1}$ in plasma normalized in this manner.

At first sight it seems illogical that the concentration of antithrombin should influence the heparin effect, because there is a large excess of antithrombin (in the $\mu$ Molar range) over heparin (in the nMolar range). It might be assumed that all heparin is bound to antithrombin anyhow, independent of the actual concentration of antithrombin. However, because heparin binds to a large number of proteins other than antithrombin ${ }^{13}$, the concentration of antithrombin determines the chances of antithrombin to bind a molecule of heparin in the competition with these other proteins. Whatever the explanation of the phenomenon, it is an experimental fact that the decay velocity is proportional to both the concentration of heparin and the concentration of antithrombin. Therefore the definition of the SIU should refer to plasma normalized to $1 \mu \mathrm{M}$ antithrombin.

From defining the activity of heparin in SIU to defining the specific activity as SIU per mole is a small step. The specific activity is a measure for the efficiency of a heparin molecule in accelerating thrombin (factor Xa) decay expressed in number of molecules of thrombin (factor $\mathrm{Xa}$ ) inactivated per molecule of heparin at the normalized antithrombin concentration.

In the previous chapter we described the relation between specific heparin activity and $\mathrm{Mr}$ in a pure antithrombin solution. In short, up to a certain limit the specific anti-factor $\mathrm{Xa}$ activity is directly proportional to 
the length of the heparin molecule because factor $\mathrm{Xa}$ will bind to a large heparin molecule more readily than to a small one. The bound factor Xa then moves via one-dimensional diffusion to the bound antithrombin. However, heparin molecules may be so long that the molecule of factor $\mathrm{Xa}$ dissociates before it reaches antithrombin. This sets a limit to the increase of heparin efficacy with length. In the case of thrombin a similar mechanism may be active, but here the activity is dependent upon the presence of a 12 sugar unit length of heparin to the left of the pentasaccharide. ${ }^{1+}$ In a purified system, the specific activity is directly proportional to the number of times that this sugar configuration is to be found in the heparin (see the previous chapter). This explains the steep, hyperbolic, increase of heparin specific anti-thrombin activity in the $5-10 \mathrm{kD}$ range.

In plasma there is a tendency for the heparins to become less active at very large $\mathrm{MW}$, that is not seen in purified antithrombin solutions. We tend to ascribe this to increased possibility of non-specific binding to other plasma proteins. This problem is at present under investigation.

It is known that the anti-thrombin activity in plasma of heparin is hindered, chain-length dependent, by non-specific binding proteins ${ }^{15}$. A synthetic heparin (17 sugar units) had been recently manufactured ${ }^{14}$, in order to circumvent this undesired interaction. We studied the biological potencies of this oligosaccharide in plasma with respect to the specific (aXa, alla) activities, and the ETP inhibition.

Strikingly, this chemical modification influenced positively the capability of this heparin to inactivate thrombin and the ETP (figs 2 and 5). Expectedly, the aXa potency of this heparin was not modified, since the proteins in plasma mask the sequences binding thrombin only (see fig. 3 ).

\section{3: What Determines the Anticoagulant Activity of a Heparin?}

The important conclusion to be dawn from figs 2 and 3 is that heparin activity is determined by its MW and not by the source or the mode of fractionation. The only determinant of the specific aXa and alla activity of a heparin is its chain-length. An important practical consequence of the phenomenon is that the activity of any heparin preparation is determined by its molecular weight profile only.

The second observation is that the specific aXa activity is strongly $\mathrm{Ca}^{2+}$ dependent, whereas the anti-thrombin activity is not. So a quantitative comparison of the activities of different heparins should be carried out in the presence of $\mathrm{Ca}^{2+}$ in order to have any relevance for the action in vivo. Most commercial anti-factor $\mathrm{Xa}$ tests are carried out in the absence of $\mathrm{Ca}^{2+}$, 
however and therefore underestimate the anti-Xa activity of the heparin standard (low and high $\mathrm{MW}$ ), which automatically leads to an overestimation of the anti-Xa activity of LMWH preparations relative to the standard. ${ }^{8.16}$ We hope that the repeated and refined demonstration of this source of error will eventually lead to the adoption of truthful methodologies.

If the relative anti-factor Xa activity of LMWHs is already less high than generally thought, its absolute activity is even much lower than that of $\mathrm{UFH}$, except for the limited MW range of $1500-5400$ (see fig. 3). It is not true for any of the preparations in clinical use (results not shown). The origin of this misconception lies in the assignment of unit activity to standard heparin, while in fact its absolute aXa activity is 2.7 times lower than its anti-thrombin activity.

\section{4: What Factors Determine the Anticoagulant Potency in vitro?}

The coagulant potency of plasma, expressed in the ETP, can be diminished by inhibition of prothrombin conversion (as in oral anticoagulation or inhibition of factor $\mathrm{Xa}$ ) or by decrease of thrombin activity (as in hirudin, dermatan sulphate etc.)

The following evidence can be brought forward to sustain the idea that heparins act primarily via their antithrombin action:

$A$. In 1987, Hemker et al developed a method to calculate the course of prothrombin conversion from the thrombin generation curve and the decay constants of thrombin in plasma. First the thrombogram is measured. At any point in this curve the velocity of change of thrombin concentration is the result of the difference between prothrombin conversion velocity and thrombin breakdown velocity. The latter is calculated independently from the thrombin decay constant and the thrombin concentration. ${ }^{9} 17$ Later the method was refined to take into account the effect of antithrombin consumption ${ }^{18}$. In this way we could demonstrate that the conversion of prothrombin is not inhibited by UFH and most LMWHs. Only those heparins where the aXa activity is very high compared to the alla activity (like the synthetic pentasaccharide) showed a small effect on prothrombin conversion as pentasaccharide.

$B$. The absolute anti-factor $\mathrm{Xa}$ activity in any heparin is lower than the absolute anti-thrombin activity except for molecules in the range 1.7 - 
$5.4 \mathrm{kD}$ lacking the capability to inactivate thrombin (figs. 2,3 ) (see above).

$C$. Prothrombin is very slowly activated by factor Xa alone, but rapidly by the complete prothrombinase complex; i.e. by a stoichiometric product ${ }^{20}$ of factors $\mathrm{Xa}$ and $\mathrm{Va}$ adsorbed onto phospholipids. Under the conditions prevailing in clotting blood factor $\mathrm{Xa}$ is present in excess over factor $\mathrm{Va}$. Factor $\mathrm{Xa}$ therefore has to be inhibited for $90 \%$ in order to inhibit prothrombinase by about $50 \%{ }^{19.20}$ On the other hand the inhibition of the thrombogram is linearly related to the breakdown velocity of thrombin.

This explains readily why the inhibition pattern of the ETP closely follows the pattern of anti-thrombin specific activity and not that of anti-factor $\mathrm{Xa}$ activity (fig. 6).

\section{5: The aPTT}

It is a common thought that the aPTT does not respond to LMWH heparins. Fig. 4 however shows that this cannot be attributed to a peculiar property of LMWHs per se. Fractions of similar MW cause similar, dose dependent, prolongation of the aPTT, independent of the origin of the fraction. This figure also shows that the aPTT poorly reflects inhibitions of thrombin generation of up to $50 \%$. Antithrombotic effects that are not accompanied by a significant increase of the aPTT therefore must be deemed possible. The MW dependency of the aPTT (fig.7) can for a large part be attributed to the change in anti-thrombin activity with MW. It seems as if higher MW fractions have a prolongation effect on the aPTT that is not reflected in the ETP.

\section{References}

1. Bendetowicz, A.V., Pacaud, E., Béguin, S., Uzan, A. \& Hemker, H.C. On the relationship between molecular mass and anticoagulant activity in a low molecular weight heparin (enoxaparin). Thromb Haemost 67, 556-62 (1992).

2. Choay, J. et al. Structure-activity relationship in heparin: a synthetic pentasaccharide with high affinity for antithrombin III and eliciting high anti-factor Xa activity. Biochem Biophys Res Commun 116, 492-9 (1983).

3. Lane, D.A., MacGregor, I.R., VanRoss, M., Cella, G. \& Kakkar, V.V. Molecular weight dependence of the anticoagulant properties of heparin: 
intravenous and subcutaneous administration of fractionated heparins to man. Thromb Res 16, 651-62 (1979).

4. Lane, D.A., Denton, J., Flynn, A.M., Thunberg, L. \& Lindahl, U. Anticoagulant activities of heparin oligosaccharides and their neutralization by platelet factor 4. Biochem $J 218,725-32$ (1984).

5. Fareed, J., Jeske, W., Hoppensteadt, D., Clarizio, R. \& Walenga, J.M. Are the available low-molecular-weight heparin preparations the same? Semin Thromb Hemost 22, 77-91 (1996).

6. Fareed, J., Hoppensteadt, D., Jeske, W., Clarizio, R. \& Walenga, J.M. Low molecular weight heparins: are they different? Can J Cardiol 14 Suppl E, 28E-34E (1998).

7. Bendetowicz, A.V., Béguin, S., Caplain, H. \& Hemker, H.C. Pharmacokinetics and pharmacodynamics of a low molecular weight heparin (enoxaparin) after subcutaneous injection, comparison with unfractionated heparin--a three way cross over study in human volunteers. Thromb Haemost 71, 305-13 (1994).

8. Hemker, H.C. \& Béguin, S. Standard and method independent units for heparin anticoagulant activities [editorial] [published erratum appears in Thromb Haemost 1993 Dec 20;70(6):1072]. Thromb Haemost 70, 724-8 (1993).

9. Béguin, S., Lindhout, T. \& Hemker, H.C. The mode of action of heparin in plasma. Thromb Haemost 60, 457-62 (1988).

10. Hemker, H.C., Béguin, S., Bendetowicz, A.V. \& Wielders, S. Determination of the levels of unfractionated and low-molecular-weight heparins in plasma: their effect on thrombin-mediated feedback reactions in vivo. Preliminary results after subcutaneous injection. Haemostasis 21, 258-72 (1991).

11. Robinson, H.C., Horner, A.A., Hook, M., Ogren, S. \& Lindahl, U. A proteoglycan form of heparin and its degradation to single-chain molecules. J Biol Chem 253, 6687-93 (1978).

12. Howell, W.H. The purification of heparin and its presence in blood. Am. J. Physiol 71, 553-562 (1925).

13. Lane, D.A. Heparin binding and neutralizing proteins. In: Heparin. Chemical and Biological properties; Clinical applications. Eds Lane D A , Edward Arnold. London., 363-392 (1989).

14. Petitou, M. et al. Synthesis of thrombin-inhibiting heparin mimetics without side effects [see comments]. Nature 398, 417-22 (1999).

15. Cosmi, B. et al. Effect of nonspecific binding to plasma proteins on the antithrombin activities of unfractionated heparin, low-molecular-weight heparin, and dermatan sulfate. Circulation 95, 118-24 (1997).

16. Hemker, H.C. \& Béguin, S. The activity of heparin in the presence and absence of $\mathrm{Ca}++$ ions; why the anti-Xa activity of LMW heparins is about two times overestimated. Thromb. Haemost 70(4), 717-718 (1993). 
17. Hemker, H.C., Willems, G.M. \& Béguin, S.A. A computer assisted method to obtain the prothrombin activation velocity in whole plasma independent of thrombin decay processes. Thromb Haemost 56, 9-17 (1986).

18. Béguin, S., Kessels, H., Dol, F. \& Hemker, H.C. The consumption of antithrombin III during coagulation, its consequences for calculation of prothrombinase activity and the standarisation of heparin activity. Thromb Haemost 68, 136-142 (1992).

19. Hemker, H.C. The mode of action of heparin in plasma. In: Thrombosis and Haemostasis. Eds. M. Verstraete. J. Vermylen, H. Rliynen, J. Arnout, University Press, Lewven, 17-36 (1987).

20. Pieters, J. \& Lindhout, T. The limited importance of factor Xa inhibition to the anticoagulant property of heparin in thromboplastin-activated plasma. Blood 72, 2048-52 (1988). 



\section{Summary and Conclusions}

The ideal antithrombotic drug is a well-defined, orally available, chemical that has a stable and predictable antithrombotic action over 24 hours per day, that however is quickly reversible and shows no side effects. Because of the predictable action, it does not need to be controlled. The very fact that heparin needs to be injected makes it less than ideal. The fact that it is a natural product that possesses other biological activities than antithrombotic properties and the fact that it needs to be injected several times daily are so many more negative points.

Low molecular weight heparins apparently have less negative properties than unfractionated heparins do. They work when injected once daily in a standard dose and are reported to cause less bleeding. LMWHs have been found to exhibit a high anti-factor Xa activity relative to their anti-thrombin activity. It was concluded that this property per se was important.

A logical discrepancy appeared when Béguin et al. found, as early as 1988, that, in vitro, the anti-Xa activity as such does hardly contribute to its anticoagulant action (Béguin et al., 1988; Béguin et al., 1989). This was reinforced by studies in healthy volunteers by Bendetowitz et al (Bendetowicz et al., 1992; Bendetowicz et al., 1994). In subsequent studies our group suggested partial solutions to this problem (ref. 5). In this thesis we report the final elements required for a rational approach. The main remaining problem will be to have this accepted in a field where habit and tradition remain forceful determinants of decision.

A rational approach in the first place requires a sharp distinction between a) How much heparin is circulating and b) How much is the clotting function inhibited by this circulating heparin. In short, between pharmacokinetics and pharmacodynamics.

The pharmacokinetic profile, i.e. the course of the plasma concentration after injection determines how much of the drug is available to interact with the biological target (AT, HCII, Proteases). The pharmacodynamics of heparin is the study of the effect of the interaction between the drug and the site of action, i.e. pharmacological response.

This narrowed the questions down to a) How to determine heparin concentration in a plasma sample and b) how to determine the effect of heparin in a plasma sample.

The traditional answers are: a) by measuring anti-factor Xa activity, and b) by measuring the activated partial thromboplastin time (aPTT) or another form of clotting time. If, however, anti-factor Xa activity does not contribute to the anticoagulant effect, then is it logical to use this activity to 
measure active heparin? Also the aPTT and other clotting times have their important drawbacks, as exposed in chapter II. In the meantime Hemker et al. developed a new function test of the coagulation system, the Thrombogram, and a new parameter for anticoagulant action, the area under the thrombogram or the endogenous thrombin potential (ETP). There were good arguments to believe that the ETP was a useful alternative to the aPTT and other clotting tests.

The fact that the beneficial effect of heparins appeared to be related to the molecular weight, automatically posed the question of what properties of heparin vary with its molecular weight and how.

From these considerations we developed the program of this thesis:

i) Prepare well-defined, narrow $\mathrm{Mr}$ fractions of unfractionated and low molecular weight heparins.

ii) Determine the concentration of antithrombin-binding sequence (Adomain) in each fraction.

iii) Determination of the catalytic activities of the fractions on the inactivation of thrombin and factor $\mathrm{Xa}$ in the presence of isolated, purified antithrombin (end-point measurement).

iv) Determination of the catalytic activities of the fractions on the inactivation of thrombin and factor Xa in plasma.

v) Determine the effect of the fractions on the overall anticoagulant potency of plasma, using the Thrombogram (i.e. determining the ETP) and compare this to the aPTT.

The outcome of this research for the first time, shows the relation between the number of active heparin molecules of a given molecular weight, their specific anti-thrombin and anti-factor Xa activities and their influence on the thrombogram and aPTT tests.

We found that the anticoagulant activity of a heparin molecule of a welldefined molecular weight is dependent upon that molecular weight and not on the origin of the heparin. LMWHs and unfractionated heparin are different because they are different MW subsets of the same family of active molecules.

Our studies (Chapters IV and V) in the purified system of the anti-factor $\mathrm{Xa}$ activity confirmed that the presence of a specific pentasaccharide, the Adomain (ref. 8) is required for the activity. It was shown that the activity increases with $\mathrm{Mr}$ because of the enhanced possibility of the enzyme to bind to heparin. After binding unidimensional diffusion of the enzyme brings it to the A-domain where antithrombin is bound. At $\mathrm{Mr}>20$ the activity of the heparin decreases because the binding of factor $\mathrm{Xa}$ to the heparin is too loose to ensure a net increase of antithrombin-enzyme collision via 
unidimensional diffusion; i.e., the enzyme dissociates from the heparin before it reaches the antithrombin.

The association of thrombin and the AT-heparin complex appeared to be $>10$ times stronger than that of F.Xa. This can account for the fact that here the decay constant is virtually constant when expressed in terms of the pentasaccharide with 12 sugar units to its left end.

From these studies it follows that the anti-thrombin activity is completely determined by the presence within the molecule of this sequence. This is the heparin that recently has been synthesized by Petitou et al (ref. 8) and that, in honor of the late Jean Choay, we call the C-domain. Our model maintains the "sliding model" for thrombin, but introduces a modified sliding model for the mechanism of factor Xa inactivation.

The molecular weight, i.e. chain-length of an AT-binding heparin, not surprisingly also has a strong influence on its anticoagulant activity in plasma (Chapter VI). Increase of the monosaccharide number results in enhanced anti-thrombin activity between 4.5 and $7.5 \mathrm{kD}$ and is practically constant above $7.5 \mathrm{kD}$. The differences with the purified system, i.e. a decrease of activity at $\mathrm{kD}>10$ we attribute to aspecific binding to plasma proteins. In contrast to the anti-thrombin activity, the aXa-activity increases between 3.5 and $4 \mathrm{kD}$, plateaus between 5 - and $7 \mathrm{kD}$ and above that limit increases practically linearly.

There is a marked $\mathrm{Ca}^{2+}$-dependency of factor $\mathrm{Xa}$ inhibition in plasma. This is at the basis of an overestimation of factor Xa-activity in standard practice. The International Standard heparin, being an unfractionated heparin, requires $\mathrm{Ca}^{2+}$ for its full activity, LMWH is less susceptible to this effect (Schoen et al, 1992. Hemker and Béguin, 1993). The LMWH standard, being defined against the UFH one, carries on the error. This is of no biological importance, because heparin in (patho-) physiology always acts in the presence of $\mathrm{Ca}^{2+}$. It is of great practical importance, however, because potency estimations and the clinical surveillance of heparin therapy are usually done without $\mathrm{Ca}^{2+}$ being present. This means that LMWHs are in an artificially favorable position if they are compared to the international standards and hence will show a spuriously high anti-factor Xa activity.

Because the aXa activity is not the main pharmacological activity to influence the clotting system, the aXa measurement is at its best useful to indicate the presence of heparin in plasma, but it does not reflect the anticoagulant action (Chapter VI) and therefore does not give comparable results between different heparins at equipotent antithrombotic doses. In those terms, an anti-thrombin method may be expected to do better.

We propose (Chapter IV) a new method that can be carried out in the presence of $\mathrm{Ca}^{2+}$ and requires only a simple end-point measurement in a 
microtiter plate reader. The amount of active heparin is estimated from the alla activity, the ratio alla/aXa gives an estimate of the MW distribution of circulating heparin.

The inhibition of the endogenous thrombin potential (ETP) is identical for LMWH and for UFH as long as fractions of the same MW are compared (Chapter VI). The same holds for the aPTT, which however is a much less sensitive test to pick up inhibition. The inhibition of the ETP at equimolar concentrations of HAM, increases with the molecular mass of the heparin between 5 and $7 \mathrm{kD}$ and plateaus afterwards. The inhibition of ETP or aPTT is independent of the origin of the fraction (LMWH or UFH). Very high $\mathrm{MW}$ fractions tend to be less active in plasma, probably because of aspecific binding to other plasma proteins as AT.

In the end, the unquestioned superiority of LMWH over UFH must be explained by a) better bioavailability of the LMW species and b) absence of fractions with a Mr $>10000$ that probably are haemorrhagic (see ref. 3).

The aPTT is used universally as a correlate to the clinical effect of heparin. It is generally recognized to be less than ideal for a number of reasons (Kher et al., 1997). The recognition that the aPTT is of limited value, together with the fact that in clinical trials satisfying results are obtained with standard doses, has led to the shortcut that control is not required. This soothes the conscience but remains an unproven statement unless it has been demonstrated with an adequate method that it is true. According to our opinion: a) in all probability control is required in the young, the old, the fat, the sick an other patients that are not generally admitted to the population of clinical trials, and b) adjusted doses might ameliorate the preventive/therapeutic results even in the "standard" patient as admitted to trials. There are two approaches to amelioration. i) Make the aPTT more reliable by standardization etc. ii) Design an alternative and better test. The first approach has practically failed (see Kher et al. 1997), so the second one imposes itself.

Our proposition is to use the ETP, in view of the fact that the function of the coagulation system is best measured by the amount of active thrombin that appears in the blood when coagulation is triggered (99\% appears after the blood/plasma has clotted). The ETP can be routinely measured by adding an artificial thrombin substrate and measuring its end-level in the serum (Hemker et al., 1993). The value obtained is increased in hypercoagulability and decreased to values of between 20 and $50 \%$ of normal in adequate anticoagulation of any type (oral or heparin or others, Wielders et al., 1997). This suggests that it might not be another surrogate variable but assess the essential function involved. 
In summary, in this thesis we demonstrate that the active species in natural heparins is always the same, i.e. the Choay sequence and that the activity of a natural heparin is determined by the concentration of that sequence. We present methods to determine the concentration of this, as well as the active pentasaccharide sequence and sensitive method for the pharmacological effect, the ETP measurement. Our studies on the mechanism of heparin action have led to an alternative to the current viewpoints, in that we maintain the "sliding" model for the inactivation of thrombin, but produce evidence that for factor Xa a similar model is valid, be it that, due to the easy dissociation of factor $\mathrm{Xa}$, this does not favor the anti-factor Xa activity at higher $\operatorname{Mr}(>15000)$ heparin molecules.

\section{References}

1. Béguin, S., Lindhout, T. \& Hemker, H.C. The mode of action of heparin in plasma. Thromb Haemost 60, 457-62 (1988).

2. Bendetowicz, A.V., Pacaud, E., Béguin, S., Uzan, A. \& Hemker, H.C. On the relationship between molecular mass and anticoagulant activity in a low molecular weight heparin (enoxaparin). Thromb Haemost 67, 556-62 (1992).

3. Bendetowicz, A.V., Béguin, S., Caplain, H. \& Hemker, H.C. Pharmacokinetics and pharmacodynamics of a low molecular weight heparin (enoxaparin) after subcutaneous injection, comparison with unfractionated heparin--a three way cross over study in human volunteers. Thromb Haemost 71, 305-13 (1994).

4. Béguin, S., Choay, J. \& Hemker, H.C. The action of a synthetic pentasaccharide on thrombin generation in whole plasma. Thromb. Haemost 61(3), 397-401 (1989).

5. Hemker, H.C. \& Béguin, S. The activity of heparin in the presence and absence of Ca++ ions; why the anti-Xa activity of LMW heparins is about two times overestimated. Thromb. Haemost 70(4), 717-718 (1993).

6. Hemker, H.C., Weilders, S., Kessels, H. \& Béguin, S. Continuous registration of thrombin generation in plasma, Its use for the determination of thrombin potential. 1993 70, 617-624 (1993).

7. Kher, A., Al Dieri, R., Hemker, H.C. \& Béguin, S. Laboratory assessment of antithrombotic therapy: what tests and if so why? [editorial]. Haemostasis 27, 211-8 (1997). 
8. Petitou, M. et al. Synthesis of thrombin-inhibiting heparin mimetics without side effects [see comments]. Nature 398, 417-22 (1999).

9. Wielders, S. et al. The routine determination of the endogenous thrombin potential, first results in different forms of hyper- and hypocoagulability. Thromb Haemost 77, 629-36 (1997). 


\section{Samenvatting en Conclusies*}

Het ideale antitromboticum is een goed gedefinieerde chemische verbinding die oraal in standaarddosering kan worden toegediend en die een stabiele en voorspelbare antitrombotische werking heeft gedurende 24 uur per dag. Het effect op het haemostase en trombosemechanisme moet echter snel reversibel zijn. Bij-effecten zijn uiteraard ongewensd. Indien de werking voldoende voorspelbaar is, is controle van het effect in de practijk niet nodig.

Het traditionele, ongefractioneerde heparine (UFH) voldoet aan weinig van deze eisen, het is een natuurlijk product van slecht gedefinieerde samenstelling dat behalve antitrombotische- ook andere, onvolledig bekende, biologische werkingen heeft. Het moet enkele malen per dag worden geïnjecteerd. Waarschijnlijk is controle van de individuele respons van de patient wenselijk maar er zijn geen routinemethoden beschikbaar die het heparine-effect betrouwbaar weerspiegelen. Van de bijwerkingen is, naast de bloeding, vooral de thrombopenie (Heparin induced thrombopenia, HIT) gevreesd.

Laag moleculaire gewicht heparines (LMWHs) hebben minder negatieve eigenschappen dan ongefractioneerde heparines. Zij kunnen één maal per dag in standaarddosering per injectie worden toegediend. Er worden minder bloedingen en minder HIT gerapporteerd dan bij UFH. LMWHs hebben, vergeleken met UFH, bij gelijke anti-trombine activiteit, een hoge anti-factor Xa activiteit. Dit leidde tot de aanname dat een antifactor Xa activiteit van kritisch belang was voor een heparine met optimale pharmacologische eigenschappen.

Hiermee in tegenspraak was de ontdekking, reeds in 1988, van Béguin et al., dat in vitro de anti-factor $\mathrm{Xa}$ activiteit nauwelijks bijdraagt tot zijn antistollende werking (Béguin et al., 1988; Béguin et al., 1989). Dit werd bevestigd door studies bij gezonde vrijwilligers door Bendetowicz et al. (Bendetowicz et al. 1992; Bendetowicz et al. 1994). Vervolgstudies van onze groep lieten zien dat de hoge anti-factor Xa activiteit van LMWH in belangrijke mate aan een laboratoriumartefact kon worden toegeschreven (Hemker \& Béguin, 1993). In het algemeen bleek dat laboratorium bepalingen van het heparine eerder gestoeld zijn op gewoonte en traditie dan op een rationele benadering.

In de eerste plaats vereist een rationele aanpak een scherpe scheiding tussen de vragen a) hoeveel heparine circuleert en b) in hoeverre remt deze heparine de stollings-functie. Kortweg, tussen farmacokinetiek en farmacodynamiek. 
De heparine concentratie wordt gebruikelijk bepaald door de anti-factor $\mathrm{Xa}$ activiteit te meten. Als echter de anti-factor $\mathrm{Xa}$ activiteit niet bijdraagt tot het anti-stollende effect, dan lijkt het niet logisch om deze activiteit te gebruiken om heparine concentraties te meten (Hoofdstuk I).

Voor de bepaling van het heparine-effect maakt men algemeen gebruik van de geactiveerde partiële tromboplastine tijd (aPTT). Zoals wij in hoofdstuk twee aantonen kleven aan de aPTT belangrijke nadelen, evenals aan andere stoltijd-bepalingen.

Gedurende de laatste jaren ontwikkelden Hemker et al. een nieuwe functie test van het stollingssysteem, gebaseerd op het meten van het verloop van de trombineconcentratie in stollend bloed: het trombogram. $\mathrm{Zij}$ vermoedden dat het oppervlak onder het trombogram, i.e. de endogene trombine potentiaal (ETP), een goede maat zou kunnen zijn voor de diepte van antistolling. Er zijn goede argumenten om aan te nemen dat de ETP een geschikt alternatief is voor de aPTT en andere stoltesten.

Het feit dat er essentiële verschillen lijken te bestaan tussen UFH en LMWH, leidt automatisch tot de vraag welke eigenschappen van heparine variëren met het molecuul gewicht en hoe. Op grond van deze overwegingen ontwikkelden wij het programma voor dit proefschrift:

i) Het verkrijgen van heparine fracties van goed gedefinieerd moleculairgewicht (d.m.v. gelfiltratie).

ii) Het bepalen van de molaire concentratie van actief, i.e. AT-bindend heparine (d.m.v. fluorescentietitratie).

iii) Het bepalen van de katalytische activiteit van het heparine-AT complex t.o.v. trombine en factor Xa voor ieder van deze fracties.

iv) Het bepalen van de katalytische activiteit van de fracties in plasma.

v) Het bepalen van het antistollend effect van de fracties m.b.v. het trombogram (d.w.z. we meten de ETP).

De uitkomst van dit onderzoek toont voor het eerst de relatie aan tussen het aantal actieve heparine moleculen van gegeven molecule massa, hun specifieke anti-trombine- en anti-factor Xa activiteit en hun invloed op het trombogram en de aPTT.

Het eerste resultaat is dat de biologische activiteit van een heparine molecuul van goed-gedefinieerde molecuul massa alleen bepaald wordt door deze massa en niet afhangt van de bron van de heparine. Het verschil tussen LMWHs en UFH wordt alleen bepaald door hun verschillend molecuulmassa-profiel.

Onze resultaten (Hoofdstukken IV en V) m.b.t. de invloed van heparine op de interactie tussen geïsoleerd AT en factor Xa, bevestigen dat een 
specifieke pentasaccharide, het A-domein (ref. 8), deze interactie specifiek versnelt. Wij konden aantonen dat deze activiteit eerst lineair toeneemt met de molecuul massa, om bij hogere molecuul massa weer af te nemen. Dit wordt verklaard door een model waarin de mogelijkheid van het enzym om te binden aan de heparine toeneemt met de afmeting van het heparinemolecuul. $\mathrm{Na}$ binding brengt een-dimensionale diffusie het enzym naar het A-domein waar de AT is gebonden. Bij een molecuul massa boven de 20.000 daalt de activiteit van de heparine, omdat de factor Xa-binding aan het heparine molecuul te zwak is om een netto toename van botsing tussen AT en enzym (FXa) via een-dimensionale diffusie te verzekeren: het enzym dissocieert van de heparine voordat het de AT bereikt.

Uit deze studies blijkt verder dat de anti-trombine activiteit volledig bepaald wordt door de aanwezigheid in het molecuul van een fragment (het $\mathrm{T}$-domein) van 12 suikereenheden met willekeurige volgorde aan het niet reducerende einde van de pentasaccharide. De combinatie van $\mathrm{T}$ - en $\mathrm{A}$ domein, die essentieel is voor de antithrombinewerking noemen wij Cdomein. (Ter gedachtenis aan Jean Choay, de initiatiefnemer en drijvende kracht achter de chemische analyse en synthese van heparines.) Dit is de heparine die kort geleden gesynthetiseerd is door Petitou et al. (ref.8).

Het boven beschreven één-dimensionale diffusiemodel is ook van toepassing op trombine maar, omdat trombine tien maal sterker aan heparine bindt dan factor Xa speelt dissociatie een kleine rol en wordt de specifieke activiteit niet nadelig beïnvloed door grote ketenlengte. Dit model verschilt wezenlijk van de tot nu toe voorgestelde modellen, omdat het de diffusie langs het hele heparinemolecuul aanneemt voor beide enzymen en voor alle ketenlengtes. Het klassieke model gaat uit van diffusie langs het $\mathrm{C}$-domein en alleen voor trombine, een mechanisme dat door onze experimenten niet wordt opndersteund.

Het verraste niet dat de molecuul massa, of wel de ketenlengte, van een AT-bindend heparine ook een sterke invloed heeft op zijn biologische activiteit in plasma (Hoofdstuk VI). Een toename van het aantal suikereenheden resulteert in een grotere anti-trombine activiteit tussen 4.5 en $7.5 \mathrm{kD}$, maar deze is daarboven vrijwel constant. Het verschil met het gezuiverde systeem is dat de activiteit boven de $10 \mathrm{kD}$ daalt, hetgeen we toeschrijven aan aspecifieke binding aan plasma eiwitten. In tegenstelling tot de anti-trombine activiteit neemt de anti-factor $\mathrm{Xa}$ activiteit toe tussen 3.5 en $4 \mathrm{kD}$, vlakt af tussen 5 en $7 \mathrm{kD}$ en neemt boven deze limiet weer vrijwel lineair toe.

$\mathrm{Er}$ is een aanmerkelijke $\mathrm{Ca}^{2+}$-afhankelijkheid van de factor $\mathrm{Xa}$ remming in plasma. Op grond hiervan wordt de anti-factor Xa activiteit in de standaard praktijk overschat. De Internationale Standaard heparine (ISH), is 
een ongefractioneerde heparine, en vereist dus $\mathrm{Ca}^{2+}$ voor zijn volle activiteit; LMWH is minder gevoelig voor dit effect (Schoen et al, 1992. Hemker en Béguin, 1993). De gebruikelijke meting van de anti-factorXa activiteit introduceert een laboratorium artefact, omdat ze worden uitgevoerd in afwezigheid van $\mathrm{Ca}^{2+}$. Onder fysiologische omstandigheden is $\mathrm{Ca}^{2+}$ echter altijd aanwezig. De activiteit van de LMWHs wordt zodoende systematisch overschat. Omdat de anti-factor $\mathrm{Xa}$ activiteit niet de belangrijkste farmacologische activiteit is die het stol-systeem beïnvloedt, is de anti-factor Xa meting op zijn best een indicator van heparine in plasma, maar is het geen goede maat voor de anti-stollende werking (Hoofdstuk VI). Daarom kunnen verschillende heparines bij gelijk antitrombotisch effect onvergelijkbare testresultaten opleveren. De anti-trombine methode is hier waarschijnlijk te prefereren, maar er bestaat geen algemeen aanvaarde routinemethode om deze eenvoudig te bepalen. Wij ontwikkelden daarom een nieuwe methode (Hoofdstuk IV) die uitgevoerd kan worden in aanwezigheid van $\mathrm{Ca}^{2+}$ en die slechts een eenvoudige eindpuntsmeting in een micro-titerplaat-lezer vereist. De hoeveelheid actieve heparine kan worden berekend uit de anti-trombine activiteit, terwijl de ratio antitrombine - anti-factor $\mathrm{Xa}$ activiteit een schatting geeft van de moleculaire massa verdeling van het circulerend heparine.

De remming van de endogene trombine potentiaal (ETP) is identiek voor LMWH en ongefractioneerd heparine, zolang we fracties van de zelfde molecuul massa vergelijken. Hetzelfde is waar voor de aPTT, die echter veel minder gevoelig is. De remming van de ETP bij gelijkblijvende molaire concentratie van HAM neemt toe met de molecuul massa van de heparine tussen 5 en $7 \mathrm{kD}$ en vlakt dan af. De remming van de ETP of de aPTT is onafhankelijk van de oorsprong van de fractie (LMWH of ongefractioneerde heparine). Zeer hoog moleculaire fracties tenderen naar lagere activiteit in plasma, waarschijnlijk omdat zij aspecifiek binden aan andere eiwitten dan AT.

De klinische voordelen van LMWH boven ongefractioneerde heparine kunnen verklaard worden door a) betere biologische beschikbaarheid van LMWH en b) afwezigheid van fracties met $\mathrm{Mr}>10000$ die waarschijnlijk een eigenstandig hemorragisch effect hebben (zie ref. 3 ).

De aPTT wordt universeel gebruikt om het klinisch effect van heparine vast te stellen. Standaardiseringvan de aPTT faalde bijna volledig en er zijn meer redenen om deze test te wantrouwen (Kher et al. 1997). De erkenning dat de aPTT slechts beperkte waarde heeft en het feit dat in klinische proefnemingen bevredigende resultaten worden verkregen met standaard doses maakt dat men in de practijk heparine meestal geeft zonder controle van het bereikte antistollingsniveau. Dit bewijst niet dat m.b.v. een 
geschikte testmethode "op maat" gedoseerde heparinetherapie niet betere klinische resultaten zou opleveren. In ieder geval líjkt controle noodzakelijk bij jonge, oude, dikke en ernstig zieke patiënten; in het algemeen bij die patienten die op grond van te verwachten afwijkende kenmerken worden uitgesloten van klinische trials. Verder blijft het goed mogelijk dat aangepaste doses de preventieve en therapeutische resultaten verbeteren zelfs bij de "standaard" patiënt, zoals die wel in klinische trials geaccepteerd wordt.

Verbetering van de bestaande controlepractijk is dus wenselijk. De hoeveelheid werkzaam heparine in plasma wordt het beste bepaald via de hier beschreven anti-trombine eindpuntsbepaling. Wij stellen voor om de ETP te gebruiken als functietest voor het stollingssysteem, met name ook voor het meten van het heparine effect. Er zijn vele argumenten om aan te nemen dat de ETP de essentiële parameter is van het stolsysteem en niet een of andere surrogaat variabele.

Samenvattend hebben wij aangetoond dat de actieve vorm in heparine altijd dezelfde is, namelijk het Choay-fragment. De activiteit van ieder heparine op het stollingsmechanisme in plasma wordt bepaald door de concentratie van dit fragment. Wij ontwikkelden methoden om de concentratie van dit fragment en ook die van het actieve pentasaccharide te bepalen. Tevens presenteren wij de ETP-meting als een gevoelige test voor het farmacologisch effect van heparines zowel als van andere anticoagulantia.

Onze studies hebben geleid tot een nieuw model voor het werkingsmechanisme van heparine. In dit model wordt thrombine zowel als factor $\mathrm{Xa}$ eerst gebonden op een willekeurige plaats van het heparinemolecuul en bereikt het A-domein van het heparine via ééndimensionale diffusie. De verschillen tussen de inactivering van beide moleculen worden verklaard doordat a) factor $\mathrm{Xa}$, in tegenstelling tot trombine, tijdens het diffusieproces gemakkelijk van heparine loslaat en b) trombine, in tegenstelling tot factor Xa, nauwelijks aan AT kan binden tenzij in aanwezigheid van het Choay-domein.

\footnotetext{
*De referenties zijn gelijk aan die van de engelstalige samevatting.
} 



\section{Curriculum Vitae}

Raed Al Dieri was born on 5 April 1968 in Sheikhmeskin, Syria. In 1986, he attended the Faculty of Pharmacy in Damascus University. He obtained the degree of B.Sc. in Pharmacy and Pharmaceutical Chemistry in 1991. In 1993, he obtained, at the Department of Biochemistry, a Postgraduate Diploma in the Lab Diagnosis. He was admitted later to prepare a Master's Degree in the Lab Diagnosis, in Al-Assad University Hospital and Faculty of Pharmacy, under the supervision of Prof. Dr. Jouma. M and Prof. Dr. Fahoum. S. In November 1995, he defended his thesis titled "Role of Insulin Resistance in Obesity, Diabetes Mellitus and Hypertension". In 1996, he was admitted to the preparation of a Ph.D. degree at the Department of Biochemistry in Maastricht University under the supervision of Drs. Suzette Béguin and Rob Wagenvoord, and Prof. Dr. H.Coen Hemker. 



\section{Acknowledgments}

This thesis on the structure-function relationship of heparins owes its existence to the enthusiasm and expertise of many people whom I would like to thank.

Its most obvious and immediate debt is to my promoter Prof. Dr. H. C. Hemker. He has given me a feast for mind. Listening to Prof. Hemker's conversations and talks or reading his articles has left me not only better informed, but also more inspired. Without his tremendous support and guidance, this treatise could not have been accomplished.

I owe a special debt to my co-promoter Dr. Suzette Béguin who conceptualized this project and saw it to completion. Her daily support, continued patience and encouragement at every step of the way are invaluable.

To Dr. Rob Wagenvoord, my co-promoter, who made fine, detailed contributions to bring the project to its final form. For his help I am greatly indebted.

Thanks are also due to Khaled Maroofi for his excellent technical assistance, friendship and ubiquitous help.

Dr. Peter Giesen, I am indebted to him for his expert advice and encouragement.

A special acknowledgment is due to Mrs. Tress Caphuisen and Mariet Molenaar for their outstanding secretarial assistance and help.

To Wielders S, Rijkers D, Keularts I, Feijge M, and Devilée P, for their help and encouragement.

To my colleagues in the Department of Biochemistry, for providing a decent scientific atmosphere.

I will always love my parents and my sister who so unselfishly supported my independent thinking and decisions.

Finally, I am grateful to all of those (family, friends and teachers) who have helped me and taught me ever since 1968.

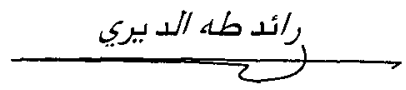

